\title{
Optimising the Management of Breast Cancer in Older Patients
}

Thesis submitted for the degree of

Doctor of Medicine

at the University of Leicester

by

\author{
Mohammad Tahir \\ Department of Breast Surgery \\ University Hospitals of Leicester \\ NHS Trust
}

December 2013 


\title{
Optimising the Management of Breast Cancer in Older Patients
}

\author{
Mohammad Tahir
}

\section{Abstract}

This study aimed to optimise the treatment of early breast cancer in older patients. It tested the hypothesis that comprehensive geriatric assessment (CGA) could be used to predict two-year survival in older breast cancer patients. Based on the CGA scoring a treatment algorithm was devised that could help in recommending whether primary endocrine treatment (PET) or surgery plus endocrine treatment would be best indicated in individual patients.

Methods: The study included women $\geq 70$ years of age with early breast cancer, seen in a dedicated Leicester clinic between 01/2005 and 04/2007. All patients had comprehensive assessment including documentation of Satariano Index of Co-morbidities (SIC), Mini-Mental State Examination (MMSE), Geriatric Depression Score (GDS), Activities of Daily Living (ADL), Instrumental Activities of Daily Living (IADL) and American Society of Anaesthesiologists (ASA) grade. Logistic regression analysis explored any association between these components and two-year survival. Components with positive association were 
formulated into a Breast Cancer in Elderly Treatment Algorithm (BCETA).

Results: 123 patients were included, age range 70-94 (median-82). Twenty-two patients died within two years. Logistic regression analysis found MMSE, ADL, and ASA score to have an independent association with two-year survival. The scores of these components were formulated into a BCETA. Logistic regression revealed a statistically significant association between the BCETA score and two-year survival ( $p$-value 0.00). Other results for the BCETA prognostic model were: sensitivity $89 \%$, specificity $46 \%$, positive predictive value $87 \%$, negative predictive value $52 \%$, odds ratio 7.1 (95\% CI $2.5-20.2$ ), and overall accuracy of $81 \%$. C-statistic value (area under ROC curve) for the BCETA score was 0.70 .

Conclusion: Breast Cancer in Elderly Treatment Algorithm is a new approach to optimise the management of breast cancer in elderly patients. It can help in identifying high-risk patients with expected short-survival who may benefit from PET, if their cancer is hormone receptor positive. Patients with predicted longer life expectancy (lowrisk) may be recommended standard treatment. Further studies are needed to validate it in a larger population. 


\section{Acknowledgements}

Sincerest thanks to my supervisor Miss Anne Stotter (consultant breast surgeon, UHL NHS Trust) and Professor R.A. Walker (Department of Cancer Studies and Molecular Medicine, University of Leicester) for the opportunity to perform this work and for their continuing guidance, supervision, and support in completing this project. In addition, I am thankful to Professor Thomson Robinson (Professor of Stroke Medicine UHL NHS Trust), Dr Robert Pretorius (Consultant Anaesthetist, UHL NHS Trust), and Dr Jacqui Shah (Department of Cancer Studies and Molecular Medicine, University of Leicester) for their help and advice. Martin Williams and Julia Chernova (Trent RDSU) also deserve gratitude for their help with the statistical analysis.

I want to pay a particular tribute to the Breast Care Team at Glenfield Hospital, Leicester, for taking up the challenge of starting and maintaining a new clinical service, which performs at an exceptionally high standard and is regarded as a model service.

Last, but not least, eternal love and many thanks to my wife, Sabba, my son, Umar, and my parents, as well as my friends, who have supported me to varying degrees throughout this project. 


\section{Published Work}

1. How not to neglect the care of elderly breast cancer patients?

Tahir M, Robinson T, Stotter A. Breast. 2011 Aug;20(4):293-6. doi:

10.1016/j.breast.2011.03.003. Epub 2011 May 6.

2. Stotter A, Tahir M, Pretorius R, Robinson T. Experiences of a multidisciplinary elderly breast cancer clinic: using the right specialists, in the same place, with time. In: Management of breast cancer in older women. Eds Reed MW, Audisio RA. Springer 2010.

3. Optimising the management of breast cancer in older patients. Tahir M, Pretorius R, Robinson TG, Walker RA, Stotter A. European Journal of Surgical Oncology (EJSO) Volume 36, Issue 11, November 2010, Pages 1117-1118. doi:10.1016/j.ejso.2010.08.045 (Abstract). 


\section{Table of Contents}

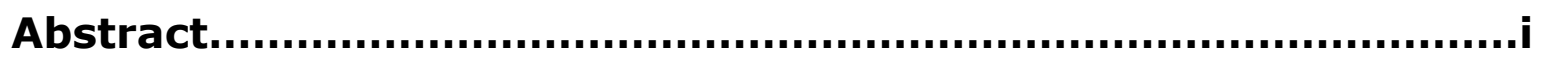

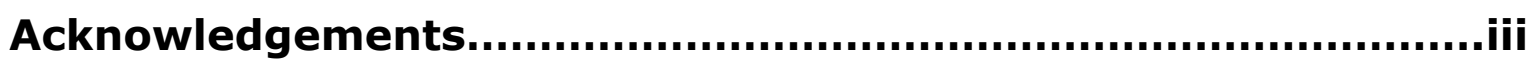

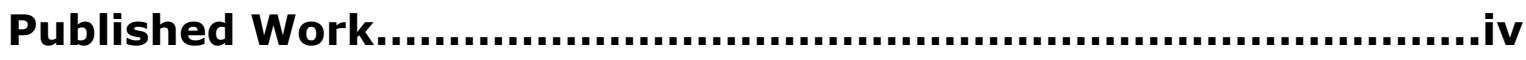

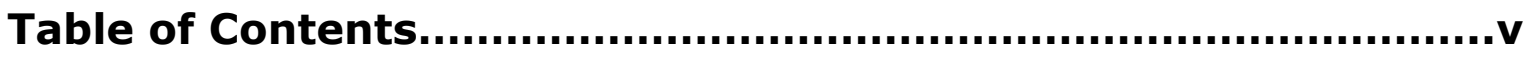

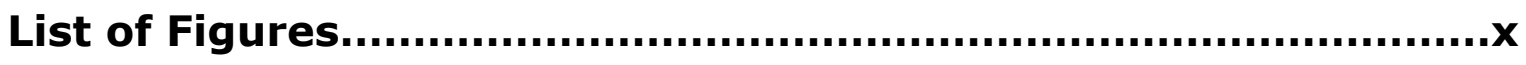

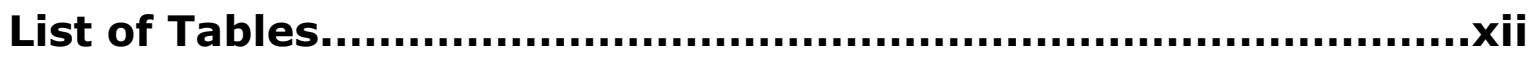

List of Abbreviations................................................................

Chapter One: Introduction.......................................

1.1 Introduction to breast cancer.........................................................

1.2 Basic pathology of breast cancer ........................................................

1.3 Breast cancer and older patients...................................................

1.4 Treatment of early breast cancer ...................................................

1.4.1 Standard treatment and issues in the treatment of older

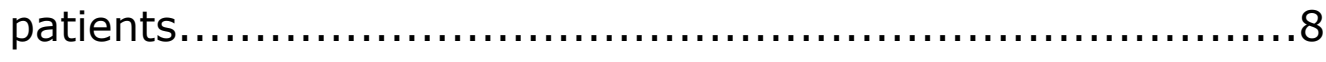

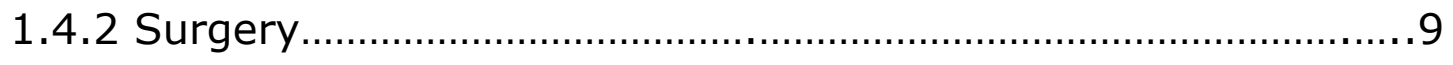

1.4.3 Surgery in older breast cancer patients...................................11 
1.4.4 Adjuvant Radiotherapy

1.4.5 Radiotherapy in older breast cancer patients..........................13

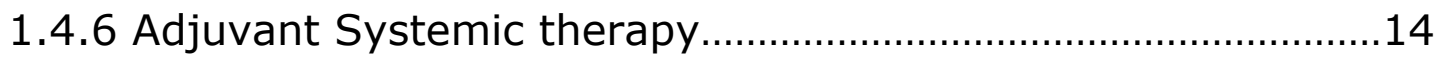

1.4.6.1 Endocrine therapy................................................. 14

1.4.6.2 Endocrine therapy in older breast cancer patients....16

1.4.6.3 Primary endocrine therapy vs. Surgery plus endocrine

therapy in older patients..............................................17

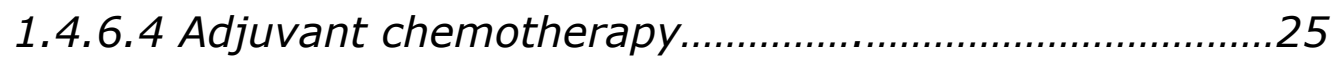

1.4.6.5 Chemotherapy in older breast cancer patients.........26

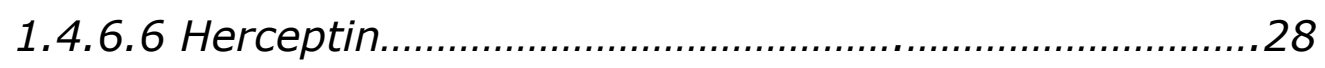

1.4.6.7 Herceptin in older breast cancer patients..................29

1.5 Under-treatment of older breast cancer patients...............................30

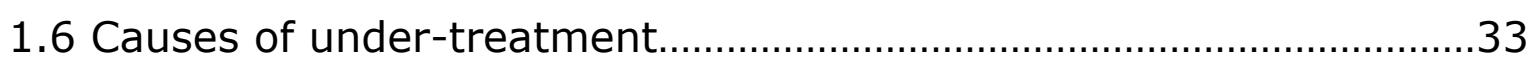

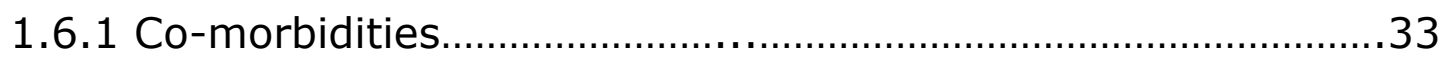

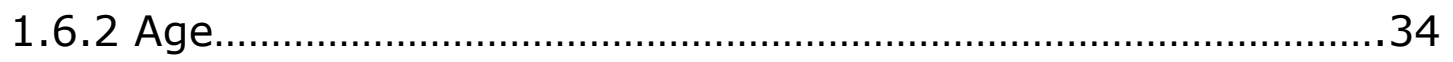

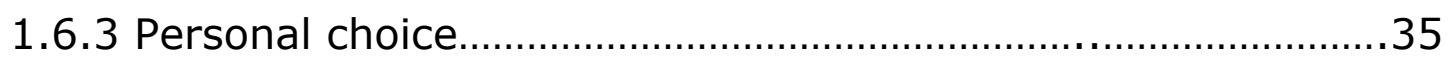

1.7 The need for survival prognostic index to improve the care of older 
breast cancer patients.

1.8 Comprehensive Geriatric Assessment............................................44

1.8.1 Assessment of Co-morbidities...........................................45

1.8.2 Assessment of Cognitive function \& Depression................49

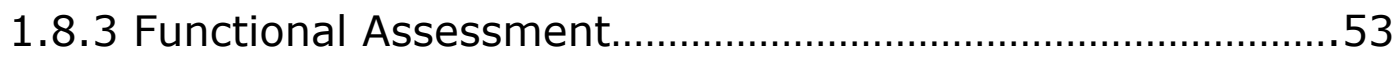

1.8.4 Assessment of fitness for Anaesthesia..................................59

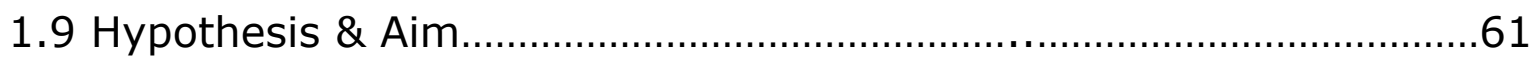

Chapter Two: Methods..........................................62

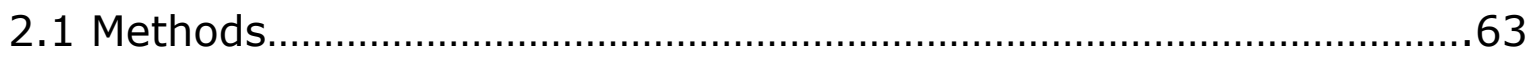

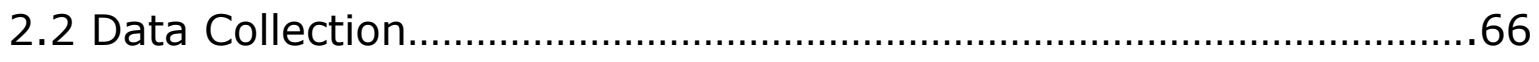

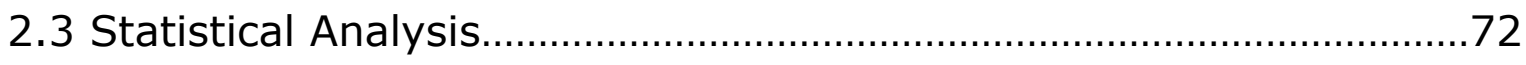

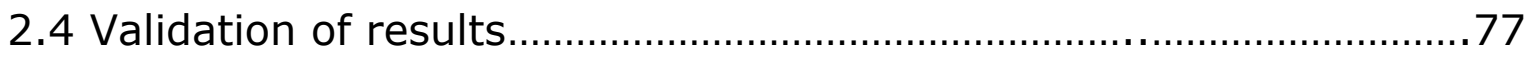

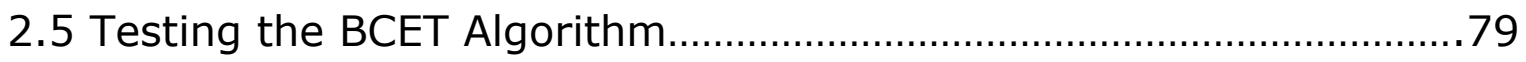

Chapter Three: Results..........................................80

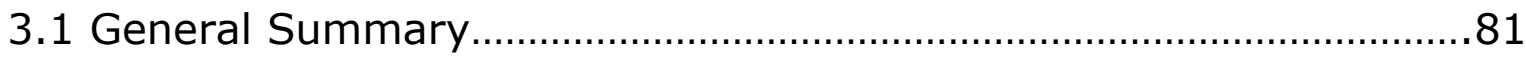

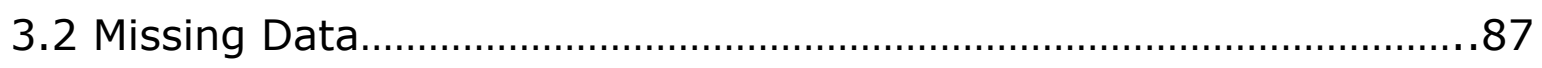


3.3 Summary of patient's variables in the study..... 90

3.4 Statistical Analysis .97

3.4.1 Age and 2-year survival 97

3.4.2 Satariano Index of Co-morbidity and 2-year survival.....100

3.4.3 Mini-Mental State Examination and 2-year survival........101

3.4.4 Geriatric Depression Score and 2-year survival. 103

3.4.5 Activities of Daily Living and 2-year survival 104

3.4.6 Instrumental Activities of Daily Living and 2-year survival 106

3.4.7 American Society of Anaesthesiologists score and 2-year survival 107

3.5 Development of BCET Algorithm 109

3.6 Summary of Statistical Analysis 113

3.7 Validation of the results 118

3.8 Testing the BCET Algorithm.

Chapter Four: Discussion \& Conclusion 
Appendix 1: Literature review for the study .......................................149

References...........................................................151 
1.1 Number of new cases and age specific incidence rates,

by sex, breast cancer, UK 2006

1.2 Age specific mortality rates, breast cancer, females, UK,

$1971-2007$

1.3 Number of deaths and age specific mortality rates, breast cancer, by sex, UK, 2007

2.1 Summary - Age of patients in the study

90

2.2 Summary - Satariano Index of Co-morbidities of patients

91 in the study

2.3 Summary - Mini-Mental State Examination score of patients in the study

2.4 Summary - Geriatric Depression Score of patients in the study

2.5 Summary - Activities of Daily Living score of patients in the study

2.6 Summary - Instrumental Activities of Daily Living of 95 patients in the study

2.7 Summary - American Society of Anaesthesiologists score of 96 patients in the study

3.1 ROC Curve illustrating discriminatory power of MMSE to 
predict 2-year survival in the study population

3.2 ROC Curve illustrating discriminatory power of ADL to

predict 2-year survival in the study population

3.3 ROC Curve illustrating discriminatory power of ASA to

predict 2-year survival in the study population

3.4 ROC Curve illustrating discriminatory power of BCETA to

predict 2-year survival in the study population 
Table 1. Satariano Index of Co-morbidities

Table 3. Geriatric Depression Scale

Table 4. Barthel Index of Daily Living 55

Table 5. The Lawton Instrumental Activities of Daily

Living scale

Table 6. American society of Anaesthesiologists scale

60

Table 7. Components of Comprehensive Geriatric

Assessment and their scoring

Table 8. Patients' baseline data

68

Table 9. General summary of the data

Table 10. Logistic regression analysis: Age and 2-year survival

in the study population

Table 11. Logistic regression analysis: SIC and 2-year survival in the study population

Table 12. Logistic regression analysis: MMSE and 2-year survival 102 in the study population

Table 13. Logistic regression analysis: GDS and 2-year survival 103 in the study population

Table 14. Logistic regression analysis: ADL and 2-year survival 105 
in the study population

Table 15. Logistic regression analysis: IADL and 2-year survival 106 in the study population

Table 16. Logistic regression analysis: ASA and 2-year survival 108 in the study population

Table 17. Logistic regression analysis: BCETA and 2-year survival 110 in the study population

Table 18. Summary statistics of Logistic regression analysing 114 correlations between components of the CGA and 2-year survival in the study population.

Table 19. Summary of MMSE, ADL, ASA and BCETA score and 115 their association with 2-year survival in the study population. Table 20. Summary statistics of MMSE, ADL, ASA and BCETA 115 score in predicting 2-year survival in the study population. Table 21. Summary statistics of Clinical Decisions and BCETA score in predicting 2-year survival in the study population. 


\section{Abbreviations}

\begin{tabular}{|l|l|}
\hline ADL & Activities of Daily Living \\
\hline AF & Atrial Fibrillation \\
\hline AIs & Aromatase Inhibitors \\
\hline ALND & Axillary Lymph Nodes Dissection \\
\hline ASA & American Society of Anaesthesiologists \\
\hline BCETA & Breast Cancer in Elderly Treatment Algorithm \\
\hline BI & Barthel Index \\
\hline CGA & Comprehensive Geriatric Assessment \\
\hline CIRS & Cumulative Illness Rating Scale \\
\hline DCIS & Ductal Carcinoma In Situ \\
\hline EBCTG & Early Breast Cancer Trialists' Group \\
\hline ECOG & Eastern Cooperative Oncology Group \\
\hline ER & Oestrogen Receptor \\
\hline ESS & Exton-Smith Scale \\
\hline ET & Endocrine Therapy \\
\hline FNA & Fine Needle Aspiration \\
\hline GDS & Geriatric Depression Scale \\
\hline HER-2 & Human Epidermal Growth Factor Receptor-2 \\
\hline IADL & Instrumental Activities of Daily Living \\
\hline ICED & Index of Co-existent Disease \\
\hline IDC & Invasive Ductal Carcinoma \\
\hline ILC & Invasive Lobular Carcinoma \\
\hline KFI & Kaplan-Feinstein Index \\
\hline LCIS & Lobular Carcinoma In Situ \\
\hline MMSE & Mini-Mental State Examination \\
\hline MNA & Mini Nutritional Assessment \\
\hline MPI & Multidimensional Prognostic Index \\
\hline NICE & National Institute for Clinical Excellence \\
\hline PET & Primary Endocrine Therapy \\
\hline PgR & Progesterone Receptor \\
\hline RDSU & Research Development and Support Unit \\
\hline ROC & Receiver Operating Characteristic \\
\hline SEER & Surveillance, Epidemiology and End Results \\
\hline SIC & Satariano Index of Co-morbidities \\
\hline SIOG & International Society of Geriatric Oncology \\
\hline SNB & Sentinel Node Biopsy \\
\hline SPMSQ & Short Portable Mental Status Questionnaire \\
\hline UTI & Urinary Tract Infection \\
\hline
\end{tabular}


Chapter 1. Introduction 


\subsection{Introduction to breast cancer}

Breast cancer is the most common cancer in the United Kingdom (UK) (excluding non-melanoma skin cancer), affecting more than 45,500 women each year [1]. The lifetime risk of being diagnosed with breast cancer in women is one in eight [2]. The incidence of breast cancer increases with age; more than $80 \%$ of breast cancer occurs in women above the age of 50 and $35 \%$ above 70 years of age [3]. With the increasingly aged population it is becoming a major health problem in older people.

Since the start of screening mammography services, breast cancer is detected in many women at the pre-invasive stage i.e. ductal carcinoma in situ (DCIS), or early invasive stage. Early detection and improvements in breast cancer treatment have resulted in much improvement in the prognosis for breast cancer. The estimated fiveyear survival rate for women diagnosed in England and Wales in the 1970s was around $50 \%$, whereas now it is closer to $80 \%$ [1]. In patients whose cancer is picked up early due to screening, their fiveyear survival approaches 93\% [2]. However, despite its good prognosis, breast cancer is still the second leading cause of cancer deaths in women. 


\subsection{Basic pathology of breast cancer}

Cancer develops via a process in which normal cells go through stages that eventually change them to abnormal cells that multiply out of control. Historically, breast cancer progression was seen as a multi-step process, encompassing progressive changes from normal, to hyperplasia with and without atypia, carcinoma in situ, invasive carcinoma, and metastasis. [4]. Whilst most of the concepts regarding the morphologically defined breast cancer precursor lesions remain valid, immunohistochemistry and molecular genetics have changed the way that the breast cancer multi-step model is seen [4].

Simpson et al. [5] suggested that the development of breast cancer comprises two different arms with their own pathways; a low-grade \& a high-grade arm. In the low-grade arm there is progression of atypical ductal/lobular hyperplasia to well-differentiated ductal/lobular carcinoma in situ (DCIS/LCIS), which in turn progresses to grade I invasive ductal/lobular carcinoma (IDC/ILC). Whereas in the high-grade arm poorly differentiated DCIS develop into grade III IDC. A high percentage of 'Low-grade arm' cancers are oestrogen receptor (ER), progesterone receptor $(\mathrm{PgR})$ positive and human epidermal growth 
factor receptor-2 (HER-2) negative. 'High-grade arm' cancers tend to show more nuclear atypia, are normally ER and PgR negative, and may be positive for HER-2 [6]. However, the majority of breast cancers (30$60 \%$ ) contain a blend of histological features common to both lowgrade (well-differentiated) and high-grade (poorly-differentiated) tumours. These are referred to as 'intermediate-grade breast cancers.' Data from molecular and genetic studies suggest that these tumours do not represent an independent disease subtype, but a blend of low-grade and high-grade cancers [7].

The progressive pattern suggested by Simpson et al. [5] is not necessarily followed in all cases of breast cancer. Some cancers may never progress beyond in situ disease [8]. The available data $[9,10]$ suggests that about one in three patients with ductal carcinoma in situ will develop invasive cancer over the course of 10 years; however, the risk of progression varies with grade; about $60 \%$ of low grade DCIS will become invasive cancer after 40 years of follow-up, whereas half of high grade DCIS will become invasive cancer after seven years [11].

Generally breast cancer is a slow growing cancer and local disease rarely causes any life threatening problems especially during the first two or three years. There are some aggressive variants such as 
inflammatory and metaplastic breast cancer, but they are rare. The actual threat to survival in breast cancer is the metastatic disease i.e. when the disease spreads beyond the axillary lymph nodes to other organs such as bone, lung, liver and brain. Metastatic disease is detectable only in a small portion $(\sim 10 \%)$ of breast cancers at the time of diagnosis and the average period of survival after its diagnosis is 1824 months, though this varies widely between patients [12].

\subsection{Breast cancer and older patients}

Older women constitute a significant proportion of breast cancer patients, with more than one third of breast cancer cases currently diagnosed in women above the age of 70 years [2]. The older population is expected to grow further with improvements in healthcare and increase in life expectancy [13], which will result in an increasing number of breast cancer cases in this age group. Figure 1.1 [2] shows the incidence of breast cancer by age in the UK.

In the last few decades, breast cancer patients have seen significant advances in care, including improvements in early detection, surgical techniques, radiotherapy, endocrine therapy and chemotherapy as well as Herceptin and related biological agents. These improvements have 
led to a significant decline in overall breast cancer mortality. In the 1970s, around five out of ten breast cancer patients survived beyond five years, now it is eight out of ten [2]. However, sub-group analysis by age, shows that only younger patients have benefited from the decline in breast cancer mortality. Breast cancer-specific mortality and overall mortality remain unchanged in older women, who have seen no major improvement in their breast cancer diagnosis or treatment strategies [14]. Figure $1.2 \& 1.3$ [2] shows breast cancer mortality rates between 1971 and 2007 . The rate fell significantly in patients younger than 70 years, but remains almost unchanged in women above the age of 70 . This may be due to several possible contributing factors such as: other causes of death predominate in older patients, which may dilute the effect of any decline in mortality from breast cancer; lack of screening in older women and delayed presentation resulting in a more advanced stage disease at diagnosis [15]; or differences in treatment with age $[16,17]$. 
Figure 1.1: Numbers of new cases and age specific incidence rates, by sex, breast cancer, UK 2006

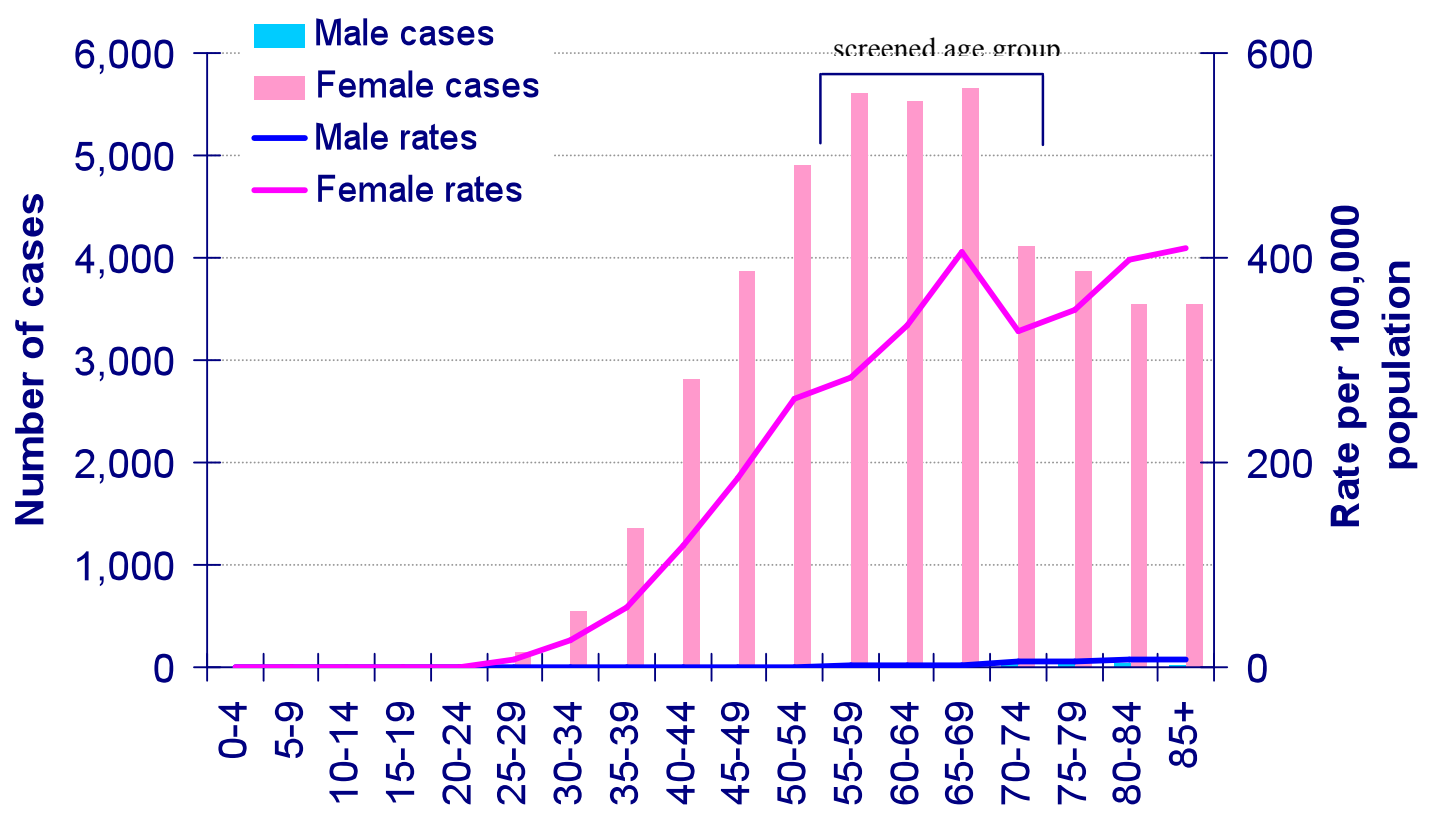

Age at diagnosis

[Figure 1.1, 1.2 courtesy of Cancer Research UK]

Figure 1.2: Age-specific mortality rates, breast cancer, females, UK, 1971 - 2007

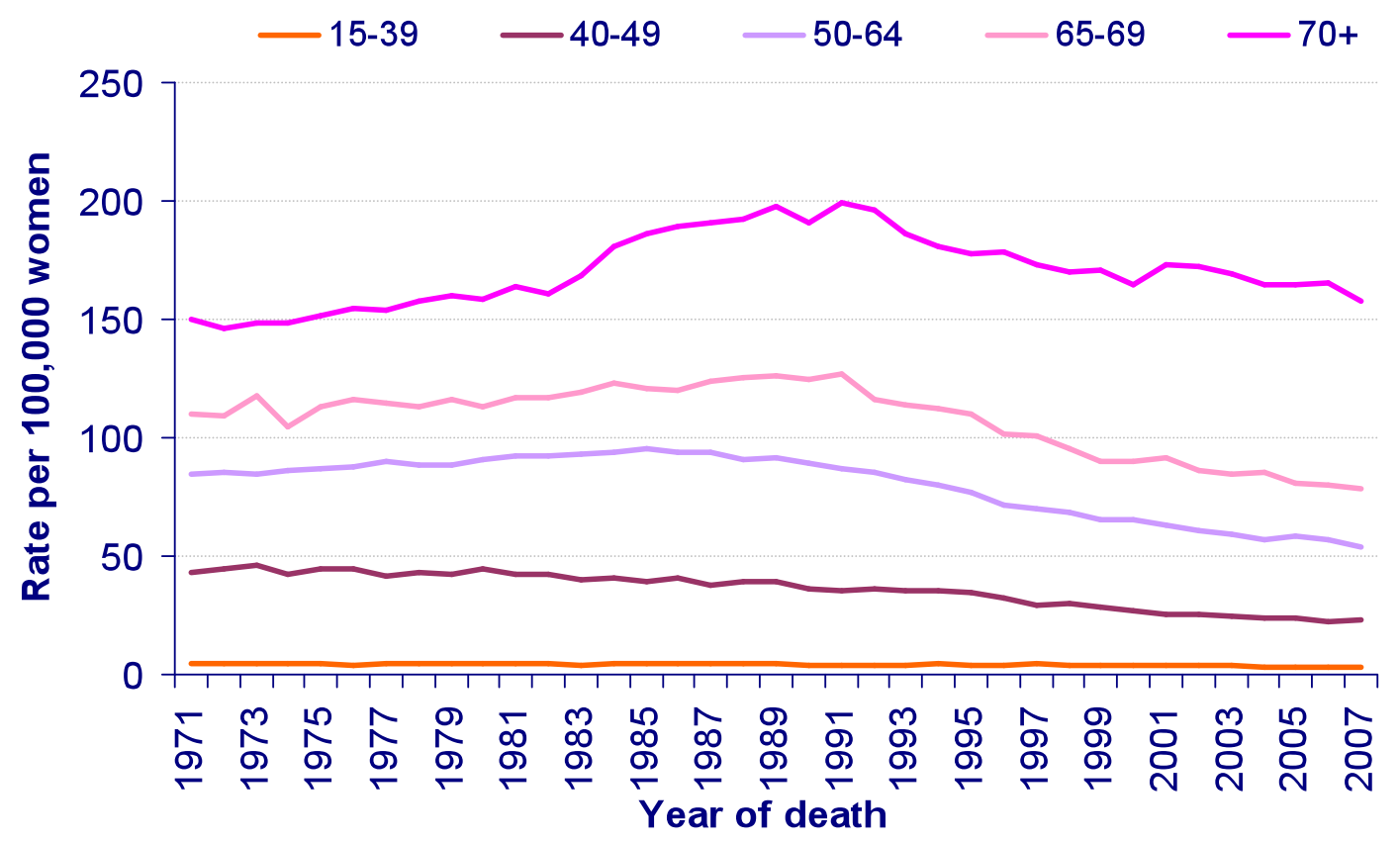


Figure 1.3: Number of deaths and age-specific mortality rates, breast cancer, by sex, UK, 2007

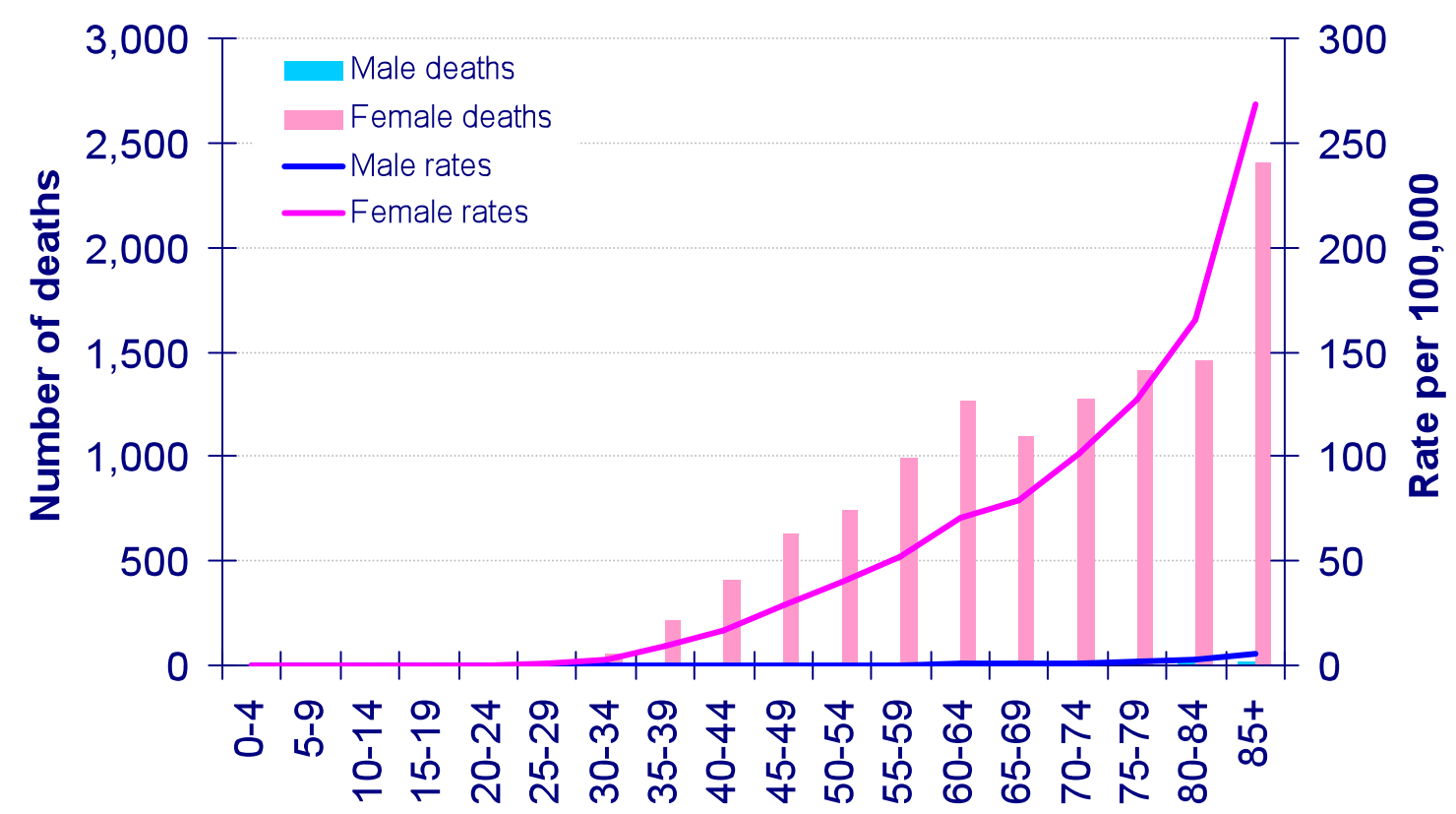

Age at death

[Courtesy of Cancer Research UK]

\subsection{Treatment of early breast cancer}

\subsubsection{Standard treatment and issues in the treatment of older patients}

Standard treatment for early breast cancer is surgery +/- radiotherapy +/- systemic therapy, depending on tumour size/extent (relative to breast size), site, and detailed histological features; however, it needs to be tailored to the patient's wishes and physical limitations. 
The evidence on which standard treatment protocols are based is derived from trials and studies into which older patients were not often recruited, and extrapolation of the results from these studies to a different, older, population may not be appropriate. Older patients have a greater incidence of co-morbidity and functional dependence [16] and in certain circumstances reduced fitness and/or life expectancy may demand modifications from standard treatment. Surgery for breast cancer has very low mortality [18] and deaths directly due to surgery are rare, therefore it can be argued that life expectancy is more important than fitness for surgery in considering treatment options, whether the patient will survive long enough to benefit from the treatment offered. Thorough assessments and analysis of risks/benefits involved should guide treatment decisions in older patients, to ensure that they receive optimal treatment for their breast cancer.

\subsubsection{Surgery}

Surgery provides local treatment in breast cancer, often with the help of radiotherapy. Treatment of local disease, though it may not have any effect on short-term survival, significantly affects long-term survival in breast cancer patients $[19,20]$. Breast cancer surgery can be in the form of breast conservation surgery or mastectomy, with axillary 
surgery in both cases. Breast conserving surgery with radiotherapy is the standard of care for early breast cancer. It has a similar outcome in terms of disease free survival and overall survival as mastectomy [21]. Mastectomy is appropriate for breast cancer patients: who cannot have radiotherapy or do not want radiotherapy, with multi-focal disease/extensive DCIS or a single large/central cancer, or who chose to have mastectomy over breast conserving surgery [22].

Axillary lymph node dissection (ALND) has been used to both stage and treat axillary disease in breast cancer. Now, with sentinel node biopsy (SNB), there is a trend towards staging surgery and then a second treatment operation if needed. Recently, with the use of pre-operative axillary ultrasound + FNA/core biopsy, some node-positive cases can be identified, and these can then proceed to a treatment axillary operation at the same time as operation for the breast cancer itself [23]. Also, axillary lymph nodes status in breast cancer provides important prognostic information, and helps in deciding the need for adjuvant treatment. Lymph node positive status and the number of nodes containing metastasis are associated with an increased risk of local recurrence and disease progression [24]. 


\subsubsection{Surgery in older breast cancer patients}

In the UK, there has been a trend towards treating older breast cancer patients with hormonal treatment alone based on the premise that they are less likely to be fit for surgery because of co-morbidity [25]. However, compared to surgery for many other cancers (Bowel, Lung, Renal \& Gynaecological cancers), breast cancer surgery has a low morbidity and mortality; even in elderly patients mortality ranges from $0-0.3 \%[18,26,27]$. Many older patients, who are unfit for general anaesthesia, can have the surgery under local anaesthetic.

Surgery for early breast cancer in older patients can be in the form of breast conservation or mastectomy with or without axillary node dissection. Breast conservation surgery is associated with a better quality of life [28] and is preferred by most elderly patients [29]; however, available data suggest that they are less likely to receive such treatment $[30,31]$. Later presentation, and tumours being large relative to the size of the older woman's atrophied breast will contribute to mastectomy. Some older women chose mastectomy because they don't want the possibility of a second operation if wide excision margins are inadequate. In older patients with early stage, hormone receptor positive breast cancer, axillary lymph nodes status may not affect the 
choice of systemic therapy in most cases. Sentinel node biopsy, which is a safe and minimally invasive procedure, may be considered in these patients. However, axillary node dissection should be used when there is evidence of lymph node involvement or in patients with aggressive cancer [32].

\subsubsection{Adjuvant Radiotherapy}

Radiotherapy is used as adjuvant treatment for control of local disease in breast cancer. It is recommended for all patients with invasive breast cancer who have breast conserving surgery and some who have mastectomy. Post-operative radiotherapy after breast conserving surgery reduces the risk of five-year local recurrence by $19 \%$ and 15 year breast cancer specific mortality by about $5.4 \%$ [20]. The Early Breast Cancer Trialists' Group (EBCTCG) overview [20] involving about 42000 women with breast cancer showed that radiotherapy after breast conserving surgery significantly reduces the risk of local recurrence in women of all ages; however, the risk reduction was greater in women below the age of 50 than in older women (five-year risk reductions of $22 \%$ vs. $11 \%)$. 
Use of chest wall radiotherapy after mastectomy reduces local recurrence rates by $18 \%$ in all age groups [20]. National Guidelines [22] advise its use if there is a high risk of local recurrence, such as if there is margin involvement, heavy nodal disease ( $>$ four positive nodes) or a large (T3) tumour.

\subsubsection{Radiotherapy in older breast cancer patients}

Radiotherapy after breast conserving surgery decreases the risk of local recurrence in all patients regardless of age; however, in clinical practice, older patients are less likely to receive such treatment $[27,33,34]$. Contrary to the common belief, there is no evidence that radiotherapy is associated with increased toxicity in older patients [35].

Meta-analysis of studies on the use of post-operative radiotherapy in older breast cancer patients by the Early Breast Cancer Trialists' Collaborative Group, showed no differences in proportional reductions in local recurrence risk by age [20]; however, the effect on overall survival is unclear. There is some evidence that local recurrence rates may be lower in older women after surgery without radiotherapy [36]. Currently a randomised trial (PRIME II Trial) is evaluating the role of adjuvant radiotherapy in older patients with good prognosis breast cancer. 
There is limited level 1 evidence on the effects of post-mastectomy radiotherapy in older patients. A meta-analysis [20] and retrospective analysis of the SEER data [37] showed that post-mastectomy radiotherapy is associated with significant reduction in recurrence and improvement in survival in high-risk women regardless of their age. The survival advantage, however, emerged only after five years. Therefore, in older patients with a limited life expectancy, the benefit from radiotherapy may not be great in terms of survival and the decision should be based more on consideration of loco-regional control.

\subsubsection{Adjuvant systemic therapy}

\subsubsection{Endocrine therapy}

Endocrine therapy (i.e. tamoxifen or an aromatase inhibitor) is used as an adjuvant to local treatment for hormone receptor positive, early breast cancers. More than two-thirds of breast cancers are hormone receptor positive; the proportion increases to $90 \%$ with increasing age [38]. Endocrine therapy significantly reduces the rate of local recurrence, the development of disease in the contra-lateral breast and at distant sites, and improves disease free and overall survival [39]. Five years of adjuvant tamoxifen reduces the annual breast cancer 
death rate by $31 \%$, compared with no adjuvant treatment, in patients with hormone receptor positive breast cancer, irrespective of their age [40].

Aromatase inhibitors (AI) are more effective than tamoxifen in terms of disease free survival and reducing the risk of distant metastases; however, so far no significant difference is reported in overall survival between the two, from the limited follow-up of patients in the adjuvant AI trials [41]. The efficacy of an aromatase inhibitor (letrozole) was compared with tamoxifen in a large multinational adjuvant trial - The BIG 1-98 [41], involving more than 8000 postmenopausal women with hormone receptor positive early breast cancer. At a median follow-up of 73 months and treatment duration of 60 months, letrozole was shown to significantly improve disease free survival and reduce the risk of distant recurrence relative to tamoxifen in postmenopausal patients with hormone receptor positive early breast cancer. AIs are now recommended as first line adjuvant hormonal therapy in many postmenopausal patients with hormone receptor positive, early breast cancer [42].

AIs and tamoxifen both have their side effects. Tamoxifen is associated with an increased risk of endometrial cancer and thromboembolic 
events; risks associated with aromatase inhibitors are myalgia, arthralgia, osteoporosis \& bone fractures. Previously AIs were thought to be associated with increased risk of cardiovascular events; however, this is not supported by more recent studies [43].

\subsubsection{Endocrine therapy in older patients}

There is no evidence of age related differences in the efficacy of tamoxifen or AIs in post-menopausal women; however, older patients are more vulnerable to some adverse events, therefore safety should be an important factor in choosing between the two. Tamoxifen is associated with increased risk of thromboembolic events and may be contra-indicated in those older patients with a past history of deep venous thrombosis (DVT) or pulmonary embolism (PE). AIs are associated with increased risk of osteoporosis, which is a particular problem for the very elderly - often already having osteoporosis, in whom a hip fracture has a $50 \%$ risk of mortality or subsequent institutional care [44]. Bisphosphonates are commonly used to prevent bone loss in these patients. The recent Z-Fast study reported that upfront Zoledronic acid therapy effectively prevents AI-associated bone loss in postmenopausal women with early breast cancer [45]. The current guidelines advise bisphosphonates for all women over 75 on an 
AI. However, this is not an easy treatment to take orally; the special dosing issues and adverse effects of bisphosphonates, especially when dosing recommendations are not followed, contribute to the very poor compliance (less than $50 \%$ ) with this medication [46].

\subsubsection{Primary endocrine therapy vs. Surgery plus endocrine therapy in older breast cancer patients}

Endocrine therapy, when used as a sole agent to treat breast cancer, is known as primary endocrine therapy (PET). It was first described in the 1980 s as an alternative to surgery for older women [47]. PET is effective in around $80 \%$ of hormone receptor positive breast cancers [48]; there is, though, at present no way of predicting which receptor positive cancers will respond to endocrine therapy and how long the response will last [49]. The median response duration is about two years with wide variation [50].

Evidence shows that there is greater utilisation of primary endocrine therapy in older patients as compared to younger patients, presumably based on the premise that they are less likely to be fit for surgery because of co-morbidity [25]; also, it is easy to give and to receive, and popular with patients. In the UK, more than $40 \%$ of breast cancers 
diagnosed in patients over 70 were treated with endocrine therapy alone [51]. This reliance on endocrine therapy, in patients who live long enough, results in persistent or recurrent local disease, sometimes becoming locally advanced and then difficult to treat, months and years after diagnosis [52].

To establish whether primary endocrine therapy is justifiable for women who are fit for surgery, several trials were conducted to compare the efficacy of primary endocrine therapy vs. surgery plus endocrine therapy in older breast cancer patients. Hind et al. [53] performed a Cochrane review and meta-analysis of the randomised controlled trials $[19,54-57]$ comparing primary endocrine therapy vs. surgery alone or with endocrine therapy, in women aged 70 years or above with clinically defined operable primary breast cancer. In these trials, surgery for breast cancer included mastectomy or breast conserving surgery, with or without axillary lymph node dissection. Primarily they were looking for overall survival and progression-free survival. Secondary outcomes were adverse effects, local disease control, distant metastasis-free interval and quality of life.

They found that patients aged 70-75 had better survival in the surgery + tamoxifen groups. There was no overall survival benefit from surgery 
in patients above 75 years of age, though better local control was demonstrated in the surgical group. They recommend the use of PET only in patients with ER positive tumours, who are unfit for surgery, have reduced life expectancy, or who refuse surgery. The National Institute for Clinical Excellence guidance [22] subsequently recommended treating patients with early invasive breast cancer, irrespective of age, with surgery and appropriate systemic therapy, rather than endocrine therapy alone, unless significant co-morbidity precludes surgery.

Some of the individual studies, where patients younger than 75 were included, showed a survival benefit in the surgical plus tamoxifen arm in the medium to long term. Fennessy et al. [19] conducted a randomised control trial comparing tamoxifen-alone vs. surgery plus tamoxifen in women aged 70 and above with early breast cancer. They reported at 12 years of follow up that both overall mortality and mortality from breast cancer was significantly increased in the tamoxifen-alone group, although the survival curves did not diverge until after the first three years. The study included 455 patients above the age of 70 with a median age of 76 years. In a subgroup analysis of survival by age group there was a highly significant benefit from surgery in patients under 75 . There was a similar trend in those aged $75-80$ but the numbers were 
small and the confidence intervals were wide. In those over 80 there was no effect on survival but the numbers were very small. They concluded that surgery decreased the mortality rate in an unselected population of elderly women with operable breast cancer who were fit for the procedure. However, for women with ER-positive breast cancer who have a short life expectancy, they recommended primary tamoxifen therapy, as surgery in addition to tamoxifen, confers no survival benefit in someone who lives less than 3 years or so.

The trial was organised by Cancer Research UK and conducted across 27 UK hospitals. Overall, it scored $13 / 19$ on Van Tulder critical appraisal score [58]. The Van Tulder score ranges from 0 (lowest quality) to 19 (highest quality) and has been commonly used to grade the quality of trials in systematic reviews [59]. Elgibility criteria were clearly specified in the trial. It included patients from all across UK hospitals who were aged 70 years or over, had a palpable breast lesion and histological or cytological evidence of invasive disease, or unequivocal mammographic evidence of breast cancer, and had operable disease. A computergenerated randomisation, stratified by hospital in block sizes of four, was produced and concealed by staff at the Cancer Research UK Clinical Trials Centre. Four hundred and fifty-five patients were randomised into two groups. One group of 230 patients received tamoxifen alone and 
the other group of 225 patients received surgery plus tamoxifen. The outcome assessors were blinded but care providers and patients were non-blinded to treatment interventions. Compliance rate was more than $95 \%$ in both groups. The outcome measures were clearly identified and were relevant. The trial objectives were to compare time to treatment failure and overall mortality in patients randomised to surgery plus tamoxifen and tamoxifen-alone. No details were provided about adverse events in either group. The withdrawal and drop out rate was less than five percent in both groups. A short-term measurement was performed in 1991 and final measurement was performed 1999. Timing was comparable for the outcome measurement in both groups. All randomised patients, regardless of whether they received the assigned treatment or not, were included in the intention to treat analysis.

The sample size of 455 patients was enough to detect a $10 \%$ difference in the treatment with $90 \%$ power. Cox proportional hazard model was used for data analysis. The two randomised groups were well matched for age, tumour size and axillary lymph nodes status; however, they did not take into account patients' co-morbidity or their socio-demographic status, both of which could have an impact on their overall survival. Also, they treated patients with endocrine therapy without testing their tumour hormone receptor status (common practice at the time). About 
$15-20 \%$ of breast cancers are hormone receptor negative. Therefore, this proportion of patients were unlikely to have received any benefit from the endocrine therapy and potentially could have disadvantaged the tamoxifen-alone group. Radiotherapy reduces the risk of local recurrence after breast conserving surgery and is a standard today. However, patients in the study were not offered radiotherapy after breast conserving surgery. Those patients were more likely to get recurrence and potentially this could have disadvantaged the surgical arm.

In another multicenter phase III randomised controlled trial, Mustacchi et al. [54] compared tamoxifen-alone versus surgery plus adjuvant tamoxifen for operable breast cancer in women above 70 years of age. After a median follow up of 80 months, they found no significant breast cancer specific or overall survival difference between the two groups ( $p$ value $>0.05)$. The local disease control, however, was much better in the surgical arm. At a median follow-up of 80 months, $27(11.2 \%)$ patients in the surgical arm and $106(45.2 \%)$ in the tamoxifen-alone arm had local progression $(P<0.0001)$.

The study was one of the largest randomised control trials on the issue. It was conducted across 19 centers in Italy. Newly diagnosed patients 
with histological or cytological evidence of invasive breast cancer, who were age 70 and above, and had operable disease were eligible for the trial. Randomisation was based on random number tables and stratified by hospital in block sizes of 10 . It was produced and concealed by staff at the central trial office. Four hundred and seventy-four patients were randomized into two groups. Two hundred and thirty-nine patients were allocated to the surgical arm and two hundred thirty-five patients were allocated to the tamoxifen-alone group. Care providers and patients were non-blinded to the treatment interventions. However, outcome assessors were blinded to the treatment interventions. Compliance rate was more than $97 \%$ in tamoxifen-alone group and $94 \%$ in the surgical group. The primary objective of the trial was to compare the overall survival in the two treatment arms. Secondary objectives were set to compare the event-free survival, breast cancer survival and local control of the disease. Adverse events were reported in both groups. The withdrawal and drop out rate was less than two percent in both groups. A short-term measurement was performed at 36 months and final measurement was performed at a median follow-up of 80 months. Timing was comparable for the outcome measurement in both groups. All patients assigned to the treatment groups were included in the analysis according to the intention to treat. Overall the trial scored 14/19 on Van Tulder critical appraisal score. 
A sample size of 570 patients was calculated to be enough to detect a $10 \%$ difference between the two treatment groups with $80 \%$ power and 0.05 significance level. However, the number of recruited patients was reduced to 474 because of a reduction in recruitment with time. The revised power of the study with the recruited number of patients was calculated to be 80 . They used the log-rank test to assess the statistical significance of treatment differences and chi-square test for differences in proportions of distant metastases. Cox proportional hazard model was used to explore any relationship between different variables and overall and breast cancer survival. The randomised groups were well matched for age, tumour size, axillary lymph node status and ECOG performance status. However, they did not assess and control the two groups for co-morbidity and socio-demographic status that might have had an impact on their overall survival.

As in the previous trial, patients in the tamoxifen-alone group received treatment without assessment of hormone receptor status. This could have potentially disadvantaged the tamoxifen-alone group, as $15-20 \%$ of patients, who were likely to be hormone receptor negative, would not have benefited from the treatment. On the other hand, patients in the surgical arm did not receive adjuvant radiotherapy after surgery. This 
could have potentially disadvantaged the surgical arm as adjuvant radiotherapy significantly reduces the risk of local recurrence.

In conclusion, primary endocrine therapy was found to be as effective as surgery plus endocrine therapy, in terms of overall survival, at least in the first three years, in older patients with hormone receptor positive, early breast cancer [53]. However, it seems that the use of primary endocrine therapy should be restricted to those with short life expectancy, who are unfit for surgery, or who refuse surgery; although, patients who are fit and refuse surgery, should be given enough time for detailed discussion and encouraged to accept standard treatment. In other words, women who are not expected to live long enough to benefit from local treatment may be safely treated with only endocrine therapy, if their breast cancer is hormone receptor positive. Tumours in patients with good life expectancy, if treated with primary endocrine therapy, may develop endocrine resistance and the disease may relapse after an average of two years of therapy, necessitating a change of management at a stage when the patient is older and usually less fit.

\subsubsection{Adjuvant Chemotherapy}


Adjuvant chemotherapy reduces the risk of relapse and death in women with early stage breast cancer; the risk reduction is larger in those below 50 years of age compared with those over 50 years [40]. Adjuvant polychemotherapy (anthracycline-containing regimen) reduces the annual breast cancer death rate by about $38 \%$ for women younger than 50 years of age when diagnosed, by $24 \%$ for those of age $50-60$ years, and about $13 \%$ for those of age $60-69$, largely irrespective of the use of tamoxifen and of oestrogen receptor (ER) status, nodal status, or other tumour characteristics [40]. The risk reduction for patients above 70 years of age was not significant probably due to small numbers recruited into trials. In general, patients with hormone receptor negative breast cancers had a greater absolute survival benefit compared to patients with hormone receptor positive cancers [60]. This will be, at least in part, because they have poorer prognosis. The absolute benefit of chemotherapy therefore varies according to both patient age and underlying prognosis. Estimates of the benefits of adjuvant chemotherapy are therefore made on the basis of patient age and prognosis, derived from the pathological features of their cancer [22].

\subsubsection{Chemotherapy in older breast cancer patients}


There is limited evidence for the role of adjuvant chemotherapy in the treatment of older women with breast cancer, mainly because very few women over 70 years of age have been included in trials. The EBCTCG overview [40] shows progressively reduced benefit from adjuvant chemotherapy for those in the age decades above 50 so that, above age 70 , only those fit patients with a poor or very poor prognosis breast cancer would be expected to gain more than they risk from adjuvant chemotherapy. More recent evidence suggests that chemotherapy for oestrogen receptor-negative poor prognosis cancers in the elderly may confer a survival advantage $[60,61]$. There are no age-specific exclusion criteria in National Guidelines [22]. However, reduced chemotherapy tolerance and lack of age-specific evidence of benefit in older women mean that at present adjuvant chemotherapy for most patients over the age of 70 has not been standard practice in the UK.

A retrospective review of data [62] comprising 6487 patients from four randomised CALBG trials comparing the benefits and toxic effects of adjuvant chemotherapy among breast cancer patients, reported significant benefits of chemotherapy in all age group patients. The trials included age groups of 50 years or younger, 51 to 64 years, and 65 years or older. Elderly patients constituted only a small percentage of the study $(n=159,2 \%)$ and they experienced significantly higher overall 
mortality, and mortality due to treatment. However, the chemotherapy benefits in terms of reductions in breast cancer mortality and recurrence were similar in all patients regardless of age. Results from another trial by Muss et al [63], comparing standard chemotherapy with capecitabine alone in older women with breast cancer, confirmed that older patients receive significant improvement in overall survival and recurrence with standard chemotherapy compared to capecitabine alone.

In the United Kingdom, a phase III, multi-center randomised trial (the ACTION trial) was initiated in 2007 to test if adjuvant chemotherapy improves the outcome in older women with high risk, ER negative/ER weakly positive breast cancer. However, the trial had to be closed due to poor recruitment.

Currently, the International Society of Geriatric Oncology (SIOG) [32] recommends that treatment with adjuvant chemotherapy should not be an age-based decision, but, instead, should take into account individual patients' estimated absolute benefit, life expectancy, treatment tolerance, and preference.

\subsubsection{Herceptin}


Herceptin (trastuzumab) is a monoclonal antibody that attaches to a growth-promoting protein known as HER2/neu, present in small amounts on the surface of normal breast cells and most breast cancers. About $25 \%$ of breast cancers have an abundance of this protein and these cancers tend to grow and spread more aggressively. Herceptin antagonizes the constitutive growth-signaling properties of the HER2 system, enlists immune cells to attack and kill the tumour target, and augments chemotherapy-induced cytotoxicity [64].

Treatment with Herceptin reduces the residual risk (after adjuvant chemotherapy) of breast cancer recurrence by about 50\% in HER2receptor positive breast cancers $[65,66]$. The Herceptin Adjuvant (HERA) trial [65] showed that one year of treatment with Herceptin after adjuvant chemotherapy significantly improves disease-free survival among women with HER2-positive breast cancer, irrespective of their age; the median age of women in this trial was 49 (range 21-80 years). The national guidelines [22] recommend trastuzumab, for 1 year or until disease recurrence, as an adjuvant treatment to women with HER2- positive early invasive breast cancer following surgery, chemotherapy, and radiotherapy when applicable.

\subsubsection{Herceptin in older breast cancer patients}


Herceptin significantly improves disease free survival in patients with HER2 receptor positive breast cancers regardless of their age. However, it is associated with cardio-toxicity, which is more of a concern in older patients, as they are at higher risk of developing Herceptin-associated cardiovascular disease [66]. SIOG [32] recommends the use of adjuvant Herceptin in healthy older patients with HER2-positive breast cancer when chemotherapy is indicated, but with close cardiac monitoring.

\subsection{Under-treatment of older breast cancer patients}

There is a significant body of evidence $[3,31,51,67,68]$ to show that older breast cancer patients are less likely to receive standard treatment than younger patients. There are situations when deviation from the standard treatment may be justified in older patients, e.g. patients who are going to survive for five years or less may not benefit from radiotherapy; the benefit of chemotherapy in patients above 70 years is limited. However, true under-treatment does occur, meaning, treatment may be omitted in those who could benefit $[25,69,70]$. 
Wyld et al. [51] compared stage and treatment of breast cancer between two cohorts of postmenopausal women (55-69 vs. >70 years) in a single UK regional cancer network (North Trent) over six months. A total of 378 patients were studied ( $>70: N=167,55-69$ years: $N=210$ ). They reported that a significantly higher percentage of the older patients did not receive standard treatment when compared to the younger age group.

Wanebo et al. [67] analyzed data from 5962 patients with breast cancer recorded in the state-wide tumour registry of the hospital association of Rhode Island between 1987 and 1995, for adequacy of primary treatment, in older women ( $\geq 65$ years of age) compared to younger women ( 40 to 64 years of age). They found that approximately $20 \%$ of the older patients had substandard treatment of favorable stage early primary breast cancer, with poorer survival.

Mandelblatt et al. [68] studied 718 breast carcinoma patients age 67 years and older who were diagnosed with localised disease between 1995 and 1997 from 29 hospitals in five regions of Washington DC, USA. Their results demonstrate that women 80 years and older were liable to receive less treatment than currently recommended in expert consensus guidelines. 
August et al. [3] performed a retrospective review of all women with primary operable invasive breast cancer treated at the University of Michigan breast care center over a 30-month period. They studied 77 patients aged $\geq 65$ years (median, 71 ; oldest patient, 92 years) and compared them with fifty-one younger patients with similar cancers aged 55-64 years (median, 59 years). They reported that while 98 per cent of patients under 65 years of age received standard treatment, only 81 per cent of those over 65 years were treated according to current guidelines.

Lavelle $\mathrm{K}$ et al. [71] analysed data from 480 women with invasive breast cancer aged 65 or older, who were registered with the North Western Cancer Registry database of the UK over a one-year period. They found that, after adjusting for tumour characteristics, older women were less likely to receive standard management than younger women. In the study cohort, $22 \%(67 / 305)$ of women aged 80 or older did not receive primary breast surgery and $41 \%$ (53/130) of women aged 75 or older did not receive radiotherapy after breast conserving surgery. The study, however, did not take into account patients' preferences and health status. So, it is difficult to ascertain the reasons for under-treatment in the study population. 
Hurria et al. [31] reported in "Factors influencing treatment patterns of breast cancer patients age 75 and older," that co-morbidity and age play a significant role in influencing treatment decisions in the older breast cancer patient. Patients were less likely to receive standard treatment with increasing age and co-morbidities.

\subsection{Causes of under-treatment}

Review of the literature $[3,25,31,51,67-70]$ and previous work in Leicester has identified three main causes for under-treatment of older breast cancer patients: these are co-morbidities, age, and personal choice of patients. However, in many cases co-morbidity is overestimated, life expectancy is under-estimated and difficulties in communication all contribute to under-treatment of these patients.

\subsubsection{Co-morbidities}

Older patients are more likely to suffer from co-morbid conditions than young patients. However, in clinical practice no formal assessment has been routinely used to measure or assess the impact of co-morbidities or functional dependence on treatment; decisions to deviate from standard treatment seem to have been based mainly on general 
impressions. This is because there has been no validated system for using co-morbidity and/or functional dependence to predict what treatment(s) will be helpful in the individual patient. Different studies $[25,72,73]$ have confirmed the correlation between co-morbidities and survival in older patients, independent of other factors. Many scales have been devised to assess co-morbidities and their effect on survival, but none of these scales has been used in clinical assessment of older breast cancer patients to help plan treatment for their breast cancer. Therefore, while deviation in treatment decisions from standard practice may be sometimes justified in older breast cancer patients with comorbidities, it needs formal assessment through a validated system to predict the impact of co-morbidities/functional dependence on treatment decisions and outcome.

\subsubsection{Age}

Age has been considered another important factor in planning treatment for elderly patients; however, life expectancy is often underestimated. In the UK, females at the age of 65 have an estimated total life expectancy of 19.4 years and the life expectancy of those who reach 75 and 80 years of age extends further to 11.8 and 8.7 years respectively [1]. Except at the extreme, no direct correlation has been 
found between age and survival in elderly patients. However, with increasing age comes an increased risk of co-morbidity, and associated disability and functional dependence, which affect life expectancy adversely. Therefore, assessment of biological rather than chronological age of patients may play an important role in the determination of appropriate treatment for these patients [74].

\subsubsection{Personal choice}

The third important reason mentioned for under treatment of elderly breast cancer patients is their 'personal choice' [68]. Informed choice has to be honoured; however, it requires that the patient has a proper understanding of the disease process and all treatment options. Our experience at the Leicester breast cancer research clinic showed that with increasing age communication becomes more difficult. There are many factors that may contribute to this such as: deafness, poor eyesight preventing the use of written information, poor understanding and less education of elderly patients etc. Also, older patients may have objections to treatment for very varied reasons, which may have their origin in experiences from several decades ago. For example, they may have unjustified beliefs such as: surgery stirs up cancer, or cancer treatment does not work or cancer is a 'punishment from God', which 
should be endured rather than fought etc. It is often difficult to find ways of discussing such personal issues since older women may not be forthcoming with strangers.

Therefore dealing with older patients needs patience and plenty of time for discussion to help them understand the disease process and different treatment options, which will enable them to make better informed decisions. However, this is very difficult in the busy breast clinic setting, which is why a special breast clinic for older breast cancer patients was established in Leicester.

\subsection{The need for survival prognostic index to improve the care of older breast cancer patients}

The National Institute for Health and Clinical Excellence guidelines [22] and Cochrane review of the randomised control trials comparing primary endocrine therapy and surgery plus endocrine therapy in elderly patients [53] recommend that elderly breast cancer patients should be considered for surgery and appropriate systemic therapy unless they refuse it, or they have a short life expectancy and are therefore unlikely to benefit from it. However, there is no validated assessment in routine clinical practice that could predict life expectancy in older breast cancer patients, based on which they may be 
recommended an optimal treatment for their breast cancer. In other cohorts of patients, assessment tools such as Comprehensive Geriatric Assessment (CGA) have been successfully used to develop survival prognostic indices [75-77].

Alberto Pilotto et al. [75] developed and validated a Multidimensional Prognostic Index (MPI) for one-year mortality in 1695 hospitalised elderly patients, from information available from comprehensive geriatric assessment, that included clinical, functional, cognitive, nutritional, and social parameters.

This prospective cohort study included 838 consecutively admitted patients to a geriatrics unit in Italy between January and December 2005. Patients were included in the study if they were of age 65 or more; provided an informed consent; had complete CGA during hospitalisation; and their mortality/survival information were available at the date of study completion. Information was gathered from the CGA performed as part of their clinical assessment in the geriatric unit. The CGA assessment included: evaluation of functional status using ADL and IADL, Short Portable Mental Status Questionnaire (SPMSQ) to evaluate cognitive status, assessment of co-morbidity using the Cumulative Illness Rating Scale (CIRS), assessment of nutritional status 
using Mini Nutritional Assessment (MNA), the Exton-Smith Scale (ESS) to evaluate the risk of developing pressure sores, use of medication, and assessment of social aspects including household composition, home services, and institutionalisation. Out of 1549 patients who were admitted to the unit during the study period, only 838 patients fulfilled the inclusion criteria. In the majority of the patients who were excluded it was because of incomplete information or lack of CGA.

Initially, they performed a cluster analysis on the CGA data to evaluate the independence of variables and identify the most relevant domains of the CGA that could predict mortality in the study population. Using logistic regression and Cox proportional hazard model they built an MPI based on eight domains of the CGA that were found to have a significant association with one year survival in the study population. These included ADL, IADL, SPMSQ, MNA, ESS, CIRS, medications, and co-habitation status. The MPI was developed by aggregating the total scores of the eight domains and expressing it as a score from zero to one. Three grades of MPI were identified: low risk, $0.0-0.33$; moderate risk, $0.34-0.66$; and severe risk, $0.67-1.0$. They studied the predictive value of the MPI for all causes of mortality over a 12-month follow-up period. One-year mortality for grade-1 was $5.7 \%$; grade-2 was $23.2 \%$; and grade-3 was $45.1 \%$. The MPI stratified the hospitalised older 
patients into three categories that experienced a significantly different one-year mortality. After adjusting for age and sex, the prognostic effect of MPI on mortality was still highly significant.

Using logistic regression analysis, they confirmed that the aggregate MPI had a stronger association with one-year survival compared to the individual variables that were used to construct the MPI. The C-statistic value (area under ROC curve) for the MPI was reported to be 0.75 , confirming that the prognostic index had good discriminatory power. The MPI was validated in another cohort of 856 consecutively admitted patients in the same unit in 2006 and reported similar values.

The MPI was developed and validated in a large cohort of patients with valid statistical analysis and good description of the results. The authors provided clear information about inclusion and exclusion criteria and final outcome. They adopted a multi-dimensional assessment approach and included variables that represent patients' different domains. However, there are some limitations and bias in the study. The authors provided no information on the sample size calculation and power analysis for the study. A large number of patients were excluded in the development and validation cohort based on incomplete information or lack of CGA assessment; however, the authors provided no reasons or 
further explanation about these patients. The study included patients from a single geriatric unit of an Italian hospital and there is no information about the geographic composition of the study population. Also, the authors provided no information as to how long an MPI assessment would take for a single patient. The devised MPI model used parameters that particularly characterise the hospitalised elderly patient and need thorough assessment and information collection that is unlikely to be possible in non-hospitalised patients. The authors also acknowledged this limitation of their study.

The study by Inouye et al. [76] demonstrated the importance of functional measures (i.e., IADL, Mini-Mental State Examination (MMSE), and shortened Geriatric Depression Scale) in predicting two-year mortality in a population of 207 hospitalized elderly patients. The study included patients aged 70 years or older, with no clinical evidence of delirium at enrollment, and admitted consecutively to the general medical units of Yale-New Haven Hospital (YNHH), Connecticut, USA, between November 6, 1989, and June 22, 1990. Patients' assessment included: demographic information, current living situation, selfreported basic ADLs and IADLs, mobility assessment, MMSE, GDS, hearing tests, the Confusion Assessment Method (CAM) rating, burden of illness, and the modified Blessed Dementia Rating scale (mBDRS). 
They developed a functional axis based on three general conceptual categories: physical, cognitive and other, each representing a different domain. Using a bivariate Cox proportional hazards analysis they assessed the relationship of individual variables with two-year survival in the study and selected those with a significant association for a multivariate analysis. In the multivariable analysis, three variables impairment in IADL, an MMSE score less than 20, and a shortened GDS score of seven or higher retained statistically significant impact on twoyear mortality. They developed a risk stratification system by categorising patients into a low-risk group (no risk factors), intermediate-risk group (one risk factor), and high-risk group (two or more risk factors). The two-year mortality rates for the low-, intermediate-, and high-risk groups were $20 \%, 32 \%$, and $60 \%$, respectively $(P<.001)$. They validated the prognostic index in another cohort of 318 patients admitted to the medical units of same hospital between July 9, 1990, and July 31, 1991.

The predictive accuracy of the final model in both the development and validation cohorts was examined using calibration and discrimination. The C-statistic values for the development and validation cohort were 0.69 and 0.66 respectively, confirming moderate discriminatory capabilities of the prognostic index. 
The study was a well-designed prospective cohort study with clearly defined inclusion and exclusion criteria, primary and secondary outcomes, and reasons for non-inclusion and exclusion of patients from the study. The authors provided clear information about the study setting and patients' demographics. Also, they selected clinically relevant variables with cut points that were clinically meaningful and used in previous published studies. They used valid statistical analysis for the development and validation of the functional index. However, the study has some limitations. The authors provided no information about sample size calculation and study power analysis. Also, the development and validation cohort included patients of the same hospital from the same catchment area of New Heaven, Connecticut. For generalisation, it needs to be tested in other geographic locations and populations.

Another study by Walter LC et al. [77] developed and validated a oneyear mortality prognostic index using six risk factors in 2922 older hospitalised patients. The study randomly selected these individuals who were enrolled in two randomised trials of an intervention to improve functional outcomes of hospitalised older adults. The trials were conducted at the University Hospitals of Cleveland (UHC) and the Akron City Hospital (ACH), in Ohio, between 1993 and 1997. Each trial 
enrolled patients who were aged 70 years or older and who were admitted to the general medical service. Data for the study was obtained from structured interviews with patients or their surrogates and from medical records.

The gathered information included four broad categories: demographic variables, medical diagnoses, functional status, and laboratory values. Using univariate regression analysis, individual risk factors were assessed for their relationship with one-year survival in these patients. Twelve Risk factors associated with one-year mortality were identified. These were then entered into a multivariable logistic regression model and yielded a final set of six risk factors that were associated with oneyear mortality in the study population. These included male sex, congestive heart failure, cancer, functional dependency in any $A D L$, creatinine level $>3.0 \mathrm{mg} / \mathrm{dL}$, and albumin level $3.4 \mathrm{~g} / \mathrm{dL}$. Based on these risk factors, they developed a weighted index, divided patients into four groups and reported mortality accordingly. One-year mortality was $4 \%$ in the lowest-risk group, $19 \%$ in the group with two or three points, $34 \%$ in the group with four to six points, and $64 \%$ in the highest-risk group. They reported good calibration and discrimination of the model with a C-statistic value of 0.75 in the derivation cohort and 0.80 in the validation cohort. 
The prognostic index was developed and validated in a large population sample, which was randomly selected from two groups enrolled in two separate trials. However, the authors did not provide details about the random selection process. The information about inclusion and exclusion criteria and final outcome was clearly outlined in the study. Valid statistical tests were used to analyse the data in the development and validation cohort. The index was developed and validated in a regional area of Ohio, USA. For generalisation, it needs to be tested in other geographic locations and populations.

Elderly breast cancer patients may also benefit from inclusion of such assessment tools into their clinical assessment, to help predict their life expectancy and hence guide treatment decisions, to ensure that they receive the most appropriate treatment for their breast cancer.

\subsection{Comprehensive Geriatric Assessment}

Comprehensive geriatric assessment is a multidimensional, interdisciplinary diagnostic process to determine the medical, psychological, and functional capabilities of elderly patients in order to develop a coordinated and integrated plan for their treatment and longterm follow-up [78]. Different components of CGA have been found 
useful in predicting mortality and morbidity for several chronic diseases in a variety of clinical settings [79-85].

There are a number of different models for the application of CGA, which have been used in different health-care settings and adapted for disease-specific management programs. The CGA model we used in our clinic includes assessment of all the key domains that could help in the management of elderly breast cancer patients and is also practical in a routine clinic setting. It includes the following components: assessment of co-morbidities, cognitive function, depression, physical function and fitness for anaesthesia.

\subsubsection{Assessment of co-morbidities}

Elderly patients are more likely to suffer from co-morbid conditions than young patients. The presence of co-morbidities, often, has a negative effect on their physical and cognitive function as well as on their survival. Different studies $[25,72,73]$ have confirmed the correlation between co-morbidities and survival in older patients, independent of other factors. A number of scales exist for assessment of comorbidities, some of them have been validated in elderly, non-cancer patients e.g. Greenfield individual disease severity index [86], others were developed in the elderly but subsequently validated in a cancer 
population. In particular, the Satariano Index of Co-morbidities (SIC, Table 1) has been assessed in older breast cancer patients; it has been reported that patients with three or more co-morbidities have an increased risk of death over a three-year follow up period, independent of age, breast cancer staging and treatment type [25].

The Charlson Index [72] is another easily applied rating system, which uses standardised criteria to identify the presence or absence of prognostic co-morbidity, though not its severity. Nagel et al. [73] also confirmed a correlation between the level of co-morbidities and threeyear survival in postmenopausal women with breast cancer. Another population-based longitudinal study of health in the older population the Medical Research Council Cognitive Function and Ageing Study [87] has identified prevalent co-morbidities associated with incident disability and mortality over a 10-year follow-up period and calculated the effect of these co-morbidities on disability-free and total life expectancy. Cumulative Illness Rating Scale (CIRS, [88]) is another widely used comorbidity index that uses a scoring system for 14 body system domains and a severity scale for each domain. Due to its complexity, it is more difficult to administer in a busy outpatient setting. 
We selected the Satariano index of co-morbidities scale to assess the impact of co-morbidities on the survival of our study population. The scale is relevant to our study patients as it has been developed and validated in a cohort of breast cancer patients and showed an independent association with their three-year survival. Patients are scored one for the presence of each of the seven disease conditions given in Table 1. The final SIC score is calculated out of seven. 
Table-1. Satariano Index of Co-morbidities

\begin{tabular}{|l|l|l|}
\hline S.No & Co-morbidity & Score \\
\hline 1 & Myocardial infarction & 1 \\
\hline 2 & Heart disease (other diseases) & 1 \\
\hline 3 & Diabetes & 1 \\
\hline 4 & Other forms of cancer (excluding breast cancer & 1 \\
\hline 5 & Respiratory & 1 \\
\hline 6 & Gallbladder diseases & 1 \\
\hline 7 & Liver conditions & 1 \\
\hline & Total SIC score (0-7) & \\
\hline
\end{tabular}

Patients are scored one for the presence of each of the seven disease conditions.

Final SIC score is calculated out of seven. Adapted from Satariano and Ragland, $1994[25]$. 


\subsubsection{Assessment of Cognitive function \& Depression}

In elderly patients cognitive status assessment is important, not only because of its impact on disability-free and total life expectancy [74], but also due to its effect on the patient's ability to participate fully in an informed discussion and consent process regarding best management, and co-operate with treatment. Lower levels of cognitive function have been associated with increased mortality in older patients $[82,83]$ as well as their inability to co-operate with standard treatments. We have used the Folstein Mini-Mental State Examination score (MMSE) to assess the cognitive status of our study patients. This [89] is a well-validated tool, which is commonly used in everyday clinical practice in geriatric medicine. It samples various functions including arithmetic, memory and orientation. MMSE is reported on a scale of $0-30$. Patients are scored on the 11 components of MMSE given in Table 2.

In addition, psychiatric morbidity, especially depression, is common in cancer patients and there is evidence that it is associated with reduced survival from conditions such as ischaemic heart disease and cancer [90]. The psychological ability to adapt to illness and treatment is an important aspect of the management of any cancer patient. We have used the short version of Geriatric Depression Score (GDS, Table 3), which is a well-validated screening tool to identify those patients 
requiring further assessment for depression (91). The GDS comprises four questions and responses are assigned a score of zero or one based on their answers as per Table 3. The final GDS is calculated out of four. 


\section{Table-2. Mini-Mental State Examination (MMSE)}

\begin{tabular}{|c|c|c|}
\hline $\begin{array}{l}\text { Maximum } \\
\text { Score }\end{array}$ & $\begin{array}{l}\text { Patient's } \\
\text { Score }\end{array}$ & Questions \\
\hline 5 & & "What is the year? Season? Date? Day of the week? Month?" \\
\hline 5 & & "Where are we now: State? County? Town/city? Hospital? Floor?" \\
\hline 3 & & $\begin{array}{l}\text { The examiner names three unrelated objects clearly and slowly, } \\
\text { then asks the patient to name all three of them. } \\
\text { The patient's response is used for scoring. The examiner repeats } \\
\text { them until patient learns all of them, if possible. Number of trials: }\end{array}$ \\
\hline 5 & & $\begin{array}{l}\text { "I would like you to count backward from } 100 \text { by sevens." }(93,86, \\
79,72,65, . .) \text { Stop after five answers. } \\
\text { Alternative: "Spell WORLD backwards." (D-L-R-O-W) }\end{array}$ \\
\hline 3 & & $\begin{array}{l}\text { "Earlier I told you the names of three things. Can you tell me what } \\
\text { those were?" }\end{array}$ \\
\hline 2 & & $\begin{array}{l}\text { Show the patient two simple objects, such as a wristwatch and a } \\
\text { pencil, and ask the patient to name them. }\end{array}$ \\
\hline 1 & & "Repeat the phrase: 'No ifs, ands, or buts."' \\
\hline 3 & & $\begin{array}{l}\text { "Take the paper in your right hand, fold it in half, and put it on the } \\
\text { floor." } \\
\text { (The examiner gives the patient a piece of blank paper.) }\end{array}$ \\
\hline 1 & & $\begin{array}{l}\text { "Please read this and do what it says." (Written instruction is } \\
\text { "Close your eyes.") }\end{array}$ \\
\hline 1 & & $\begin{array}{l}\text { "Make up and write a sentence about anything." (This sentence } \\
\text { must contain a noun and a verb.) }\end{array}$ \\
\hline 1 & & $\begin{array}{l}\text { "Please copy this picture." (The examiner gives the patient a blank } \\
\text { piece of paper and asks him/her to draw the symbol below. All } 10 \\
\text { angles must be present and two must intersect.) }\end{array}$ \\
\hline 30 & & TOTAL \\
\hline
\end{tabular}

Patients are scored based on their responses to the above questions and the tasks

assigned. Final MMSE score is calculated out of 30. (Adapted from Rovner \& Folstein, 1987 [89]). 
Table-3. Geriatric Depression Score (GDS-4)

\begin{tabular}{|l|l|l|}
\hline S.No & Questions & Answer/Score \\
\hline 1 & Are you basically satisfied with your life? & $\begin{array}{l}\text { Yes=0 } \\
\text { No=1 }\end{array}$ \\
\hline 2 & Do you feel that your life is empty? & $\begin{array}{l}\text { Yes }=1 \\
\text { No }=0\end{array}$ \\
\hline 3 & Are you afraid that something bad is going to happen to you? & $\begin{array}{l}\text { Yes }=1 \\
\text { No=0 } \\
\text { Yes }=0 \\
\text { No=1 }\end{array}$ \\
\hline 4 & Do you feel happy most of the time? & $/ 4$ \\
\hline & Total score & \\
\hline
\end{tabular}

Patients are asked the above four questions and assigned a score of zero or one. Final GDS is calculated out of four. (Adapted from D'Ath P and Katona P, 1994 [91]). 


\subsubsection{Functional Assessment}

Functional dependence has been shown to have an independent association with mortality in older people $[84,85]$. A number of scales are available that assess the older person's ability to function in a personal, as well as in a global setting, though evidence is often obtained from the elderly without cancer (e.g. Katz index [77]) or nonelderly cancer patients (e.g. Karnofsky performance status [92]). The Barthel Index for Activities of Daily Living [93], originally developed to assess patients with neurological disorders, has been recommended by the Royal College of Physicians and British Geriatrics Society [94] for the assessment of activities of daily living. We also used the Barthel Index ( $A D L$, Table 4) to assess personal activities of daily living in our study group. It comprises 10 sections and can use patient reports, direct health care professional or carer observations to assess dependence in activities of daily living, and is useful for identifying specific care needs.

In addition, to assess function in more global domains, like shopping, cleaning, driving, drug management \& finances, etc, Instrumental Activities of Daily Living Index [95] or ECOG Performance Status [96] is used. The Lawton Instrumental Activities of Daily Living Scale (IADL, Table 5) is an appropriate instrument to assess independent living 
skills. These skills are considered more complex than the basic activities of daily living. The instrument is most useful for identifying how a person is functioning at the present time, and to identify improvement or deterioration over time. There are eight domains of function measured with the Lawton IADL scale. Women are scored on all eight areas of function (for men, the areas of food preparation, housekeeping, laundering are excluded). A summary score ranges from zero (low function, dependent) to eight (high function, independent) for women. 
Table-4. Barthel Index of Daily Living (ADL)

\begin{tabular}{|c|c|c|c|}
\hline No & \multicolumn{2}{|c|}{ Assessment of activities } & Score \\
\hline \multirow[t]{3}{*}{1} & \multirow[t]{3}{*}{ Bowel status } & $\begin{array}{l}\text { Incontinent (or needs to be given } \\
\text { enema) }\end{array}$ & 0 points \\
\hline & & Occasional accident (once a week) & 1 point \\
\hline & & Fully continent & 2 points \\
\hline \multirow[t]{3}{*}{2} & \multirow[t]{3}{*}{ Bladder status } & $\begin{array}{l}\text { Incontinent or catheterized and } \\
\text { unable to manage }\end{array}$ & 0 points \\
\hline & & $\begin{array}{l}\text { Occasional accident (max once per } \\
24 \text { hours) }\end{array}$ & 1 point \\
\hline & & $\begin{array}{l}\text { Continent (for more than seven } \\
\text { days) }\end{array}$ & 2 points \\
\hline \multirow[t]{2}{*}{3.} & \multirow[t]{2}{*}{ Grooming } & $\begin{array}{l}\text { Needs help with personal care: face/ } \\
\text { hair/ teeth / shaving }\end{array}$ & 0 points \\
\hline & & Independent (implements provided) & 1 point \\
\hline \multirow[t]{3}{*}{4.} & \multirow[t]{3}{*}{ Toilet Use } & Dependent & 0 points \\
\hline & & $\begin{array}{l}\text { Needs some help but can do } \\
\text { something alone }\end{array}$ & 1 point \\
\hline & & $\begin{array}{l}\text { Independent (on and off/ wiping/ } \\
\text { dressing) }\end{array}$ & 2 points \\
\hline \multirow[t]{3}{*}{5.} & \multirow[t]{3}{*}{ Feeding } & Unable & 0 points \\
\hline & & $\begin{array}{l}\text { Needs help in cutting / spreading } \\
\text { butter/ etc }\end{array}$ & 1 point \\
\hline & & $\begin{array}{l}\text { Independent (food provided within } \\
\text { reach) }\end{array}$ & 2 points \\
\hline \multirow[t]{4}{*}{6.} & \multirow[t]{4}{*}{ Transfer } & Unable (as no sitting balance) & 0 points \\
\hline & & $\begin{array}{l}\text { Major help (physical/ one or two } \\
\text { people) }\end{array}$ & 1 point \\
\hline & & $\begin{array}{l}\text { Can sit minor help (verbal or } \\
\text { physical) }\end{array}$ & 2 points \\
\hline & & Independent & 3 points \\
\hline \multirow[t]{4}{*}{7.} & \multirow[t]{4}{*}{ Mobility } & Immobile & 0 points \\
\hline & & $\begin{array}{l}\text { Wheelchair-independent (including } \\
\text { corners etc) }\end{array}$ & 1 point \\
\hline & & $\begin{array}{l}\text { Walks with help of one person } \\
\text { (verbal or physical) }\end{array}$ & 2 points \\
\hline & & Independent & 3 points \\
\hline \multirow[t]{3}{*}{8.} & \multirow[t]{3}{*}{ Dressing } & Dependent & 0 points \\
\hline & & $\begin{array}{l}\text { Needs help but can do about half } \\
\text { unaided }\end{array}$ & 1 point \\
\hline & & $\begin{array}{l}\text { Independent (including buttons/ } \\
\text { zips/ laces/ etc.) }\end{array}$ & 2 points \\
\hline \multirow[t]{2}{*}{9.} & \multirow[t]{2}{*}{ Stairs } & Unable & 0 points \\
\hline & & $\begin{array}{l}\text { Needs help (verbal/ physical/ } \\
\text { carrying aid) }\end{array}$ & 1 point \\
\hline
\end{tabular}




\begin{tabular}{|l|l|l|l|}
\hline & & Independent up and down & 2 points \\
\hline 10 & Bathing & Dependent & 0 points \\
\cline { 3 - 4 } & Independent & 1 point \\
\hline & $\begin{array}{l}\text { Barthel Index/ } \\
\text { ADL score (Max } \\
20)\end{array}$ & & $/ 20$ \\
\hline
\end{tabular}

Patients are assessed and/or evidence about dependence is sought from observers, in the 10 sections of personal activities of daily living, and scored accordingly. Final ADL score is calculated out of 20. (Adapted from Mahoney F, Barthel D. Functional evaluation: the Barthel Index. MD State Med J 1965; 14: 61-66 [93]). 
Table-5. The Lawton Instrumental Activities of Daily Living Scale

\begin{tabular}{|c|c|c|}
\hline S.No & Tasks & Score \\
\hline \multirow[t]{5}{*}{1} & Ability to Use Telephone & \\
\hline & $\begin{array}{l}\text { Operates telephone on own initiative; looks up and dials } \\
\text { numbers }\end{array}$ & 1 \\
\hline & Dials a few well-known numbers & 1 \\
\hline & Answers telephone, but does not dial & 1 \\
\hline & Does not use telephone at all & 0 \\
\hline \multirow[t]{5}{*}{2} & Shopping & \\
\hline & Takes care of all shopping needs independently & 1 \\
\hline & Shops independently for small purchases & 0 \\
\hline & Needs to be accompanied on any shopping trip & 0 \\
\hline & Completely unable to shop & 0 \\
\hline \multirow[t]{5}{*}{3} & Food Preparation & \\
\hline & Plans, prepares, and serves adequate meals independently & 1 \\
\hline & Prepares adequate meals if supplied with ingredients & 0 \\
\hline & $\begin{array}{l}\text { Heats and serves prepared meals or prepares meals but does } \\
\text { not maintain adequate diet }\end{array}$ & 0 \\
\hline & Needs to have meals prepared and served & 0 \\
\hline \multirow[t]{6}{*}{4} & Housekeeping & \\
\hline & Maintains house alone with occasion assistance (heavy work) & 1 \\
\hline & Performs light daily tasks such as dishwashing, bed making & 1 \\
\hline & $\begin{array}{l}\text { Performs light daily tasks, but cannot maintain acceptable } \\
\text { level of cleanliness }\end{array}$ & 1 \\
\hline & Needs help with all home maintenance tasks & 1 \\
\hline & Does not participate in any housekeeping tasks & 0 \\
\hline \multirow[t]{4}{*}{5} & Laundry & \\
\hline & Does personal laundry completely & 1 \\
\hline & Launders small items, rinses socks, stockings, etc & 1 \\
\hline & All laundry must be done by others & 0 \\
\hline \multirow[t]{3}{*}{6} & Mode of Transportation & \\
\hline & $\begin{array}{l}\text { Travels independently on public transportation or drives own } \\
\text { car }\end{array}$ & 1 \\
\hline & Arranges own travel via taxi, but does not otherwise use & 1 \\
\hline
\end{tabular}




\begin{tabular}{|c|c|c|}
\hline & public transportation & \\
\hline & $\begin{array}{l}\text { Travels on public transportation when assisted or } \\
\text { accompanied by another }\end{array}$ & 1 \\
\hline & Travel limited to taxi or automobile with assistance of another & 0 \\
\hline & Does not travel at all & 0 \\
\hline \multirow[t]{4}{*}{7} & Responsibility for Own Medications & \\
\hline & $\begin{array}{l}\text { Is responsible for taking medication in correct dosages at } \\
\text { correct time }\end{array}$ & 1 \\
\hline & $\begin{array}{l}\text { Takes responsibility if medication is prepared in advance in } \\
\text { separate dosages }\end{array}$ & 0 \\
\hline & Is not capable of dispensing own medication & 0 \\
\hline \multirow[t]{6}{*}{8} & Ability to Handle Finances & \\
\hline & $\begin{array}{l}\text { Manages financial matters independently (budgets, writes } \\
\text { checks, pays rent and bills, goes to bank); collects and keeps } \\
\text { track of income }\end{array}$ & 1 \\
\hline & $\begin{array}{l}\text { Manages day-to-day purchases, but needs help with banking, } \\
\text { major purchases, etc }\end{array}$ & 1 \\
\hline & Incapable of handling money & 0 \\
\hline & Total Score (maximum 8) & \\
\hline & $\begin{array}{l}\text { Scoring: For each category, circle the item description } \\
\text { that most closely resembles the client's highest } \\
\text { functional level (either } 0 \text { or } 1 \text { ). }\end{array}$ & \\
\hline
\end{tabular}

Patients are assessed and/or evidence about dependence is sought from observers, in each of the eight domains in the table and scored accordingly. Final IADL score is calculated out of 8. (Adapted from Lawton, M.P., \& Brody, E.M. (1969) [95]). 


\subsubsection{Assessment of Fitness for Anaesthesia}

The American Society of Anaesthesiologists grade was developed in 1963 as an attempt to estimate fitness for anaesthesia. In the UK, preoperatively, patients are assigned an ASA score (Table 6) after assessment by an anaesthetist. Although the ASA score provides a general measure of the well being of patients, it has been reported as an important predictor of peri-operative and early post-operative mortality in patients undergoing surgery $[97,98]$. We have used ASA as part of our comprehensive geriatric assessment and to assess patients' fitness for general anaesthesia. The anaesthetic assessment includes previous surgical history, medical and drug history, and clinical examination, including that of the airway and the teeth. 
Table-6. American Society of Anesthesiologists (ASA) scale

\begin{tabular}{|c|c|c|c|c|}
\hline $\begin{array}{l}\text { ASA } \\
\text { Grade }\end{array}$ & Patient's Health & $\begin{array}{l}\text { Status of Under- } \\
\text { lying Disease }\end{array}$ & $\begin{array}{l}\text { Limitations on } \\
\text { Activities }\end{array}$ & Risk of Death \\
\hline I & $\begin{array}{l}\text { Excellent; no } \\
\text { systemic disease; } \\
\text { excludes persons } \\
\text { at extremes of age }\end{array}$ & None & None & None \\
\hline II & $\begin{array}{l}\text { Disease of one } \\
\text { body system }\end{array}$ & Well-controlled & None & None \\
\hline III & $\begin{array}{l}\text { Disease of more } \\
\text { than one body } \\
\text { system or one } \\
\text { major system }\end{array}$ & Controlled & $\begin{array}{l}\text { Present but } \\
\text { not } \\
\text { incapacitated }\end{array}$ & $\begin{array}{l}\text { No immediate } \\
\text { danger }\end{array}$ \\
\hline IV & $\begin{array}{l}\text { Poor with at least } \\
1 \text { severe disease }\end{array}$ & $\begin{array}{l}\text { Poorly controlled } \\
\text { or end stage }\end{array}$ & Incapacitated & Possible \\
\hline V & $\begin{array}{l}\text { Very poor, } \\
\text { moribund }\end{array}$ & & Incapacitated & Imminent \\
\hline
\end{tabular}

Patients are assessed and assigned an ASA grade based on their health assessment as outlined in the table. (Adapted from The Institute for Algorithmic Medicine, Houston, TX, USA). 


\subsection{Hypothesis \& Aim}

This study tested the hypothesis that comprehensive geriatric assessment can be used to predict two-year survival in older patients with early breast cancer.

The specific aims of this project were:

1. To develop a treatment algorithm, based on comprehensive geriatric assessment scoring and its predicted survival, which could then be used for guidance to recommend whether primary endocrine treatment or surgery plus endocrine treatment would be best indicated in individual older breast cancer patients.

2. To apply the developed algorithm to the process of comprehensive assessment of older breast cancer patients, as used in the Leicester research clinic, to assess the relationship between treatment decisions and survival and hence test the validity of the algorithm. 
Chapter 2. Methods 


\subsection{Methods}

\section{Study Design:}

The study was designed as a prospective cohort study to evaluate comprehensive geriatric assessment as an intervention to guide treatment of breast cancer in elderly patients.

\section{Setting:}

The study was conducted at the department of breast surgery, University Hospitals of Leicester, NHS trust, United Kingdom. This department is part of a large breast cancer centre and caters for patients from all the Leicestershire area with a population of more than 900,000. Data for this study was collected from a special clinic established for patients with early breast cancer considered unfit for, or declining, standard treatment. Patients were referred to this special clinic, by any of the consultant breast surgeons in the unit, after they had a core biopsy confirming cancer, with tumour hormone receptor status, breast imaging, simple staging investigations and an ECG.

\section{Inclusion criteria:}

Breast cancer patients seen in the Leicester clinic for patients with early breast cancer considered potential unfit for, or declining, standard 
treatment from January 2005 to April 2007 were included in this study if they:

1. were of age 70 years or above

2. had early stage breast cancer

3. had been diagnosed within the last year

\section{Exclusion criteria:}

1. Patients not considered for surgery or PET

2. Patients with locally advanced or metastatic disease

3. Patients lost to follow up in the two years since they were first seen

4. Patients with missing CGA records

End point: Survival at two-year was the end point. Patients were followed up every 3,6 , or 12 months for two years or till death if they died earlier. The study ended in May 2009, after the two-year follow-up of all patients was completed (see recruitment flow chart for enrollment, page 63). 


\section{Flow chart of recruitment process}

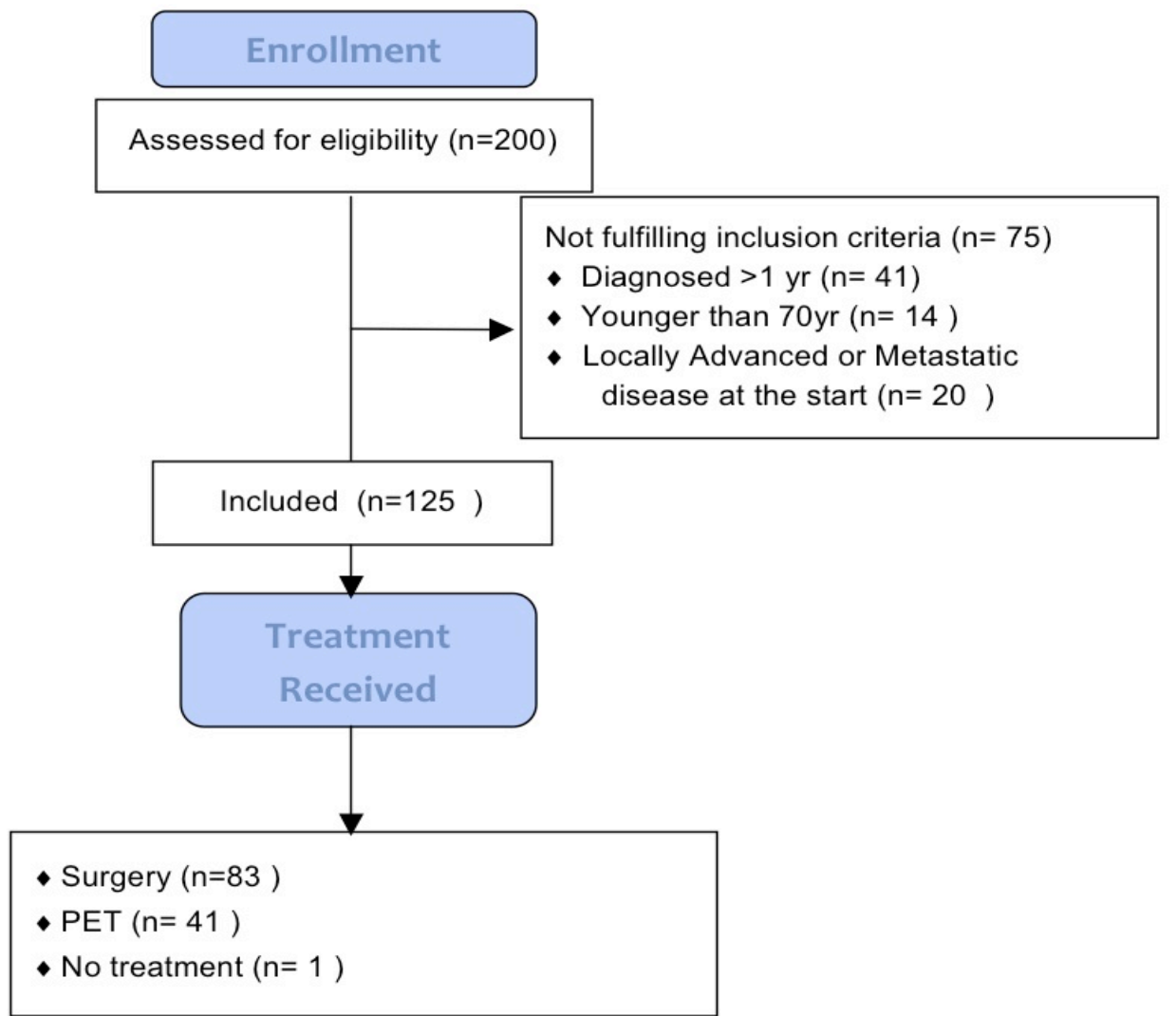

\section{Follow-Up}

Patients who completed 2 yr follow-up $(n=125)$

Lost to follow-up $(n=0)$

\section{Analysis}

Analysed $(n=123)$

- Excluded from analysis $(n=2)$ (1 patient had surgery and developed metastatic disease, 1 patient with DCIS received no treatment) 


\subsection{Data collection:}

All patients in the study had comprehensive assessment and scoring of physical and mental function plus co-morbidity, using a standardised proforma, undertaken by a team of clinicians including a Geriatrician, Anaesthetist and a Breast Surgeon. A summary of the CGA components and their scoring is given in Table-7. A Microsoft Excel spreadsheet was developed in which data from the standardised proforma was collected. Validation checks of quality of data entry were performed and verified. Apart from the CGA, other baseline data was collected as in Table-8: 
Table-7. Components of Comprehensive Geriatric Assessment and their scoring

\begin{tabular}{|l|l|l|l|}
\hline Component of CGA & Acronym & $\begin{array}{l}\text { Score } \\
\text { range }\end{array}$ & Interpretation \\
\hline $\begin{array}{l}\text { Satariano's Index of } \\
\text { Co-morbidities }\end{array}$ & SIC & $0-7$ & $\begin{array}{l}\text { Increasing score = Increasing } \\
\text { number of key co-morbidities }\end{array}$ \\
\hline $\begin{array}{l}\text { Mini-Mental State } \\
\text { Examination }\end{array}$ & MMSE & $0-30$ & $\begin{array}{l}\text { Increasing score = Increasing } \\
\text { level of cognition }\end{array}$ \\
\hline $\begin{array}{l}\text { Geriatric Depression } \\
\text { Score }\end{array}$ & GDS & $0-4$ & $\begin{array}{l}\text { Increasing score = Increasing } \\
\text { depression }\end{array}$ \\
\hline $\begin{array}{l}\text { Activities of Daily Living } \\
\text { ADL }\end{array}$ & $0-20$ & $\begin{array}{l}\text { Increasing score = Increasing } \\
\text { level of independence }\end{array}$ \\
\hline $\begin{array}{l}\text { Instrumental Activities } \\
\text { of Daily Living }\end{array}$ & IADL & $0-8$ & $\begin{array}{l}\text { Increasing score = Increasing } \\
\text { level of independence }\end{array}$ \\
\hline $\begin{array}{l}\text { American Society of } \\
\text { Anaesthesiologist Scale }\end{array}$ & ASA & $1-4$ & $\begin{array}{l}\text { Increasing score = Increasing } \\
\text { risk of death with anaesthesia } \\
\text { and surgery }\end{array}$ \\
\hline
\end{tabular}


Table-8. Patients' baseline data record

\begin{tabular}{|c|c|c|}
\hline S.No & Patients data & Recorded \\
\hline 1. & Patient identification number & Hospital number \\
\hline 2. & $\begin{array}{l}\text { Age of patient at the time of first clinic } \\
\text { appointment }\end{array}$ & In years \\
\hline 3. & Date of diagnosis & Day/month/year \\
\hline 4. & Core Biopsy results & Type and grade of cancer \\
\hline 5. & $\begin{array}{l}\text { Oestrogen receptor and Progesterone } \\
\text { receptor status of the tumour on core } \\
\text { biopsy }\end{array}$ & Positive/negative \\
\hline 6. & $\begin{array}{l}\text { Locally advanced or metastatic breast } \\
\text { cancer }\end{array}$ & Yes/no \\
\hline 7. & Type of treatment recommended & Surgery/PET \\
\hline 8. & Type of treatment received & Surgery/PET \\
\hline 9. & Type of Anaesthesia & General or Local Anaesthesia \\
\hline 10. & $\begin{array}{l}\text { Type of Adjuvant treatment } \\
\text { recommended }\end{array}$ & $\begin{array}{l}\text { Endocrine therapy/ } \\
\text { Radiotherapy/chemotherapy }\end{array}$ \\
\hline 11. & Histopathology result after surgery & Tumour size, grade, receptor status \\
\hline 12. & Peri and Post-operative mortality & $\begin{array}{l}\text { During the operation or within the } \\
\text { first } 30 \text { days after the operation }\end{array}$ \\
\hline 13. & Post-operative local complications & $\begin{array}{l}\text { Wound infection, seroma, } \\
\text { hematoma }\end{array}$ \\
\hline 14. & Post-operative systemic complications & $\begin{array}{l}\text { Chest infection, vomiting, urinary } \\
\text { tract infection, post-operative Atrial } \\
\text { fibrillation, other problems. }\end{array}$ \\
\hline 15. & Post-op hospital stay & In days \\
\hline 16. & Date of last follow-up & Day/month/year \\
\hline 17. & Survival & Alive/dead \\
\hline 18. & $\begin{array}{l}\text { Duration of follow-up (last visit if alive } \\
\text { or the date when died) }\end{array}$ & In months \\
\hline 19. & Follow-up status & Disease free/recurrence \\
\hline 20. & $\begin{array}{l}\text { Progression of disease on clinical and/or } \\
\text { radiological measurement }\end{array}$ & Yes/no \\
\hline 21. & Cause of death if dead & From death certificate if available \\
\hline
\end{tabular}




\section{Variables' scoring and cut-offs:}

To develop a simple and clinically useful prognostic index that could be used in a busy breast clinic, we dichotomised the scores of the CGA components for our analysis. The cut-offs used for dichotomising variables scores were based on clinical relevance and evidence from previous published studies.

1). Satariano's Index of Co-morbidities (SIC): SIC has been scored according to Table-1. Based on evidence and recommendations from the original study by Satariano et al. (25) we grouped patients into two categories for data analysis. Patients who had less than three co-morbid conditions were scored as 0 , whereas those with three or more comorbid conditions were scored as 1 .

SATARIANO INDEX OF CO-MORBIDITIES

\begin{tabular}{|l|l|}
\hline SIC SCORE & \multicolumn{1}{c|}{ SCORE FOR ANALYSIS } \\
\hline $0-2$ & 0 \\
\hline $3-7$ & 1 \\
\hline
\end{tabular}

2). Mini Mental State Examination (MMSE): MMSE was scored according to Table-2. Consistent with earlier studies $[76,99,100]$ patients were grouped into two categories for this analysis. Those with 
little evidence of significant cognitive impairment (MMSE 20-30) were scored as 0. Patients with a lower MMSE (0-19), indicating significant cognitive impairment, were scored as 1.

MINI-MENTAL STATE EXAMINATION

\begin{tabular}{|l|l|}
\hline MMSE SCORE & SCORE FOR ANALYSIS \\
\hline $20-30$ & 0 \\
\hline $0-19$ & 1 \\
\hline
\end{tabular}

Patients who had no formal MMSE due to language \& other problems were considered as missing in the MMSE data analysis. Those patients who had incomplete MMSE due to eyesight problems, inability to write or other reasons; their score was re-calculated out of 30 and then grouped accordingly [100].

3). Geriatric Depression Score (GDS): GDS scoring was recorded according to Table-3. Patients were categorised into two groups based on their GDS, as used in other studies $[91,101]$; those with no evidence of depression were scored as 0 , and those with depressive symptoms were scored as 1.

GERIATRIC DEPRESSION SCALE

\begin{tabular}{|l|l|}
\hline GDS SCORE & SCORE FOR ANALYSIS \\
\hline 0 & 0 \\
\hline $1-4$ & 1 \\
\hline
\end{tabular}




\section{4). Activities of Daily Living (ADL) score: the ADL score was}

recorded according to Table-4. Patients were grouped into two

categories based on their ADL score. Those with no or minor

dependency in their ADL functions (ADL score of 12-20) were scored as

0. Patients who had significant dependency in their ADL functions (ADL score of $<12$ ) were scored as 1 . This cut-off is clinically meaningful and has been used by other published studies $[102,103,104]$.

\section{ACTIVITIES OF DAILY LIVING}

\begin{tabular}{|l|l|}
\hline ADL SCORE & SCORE FOR ANALYSIS \\
\hline $12-20$ & 0 \\
\hline $0-11$ & 1 \\
\hline
\end{tabular}

5). Instrumental Activities of Daily Living (IADL) score: Patients had their IADL recorded according to Table-5. Patients were grouped into two categories based on their IADL score; those with a normal IADL score (8) and those with limitations on IADL (0-7) showing dependency in one or more IADL functions. This cut-off has been used by other published studies $[82,105]$.

INSTRUMENTAL ACTIVITIES OF DAILY LIVING

\begin{tabular}{|l|l|}
\hline IADL SCORE & SCORE FOR ANALYSIS \\
\hline 8 & 0 \\
\hline $0-7$ & 1 \\
\hline
\end{tabular}




\section{6). American Society of Anaesthesiologists (ASA) score: The ASA}

score was recorded according to Table-6. Patient's age and breast cancer did not contribute to the ASA score. Consistent with other studies [97] patients with an ASA score of 1-3 were grouped as having mild to moderate risk and given a score of 0 . Those with ASA score of 4 were grouped as high risk and scored as 1 . There was no patient with ASA grade 5 in the study.

AMERICAN SOCIETY OF ANAESTHESIOLOGIST SCORE

\begin{tabular}{|l|l|}
\hline ASA SCORE & SCORE FOR ANALYSIS \\
\hline $1-3$ & 0 \\
\hline 4 & 1 \\
\hline
\end{tabular}

\subsection{Statistical Analysis}

Various statistical tests could be used to explore relationship between a dependent variable and independent variable/s. The two commonly used tests are logistic regression and Cox proportional hazards model. Other tests include Fisher's exact and chi square.

Both logistic regression and Cox proportional hazards models are widely used in medical studies $(75,76,77,84)$ for analysing a relationship between several risk factors and a time-related event. The Cox model 
uses outcome as 'time to event' whereas in Logistic regression the outcome is a binary or dichotomous variable.

Fisher's exact test can be used for data in a two by two contingency table. It provides a p-value without confidence intervals and cannot adjust for confounding variables. The Chi-square test can also explore whether two categorical variables are related by comparing expected counts to observed counts.

Statistical analysis for this study was designed with the help of a qualified statistician from the Trent Research \& Development Support Unit, Leicester. We used logistic regression analysis to explore any association between the components of the CGA and two-year survival in the study population. Statistical software SPSS version 19 was used for this analysis.

Logistic regression is a flexible technique for analysing relationships between multiple independent variables and a single dependent variable. It is relatively free of restrictions, and with the capacity to analyse a mix of all types of predictors (continuous, discrete, and dichotomous). There are no assumptions for predictors to be normally distributed, linearly related, or of equal variance in logistic regression. 
The minimum ratio of valid cases to independent variables for logistic regression is 10 to 1 . In our study, there were six variables (components of the CGA). We planned to run a univariate regression analysis with individual components of the CGA, to explore their association with two-year survival. The variables with significant association were to be included into a multivariate regression analysis to find if they retain their ability to predict two-year survival in the study population. Based on these predictor variables a prognostic model was planned to be built that could help in predicting two-year survival in elderly breast cancer patients. We were expecting no more than four variables having a significant association with two-year survival in our study population. Therefore, we needed at least 40 events (deaths in the study population within two years of assessment) in order to perform a valid multivariate logistic regression analysis. A p-value of $<0.05$ was selected as a cut-off for significant association between the variables and two-year survival.

Univariate logistic regression analysis was performed using patients' survival at two-year (Dead/Alive) as the dependent variable and components of the CGA individually as covariates/variables. Association was also explored between patients' age and their two-year survival. We used the default forced entry method in SPSS for model building. 
Initially, analysis was done with the original score of the CGA component as a continuous variable to find if there was a valid statistically significant correlation between the covariate and the dependent variable. Analysis was then performed with the dichotomised score of the component, to make sure the relation was clinically relevant. Because of the low number of events in the study population (22 deaths before two years) a multivariate logistic regression analysis that would include all significant variables could not be performed. Therefore, the dichotomised score of individual variables that proved to have significant association with two-year survival in the study population were combined into a single variable named as Breast Cancer in Elderly Treatment Algorithm (BCETA) score. The BCETA score was analysed further using logistic regression analysis to see if it could be used as a prognostic index for two-year survival in the study population. Analysis was performed again after including patients' age and co-morbidity status in the model. Finally, it was made sure that the survival prognostic value of the BCETA score is higher than those provided by the individual variables utilised for constructing it by calculating C-statistics value (area under ROC curve) for BCETA and the individual variables. 
The logistic regression analysis output using SPSS is summarised below in four steps:

\section{Step 1}

Case processing summary: This is a summary of the number of cases included in the analysis and the missing data.

\section{Step 2}

Omnibus Tests of Model Coefficients: The presence of a relationship between the dependent variable and independent variables is based on the statistical significance of the model chi-square. The probability of the model chi-square (shown as "Sig" in the table) in the Omnibus test should be less than or equal to the level of significance of 0.05 . This corresponds to the research conclusion that there is adequate fit of the data to the model.

\section{Step 3}

Variables in the Equation: In this step logistic regression analysis shows if there is any statistically significant correlation between the independent variable and dependent variable (shown as "Sig or pvalue" in the table). A value of $<0.05$ is taken to show significance. 


\section{Step 4}

Classification Table: If a statistically significant correlation is found between independent variables and the dependent variable then the classification table shows the predictive value of the independent variable. In this analysis it shows how exactly a component of CGA can predict two-year survival in older breast cancer patients.

Note: Step 4 is omitted if no statistically significant correlation is found in step 3.

\subsection{Validation of results}

Results of the statistical analysis were reviewed and confirmed by a statistician from the Trent RDSU and Audit \& case team, University Hospitals of Leicester, NHS trust. Ideally, the results should be validated by applying the BCET Algorithm to a prospective set of similar patients, preferably in a different location; however, due to restriction of time $\&$ resources it was not possible. We therefore used a bootstrapping technique for validation of the results.

Bootstrapping is a valid method for internal replication \& validation of statistical analysis and has been used in other medical studies $[106,107]$. The bootstrap method analyses results by replication across 
studies, mixing up the participants in a given study in many different ways, to determine whether the results are stable across numerous combinations of study participants [108]. With bootstrapping, the only assumption required is that the sample be representative of the population $[109,110]$. Like any method, the bootstrap has advantages and limitations. For example, the bootstrap cannot make an unrepresentative sample representative. Nevertheless, given reasonable sample data, the advantages of the bootstrap method include freedom from distributional assumptions \& the ability to study any statistic of interest [109].

We used SPSS version 19 to perform the bootstrap analysis. One thousand bootstrap samples were selected of the same size as the original dataset, but chosen with replacement. Bootstrap analysis of the 1000 bootstrap samples was performed to confirm the stability of our results. Results were displayed to show the significance level ( $p$-value) and the confidence interval of B-coefficients from the logistic regression analysis of the bootstrap samples. A p-value of less than 0.05 was considered as significant and confirming the stable association of the BCETA score and two-year survival in our patients. 


\subsection{Testing the BCET Algorithm}

In the Leicester research clinic for early breast cancer, a team of clinicians including a Geriatrician, Anaesthetist and a Breast Surgeon, comprehensively assessed elderly breast cancer patients and recommended treatment decisions based on their clinical assessment. I selected all eligible patients seen in the Leicester research clinic from January 2005 to April 2007, and compared the clinical decisions made in Leicester research clinic with the treatment decisions that would have been made if we had applied BCETA to those patients. Results were analysed to find if clinical assessment supplemented by the BCETA score is a better approach than clinical assessment alone in identifying patients who would or would not survive for two years, based on which an optimal treatment could be recommended for their breast cancer. 
Chapter 3. Results 


\subsection{General Summary of the Data}

Two hundred patients were seen in the Leicester clinic for frail and/or reluctant patients with early breast cancer, from January 2005 to April 2007. Seventy-five patients did not fulfill the inclusion criteria. Fourteen of them were younger than 70 . Forty-one were diagnosed more than a year ago and twenty patients already had locally advanced or metastatic disease.

A total of 125 patients fulfilled the inclusion criteria. Two patients were excluded from the final analysis. One patient developed metastatic disease after surgery and second patient was diagnosed with DCIS but received no treatment.

The study, therefore, included a total of 123 patients seen in the Leicester clinic who fulfilled the inclusion and exclusion criteria. Twentytwo $(18 \%)$ of them died before two years and $101(82 \%)$ were alive and completed two-year follow up. The median age of these patients was 82 with a range of $70-94$.

\section{Surgical treatment}


Sixty-seven percent (82/123) patients received surgery for their breast cancer. Forty-one percent (34/82) had mastectomy plus axillary node surgery and forty-three percent (35/82) had wide local excision plus axillary node surgery. Sixteen percent $(13 / 82)$ of the patients who had wide local excision had no axillary surgery. A total of $84 \%(69 / 82)$ patients had axillary surgery. Sixty-five percent (53/82) of patients had sentinel node biopsy or axillary node sampling and twenty percent $(16 / 82)$ had axillary node clearance. Of the 13 patients who did not receive any axillary surgery, 5 had DCIS and required no axillary surgery. Axillary surgery omitted in the remaining eight patients was not expected to benefit them or impact on their further management.

Ninety-six percent (79/82) patients had an operative procedure under general anaesthesia. Only four percent (3/82) patients had their operative procedure (wide local excision) under local anaesthesia.

\section{Primary Endocrine Treatment}

Thirty-three percent (41/123) patients received PET. Of these 73\% (30/41) patients received tamoxifen and 27\% (11/41) received anastrazole as PET. Those who received PET, 29\% (12/41) of them had 
a complete response and $71 \%(29 / 41)$ had a partial response or their disease was static.

\section{Histology}

Histology of the core biopsies showed majority of the cancers to be ductal carcinomas $(96 / 123,78 \%)$. Ten percent $(12 / 123)$ of patients had lobular cancer and eight percent (10/123) had DCIS. Another two percent (3/123) of patients had mucinous cancer and two percent $(2 / 123)$ had a mixed pattern of breast cancer.

Hormone receptors (Oestrogen receptors) were positive in $90 \%$ (111/123) of patients. Receptor status was not reported for five percent $(6 / 123)$, in patients who had DCIS alone. Five percent $(6 / 123)$ of patients had hormone receptor negative breast cancer (and all of them had surgery).

The size of the breast cancer varied from $3-60 \mathrm{~mm}$ with a mean size of $23 \mathrm{~mm}$. Histology of the breast cancer after surgery showed $48 / 82$ (59\%) patients had grade-2 cancer. Fifteen out of eighty-two (18\%) patients had grade-3 and twelve out of eighty-two (15\%) patients had grade-1 cancer. Seven (9\%) patients had DCIS alone on final histology. 


\section{Peri-operative \& Post-operative morbidity \& mortality}

None of the patients died within the first 30 days of their surgery.

Twenty-two patients died during the two-year follow-up; however, none of them died because of breast cancer. Ten percent (8/82) of patients had some sort of systemic complication such as a chest infection, vomiting, urinary tract infection (UTI), and post-operative Atrial Fibrillation (AF). Twenty-one percent (17/82) had experienced local complications such as a wound infection, haematoma or seroma. 
Table 9. General Summary of the Data

\begin{tabular}{|c|c|}
\hline \multicolumn{2}{|l|}{ General Summary } \\
\hline $\begin{array}{l}\text { Total patients seen in Leicester clinic for } \\
\text { frail and/or reluctant patients with early } \\
\text { breast cancer from } 01 / 2005 \text { to } 04 / 2007\end{array}$ & 200 \\
\hline Patients who fulfilled inclusion criteria & 125 \\
\hline $\begin{array}{l}\text { Patients who were excluded from the final } \\
\text { analysis based on the exclusion criteria }\end{array}$ & 2 \\
\hline Total patients in the final analysis & 123 \\
\hline Patients' age & Median 82 (range 70-94) \\
\hline Patients who completed 2-year follow-up & $101 / 123(82 \%)$ \\
\hline $\begin{array}{l}\text { Patients who died before completing 2-year } \\
\text { follow-up }\end{array}$ & $22 / 123(18 \%)$ \\
\hline \multicolumn{2}{|l|}{ Surgical Treatment } \\
\hline Patients who had surgery & $82 / 123(67 \%)$ \\
\hline $\begin{array}{l}\text { Patients who had mastectomy plus axillary } \\
\text { surgery }\end{array}$ & $34 / 82(41 \%)$ \\
\hline $\begin{array}{l}\text { Patients who had wide local excision plus } \\
\text { axillary surgery }\end{array}$ & $35 / 82(43 \%)$ \\
\hline $\begin{array}{l}\text { Patients who had wide local excision } \\
\text { without axillary surgery }\end{array}$ & $13 / 82(16 \%)$ \\
\hline Axillary surgery & $\begin{array}{l}\text { Sentinel node biopsy/Axillary } \\
\text { node sampling }=53 / 82(65 \%) \\
\text { Axillary node } \\
\text { clearance }=16 / 82(20 \%) \\
\text { No axillary surgery }=13 / 82(16 \%)\end{array}$ \\
\hline Anaesthesia for surgery & $\begin{array}{l}\text { General anaesthetic }=79 / 82 \\
(96 \%) \\
\text { Local anaesthesia }(W L E)=3 / 82 \\
(4 \%)\end{array}$ \\
\hline
\end{tabular}


Table 9. continued:

\begin{tabular}{|c|c|}
\hline \multicolumn{2}{|l|}{ Histology } \\
\hline Cancer type (core biopsy) & $\begin{array}{l}\text { Ductal carcinoma }=96 / 123 \\
(78 \%) \\
\text { Lobular carcinoma }=12 / 123 \\
(10 \%) \\
\text { DCIS }=10 / 123(8 \%) \\
\text { Mucinous }=3 / 123(2 \%) \\
\text { Mix }=2 / 123(2 \%)\end{array}$ \\
\hline Cancer Grade (main specimen) & $\begin{array}{l}\text { Grade } 1=12 / 82(15 \%) \\
\text { Grade } 2=48 / 123(59 \%) \\
\text { Grade } 3=15 / 82(18 \%) \\
\text { DCIS }=7 / 82(9 \%)\end{array}$ \\
\hline Tumour Size & Mean $=23 \mathrm{~mm}(3-60)$ \\
\hline Hormone Receptor status (core biopsy) & $\begin{array}{l}\text { ER positive }=111 / 123(90 \%) \\
\text { ER negative }=6 / 123(5 \%) \\
\text { No receptor status }=6 / 123 \\
(5 \%)\end{array}$ \\
\hline \multicolumn{2}{|l|}{ Primary Endocrine Treatment } \\
\hline Patients who had PET & $41 / 123(33 \%)$ \\
\hline Type of Primary Endocrine Treatment & $\begin{array}{l}\text { Tamoxifen }=30 / 41(73 \%) \\
\text { Anastrazole }=11 / 41(27 \%)\end{array}$ \\
\hline Response to Endocrine therapy & $\begin{array}{l}\text { Complete response }=12 / 41 \\
(29 \%) \\
\text { Partial response/static }=29 / 41 \\
(71 \%)\end{array}$ \\
\hline \multicolumn{2}{|c|}{ Peri-operative \& Post-operative morbidity \& mortality } \\
\hline $\begin{array}{l}\text { Peri-operative \& Post-operative mortality } \\
\text { (within } 30 \text { days) }\end{array}$ & None $(0 \%)$ \\
\hline $\begin{array}{l}\text { Systemic complications (chest infection, } \\
\text { UTI, vomiting, post-operative AF) }\end{array}$ & $8 / 82(10 \%)$ \\
\hline $\begin{array}{l}\text { Local complications (wound infection, } \\
\text { hematoma, seroma) }\end{array}$ & $17 / 82(21 \%)$ \\
\hline
\end{tabular}




\subsection{Missing data}

A total of 123 cases qualified for the study analysis. Only five patients could not complete MMSE score due to language problems. Geriatric depression score could not be ascertained for 10 patients due to language problems and other reasons such as severe dementia. All 123 patients had complete assessment scores for the other four variables (SIC, ADL, IADL \& ASA).

There was no drop out or loss to follow-up in the study. Those patients who could not complete MMSE or GDS, their scores were recorded as missing. Missing data is always prone to impact results and different measures are adopted to reduce the risk of bias due to missing data. These include: complete case analysis, available case analysis, and various imputation based approaches. In our study there were only two variables (MMSE and GDS) with few missing values. The values of these two variables were missing completely at random due to language and other problems that had no direct relation to the patients' survival. Therefore, we handled the missing data based on available case analysis. Patients with missing variable scores were excluded from analysis when exploring the individual variable relationship with the dependent variable. The available case analysis is appropriate only 
when there are few incomplete instances, whose influence on the rest of the population is minimal. It is commonly used in studies with limited missing data, resulting in an insignificant data loss from missing cases exclusion. This approach, however, has the problem that different analysis is based on different subsets of data and thus is not necessarily consistent with each other. To reduce the risk of bias and confirm the validity of our results we further assessed the impact of missing data in our final analysis by sensitivity analysis.

There were five patients with missing MMSE score. They were excluded from the data analysis to find correlation between MMSE score and twoyear survival in our patients. Three out of the five patients with missing MMSE score had surgery and two of them survived beyond 2 years. The other two patients had endocrine therapy and survived more than 2 years. Their mean age was 81 (Age range 71-90).

GDS score could not be recorded for 10 patients. They were excluded from the data analysis to find correlation between GDS score and 2year survival in our patients. Eight of these ten patients had surgery and the remaining two had PET. All 10 survived beyond two years. Their mean age was 79 (age range 76-84). 
The final BCETA score analysis in our study included 119 out of 123 patients. Four patients were excluded from this analysis because of their missing MMSE score. We studied the potential impact of the missing MMSE score on the BCETA analysis results using best-case and worst-case scenario. We ran a sensitivity analysis by imputing the missing MMSE with a score of zero (best-case scenario), and then with a score of one (worst-case scenario). However, there was no significant change in the final outcome of BCETA analysis. The BCETA score remained highly significant ( $p$-value 0.00 ) in predicting two-year survival in our study population. 


\subsection{Summary of Patients' Variables in the Study}

\section{Age of patients:}

The study included 123 patients, aged 70-94, with a median age of 82 .

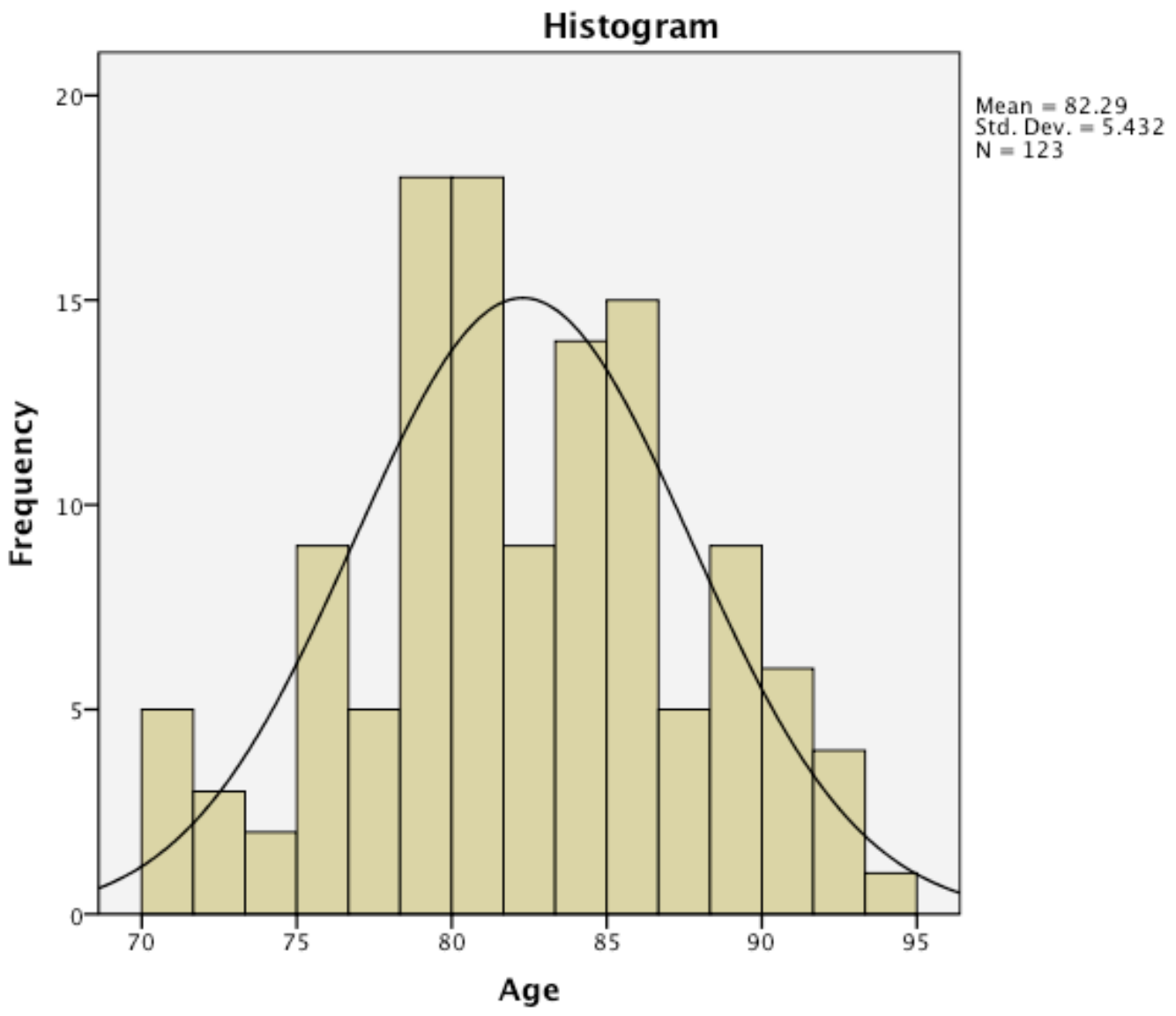




\section{Satariano Index of Co-morbidities (SIC):}

The Satariano Index of Co-morbidities data was recorded for all 123 patients in the study. The SIC score of patients ranged from zero to five, with a median score of one. Eighty-seven percent (107/123) patients in the study had two or fewer co-morbidities.

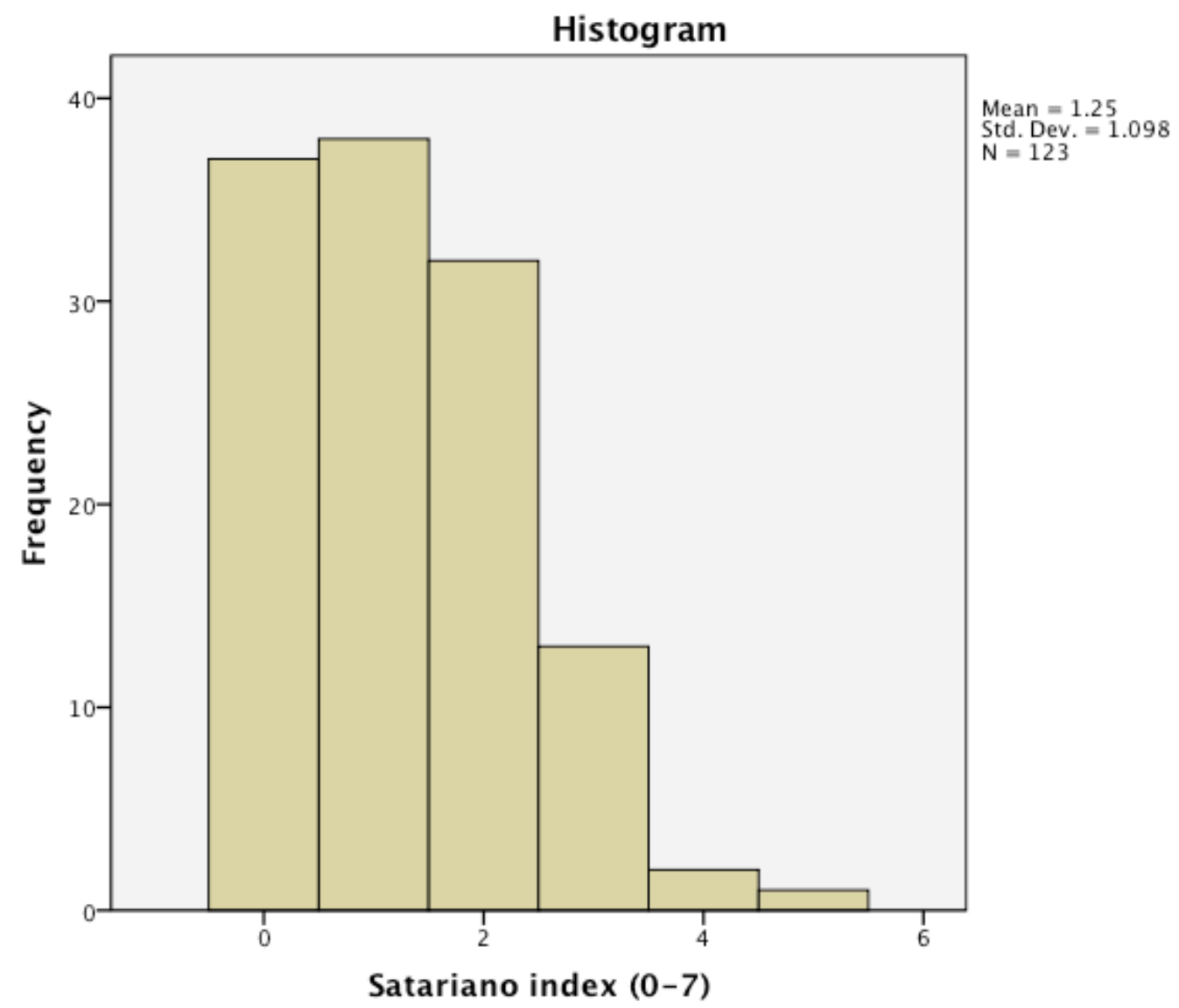




\section{Mini-Mental State Examination score (MMSE):}

The Mini-Mental State Examination score was recorded for 118 patients in the study. Five patients were unable to have the assessment due to language problem. The MMSE score of patients in the study ranged from 3 to 30, with a median score of 28 . Ninety-two percent $(108 / 118)$ patients in the study population had minimal or no cognitive impairment.

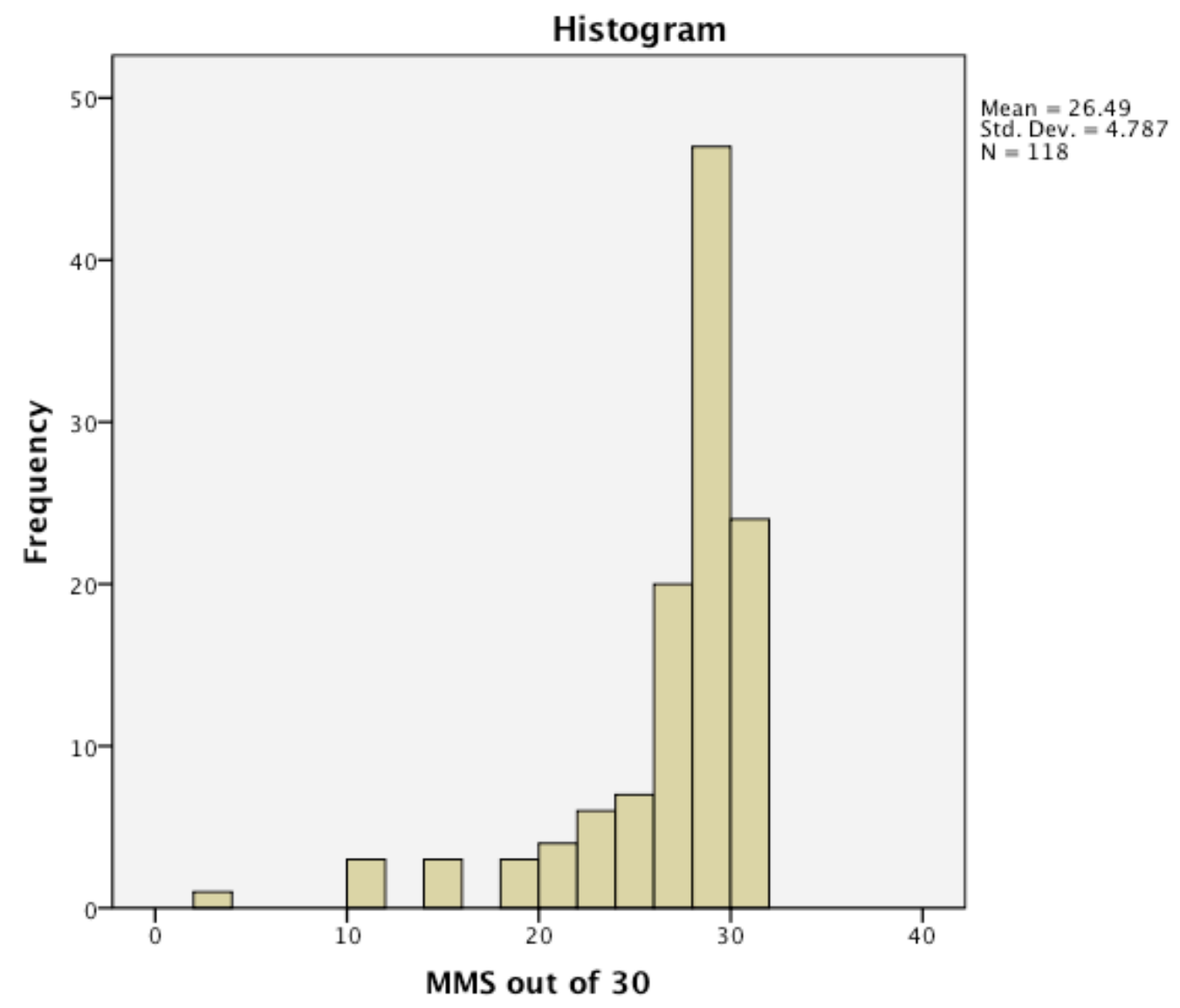




\section{Geriatric Depression Score (GDS):}

The Geriatric Depression Score was recorded for 113 patients in the study; data for 10 patients was missing. The GDS of patients in the study ranged from zero to four, with a median score of zero. Sixty-two percent $(70 / 113)$ patients in the study population reported no depressive symptoms.

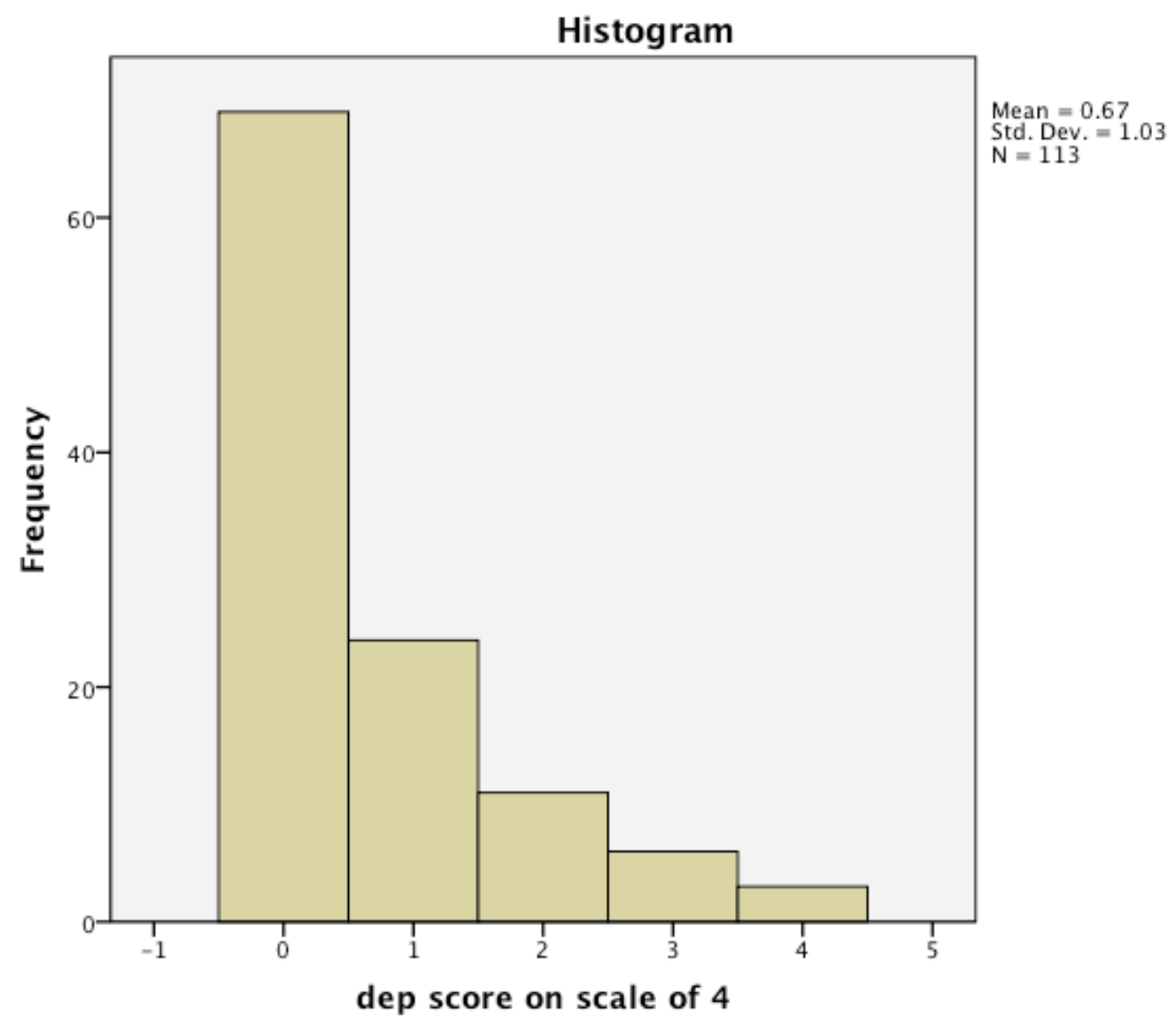




\section{Activities of Daily Living score (ADL):}

The Activities of Daily Living score (Barthel Index) was recorded for all 123 patients in the study. The ADL score ranged from 2 to 20 , with a median score of 19 . About $11 \%$ patients $(13 / 123)$ in the study had significant dependence in their ADL.

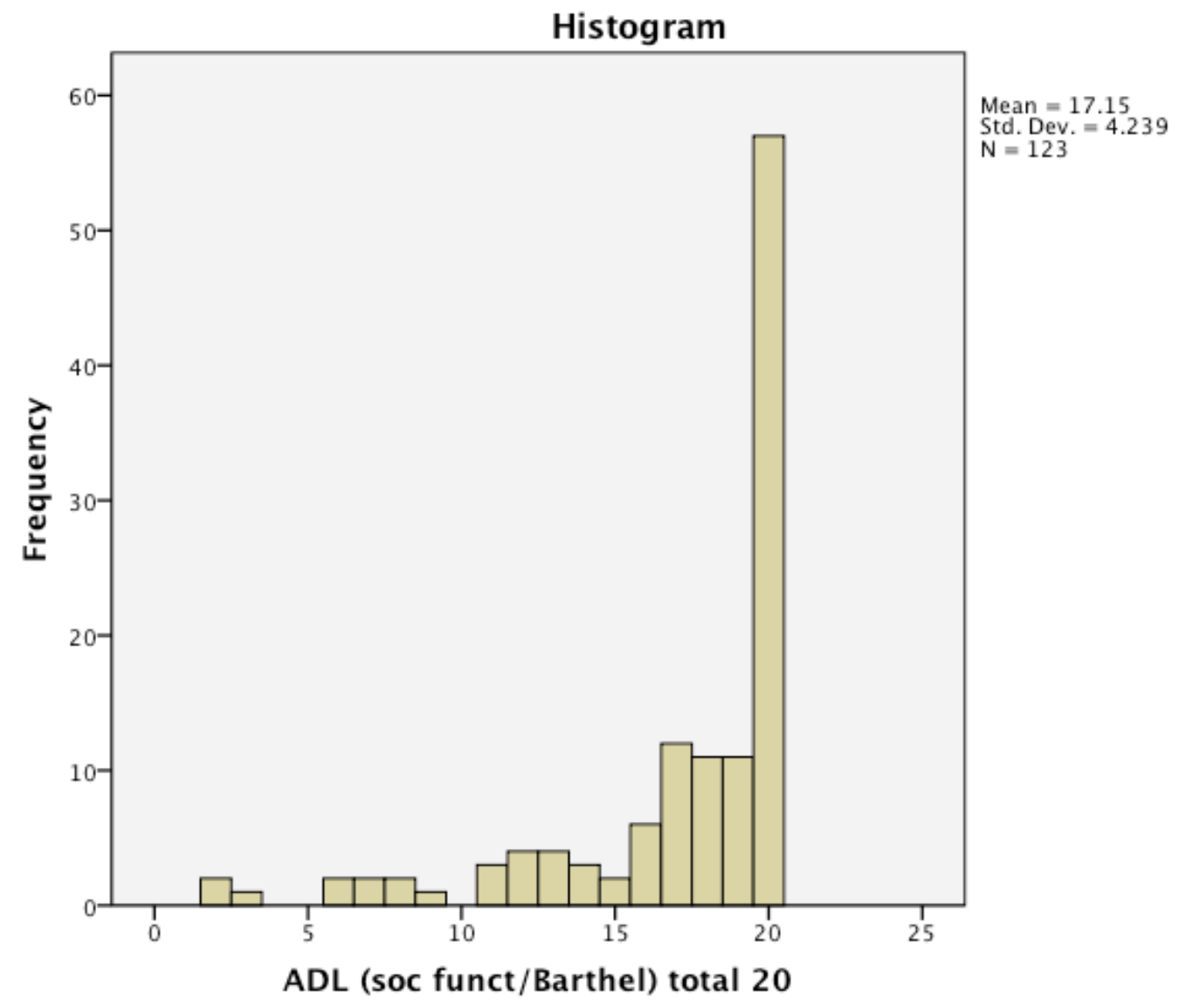




\section{Instrumental Activities of Daily Living score (IADL):}

The Instrumental Activities of Daily Living score was recorded for all 123 patients in the study. The IADL score ranged from zero to eight, with a median score of six. Seventy-three percent (90/123) patients of the study population had dependence in one or more IADL.

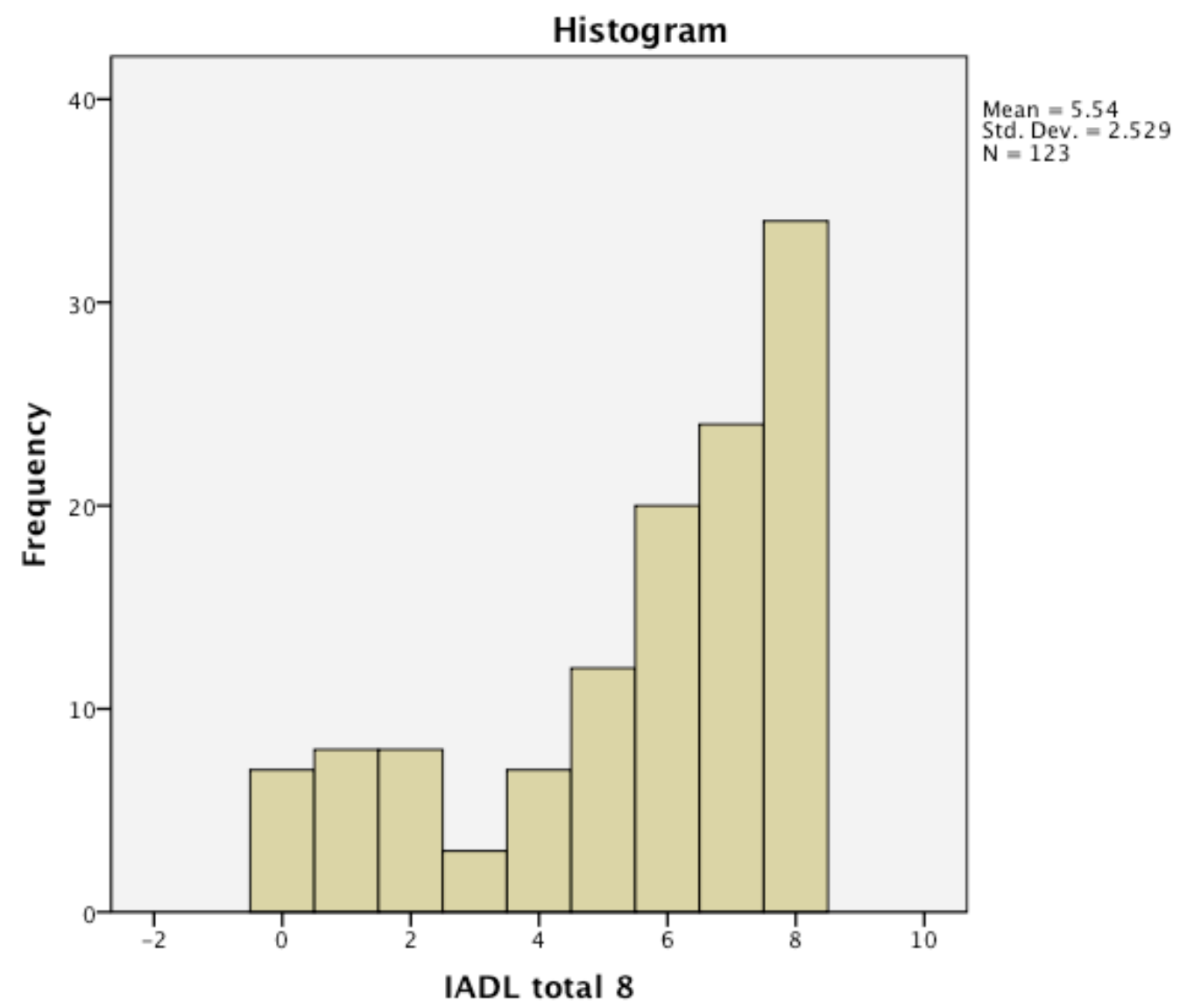




\section{American Society of Anaesthesiologists score (ASA):}

The American Society of Anaesthesiologists score was recorded for all 123 patients in the study. The ASA score ranged from one to four, with a median score of three. Apart from a very small proportion $(10 / 123)$ of the study population who were considered as high-risk (ASA 4), majority of the patients were assessed as mild to moderate risk for general anaesthetic.

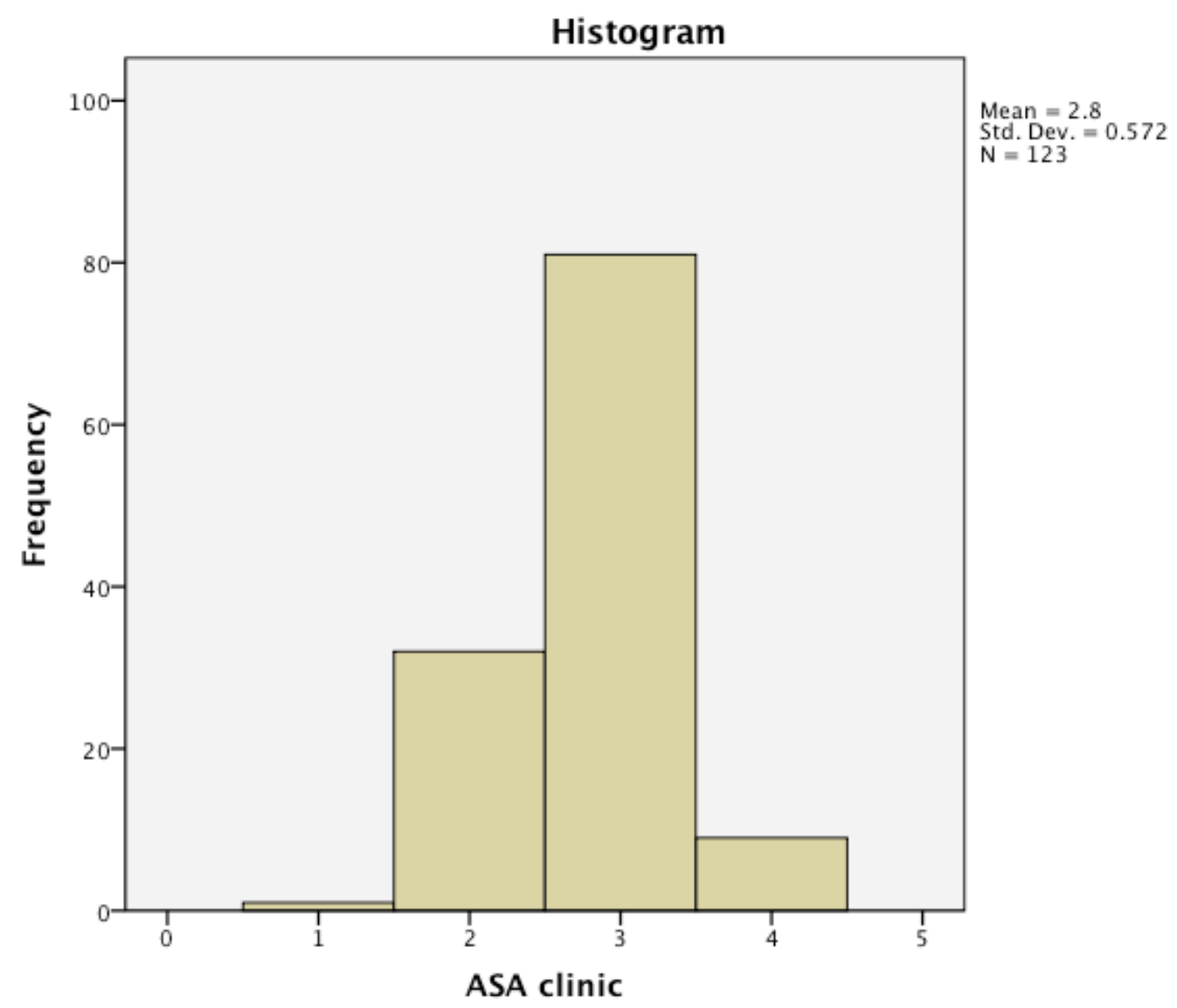




\subsection{Statistical Analysis}

Univariate logistic regression analysis using individual components of the CGA as independent variables and survival at two years as the dependent variable was performed to explore if any of the patients' variables, including age, were helpful in predicting their two-year survival.

\subsubsection{Age and two-year survival}

Table 10. Logistic regression analysis: Age and two-year survival in the study population

\begin{tabular}{|l|l|l|l|}
\hline Step & $\begin{array}{l}\text { Summary of logistic } \\
\text { regression }\end{array}$ & \multicolumn{2}{|l|}{ Results } \\
\hline 1 & Case processing summary & $\begin{array}{l}\text { Included in the } \\
\text { analysis }\end{array}$ & 123 \\
\cline { 3 - 4 } & & Missing cases & 0 \\
\cline { 3 - 4 } & & Total & 123 \\
\hline 2 & $\begin{array}{l}\text { Omnibus tests of model } \\
\text { coefficients }\end{array}$ & Sig (p-value) & 0.46 \\
\hline 3 & Variables in the equation & $\mathrm{B}$ & 0.03 \\
\cline { 4 - 4 } & \multirow{n}{*}{} & S.E & 0.04 \\
\cline { 3 - 4 } & & Wald & 0.54 \\
\cline { 3 - 4 } & & Df & 1 \\
\cline { 3 - 4 } & & Sig (p-value) & 0.46 \\
\cline { 3 - 4 } & & $\begin{array}{l}\text { Exp (B) } \\
(95 \% \text { CI })\end{array}$ & 1.0 \\
& & & $0.9-1.1)$ \\
\hline
\end{tabular}


Logistic regression analysis was performed to explore if there is a statistically significant correlation between patients' age and their twoyear survival in our study population. The analysis showed no statistically significant correlation between the two. Results of the analysis are summarized in table-10.

All 123 patients were included in the analysis based on available case analysis. The Omnibus test of model coefficients did not support the existence of a relationship between the age of patients and their twoyear survival $(p=0.46)$.

Variables in the equation provide final results of the regression analysis.

B - is the coefficient of regression and is in log-odds units. It denotes the value for the logistic regression equation for predicting the dependent variable (two-year survival) from the independent variable (age). As the value of the coefficient in this equation (0.03) is not significantly different from zero, therefore it means that age, as an independent variable is not a significant predictor of two-year survival in our study population. 
S.E. - is the standard error associated with the coefficient. It is used for testing whether the parameter is significantly different from zero.

Wald and Sig. - These provide the Wald chi-square value and the pvalue used in testing the null hypothesis that the coefficient is zero. In this equation, the value of coefficient $p$-value (Sig. 0.46 ) is higher than 0.05 , therefore, the null hypothesis is considered as true signifying no statistically significant correlation between age and two-year survival in our study patients.

df - This lists the degrees of freedom for each of the tests of the coefficients.

$\operatorname{Exp}(\mathbf{B})$ - It is the odds ratio for the predictor (age) and is the exponentiation of the coefficient (B). It provides information about the relationship between the independent variable and the dependent variable, where the dependent variable is on the logit scale. This estimate tells us the amount of increase (or decrease, if the sign of the coefficient is negative) in the predicted log odds of a variable (two-year survival) that would be predicted by a 1 unit increase (or decrease) in the predictor (age), holding all other predictors constant. The odds ratio value of 1 indicates no significant correlation between age and 
two-year survival in our patients with $95 \%$ confidence that the true value of odds ratio is between 0.9 and 1.1 (a value of odds ratio confidence intervals that contain 1 is non-significant).

\subsubsection{Satariano Index of Co-morbidities (SIC) and two-year survival}

Table 11. Logistic regression analysis: SIC and two-year survival in the study population

\begin{tabular}{|c|c|c|c|}
\hline Step & Summary of logistic & \multicolumn{2}{|l|}{ Results } \\
\hline \multirow[t]{3}{*}{1} & \multirow[t]{3}{*}{ Case processing summary } & $\begin{array}{l}\text { Included in the } \\
\text { analysis }\end{array}$ & 123 \\
\hline & & Missing cases & 0 \\
\hline & & Total & 123 \\
\hline 2 & $\begin{array}{l}\text { Omnibus tests of model } \\
\text { coefficients }\end{array}$ & Sig ( $p$-value) & 0.91 \\
\hline \multirow[t]{6}{*}{3} & \multirow[t]{6}{*}{ Variables in the equation } & B & -0.47 \\
\hline & & S.E & 0.79 \\
\hline & & Wald & 0.35 \\
\hline & & Df & 1 \\
\hline & & Sig ( $p$-value) & 0.55 \\
\hline & & $\begin{array}{l}\operatorname{Exp}(B) \\
(95 \% C I)\end{array}$ & $\begin{array}{l}0.6 \\
(0.1-2.2)\end{array}$ \\
\hline
\end{tabular}

Logistic regression analysis explored the relationship between patients' SIC score and their two-year survival in the study population. The 
analysis showed no statistically significant correlation between the two. Results of the analysis are summarized in table- 11.

The value of regression coefficient $(-0.47)$ as well as the Sig. ( $p$-value) of 0.55 supports the null hypothesis that SIC is not a significant predictor of two-year survival in our patients. The odds ratio of 0.6 indicates a negative relationship, meaning that patients with an SIC score of 3 or higher are 1.7 times less likely to die before two years compared to those who have an SIC score of less than 3. However, the $95 \%$ confidence intervals of the odds ratio vary from $0.1-2.2$. This means the relationship could be a positive or negative relationship and is non-significant as the $95 \%$ confidence intervals contains 1 .

\subsubsection{Mini Mental State Examination (MMSE) score and two-year survival}

Logistic regression analysis explored the relationship between patients' MMSE score and their two-year survival in the study population. Five patients with missing MMSE values were excluded and analysis was run on available case basis. The analysis showed a statistically significant correlation between patients' MMSE and their two-year survival. Results of the analysis are summarized in table- 12 . 
Table 12. Logistic regression analysis: MMSE and two-year survival in the study population

\begin{tabular}{|c|c|c|c|}
\hline Step & Summary of logistic & \multicolumn{2}{|l|}{ Results } \\
\hline \multirow[t]{3}{*}{1} & \multirow[t]{3}{*}{ Case processing summary } & $\begin{array}{l}\text { Included in the } \\
\text { analysis }\end{array}$ & 118 \\
\hline & & Missing cases & 5 \\
\hline & & Total & 123 \\
\hline 2 & $\begin{array}{l}\text { Omnibus tests of model } \\
\text { coefficients }\end{array}$ & Sig (p-value) & 0.02 \\
\hline \multirow[t]{6}{*}{3} & \multirow[t]{6}{*}{ Variables in the equation } & B & 1.74 \\
\hline & & S.E & 0.69 \\
\hline & & Wald & 6.46 \\
\hline & & Df & 1 \\
\hline & & Sig (p-value) & 0.01 \\
\hline & & $\begin{array}{l}\operatorname{Exp}(B) \\
(95 \% \mathrm{CI})\end{array}$ & $\begin{array}{l}5.7 \\
(1.5-22.1)\end{array}$ \\
\hline \multirow[t]{3}{*}{4} & \multirow[t]{3}{*}{ Classification table } & $\begin{array}{l}\text { Percentage } \\
\text { correct (Alive) }\end{array}$ & 94.8 \\
\hline & & $\begin{array}{l}\text { Percentage } \\
\text { correct (Dead) }\end{array}$ & 23.8 \\
\hline & & Total & 82.2 \\
\hline
\end{tabular}

The value of regression coefficient (1.74) and Sig. ( $p$-value) of 0.01 supports that MMSE is a significant predictor of two-year survival in our patients. The odds ratio of 5.7 indicates a positive relationship, meaning that patients with an MMSE score of 19 or less are 5.7 times more likely to die before two years compared to those who have MMSE score of 
greater than 19 . The $95 \%$ confidence intervals of the odds ratio supports this relationship and indicates that with $95 \%$ confidence it could be predicted that the true value of MMSE odds ratio lies between 1.5 and 22.1. The confidence intervals do not contain 1 confirming a statistically significant relationship. The classification table data shows percentage of cases correctly predicted and the overall accuracy of MMSE score to predict two-year survival in the study population.

\subsubsection{Geriatric Depression Score (GDS) and two-year survival}

Table 13. Logistic regression analysis: GDS and two-year survival in the study population

\begin{tabular}{|c|c|c|c|}
\hline Step & Summary of logistic & \multicolumn{2}{|l|}{ Results } \\
\hline \multirow[t]{3}{*}{1} & \multirow[t]{3}{*}{ Case processing summary } & $\begin{array}{l}\text { Included in the } \\
\text { analysis }\end{array}$ & 113 \\
\hline & & Missing cases & 10 \\
\hline & & Total & 123 \\
\hline 2 & $\begin{array}{l}\text { Omnibus tests of model } \\
\text { coefficients }\end{array}$ & Sig (p-value) & 0.52 \\
\hline \multirow[t]{6}{*}{3} & \multirow[t]{6}{*}{ Variables in the equation } & $B$ & 0.16 \\
\hline & & S.E & 0.22 \\
\hline & & Wald & 0.54 \\
\hline & & Df & 1 \\
\hline & & Sig (p-value) & 0.46 \\
\hline & & $\begin{array}{l}\operatorname{Exp}(B) \\
(95 \% \mathrm{CI})\end{array}$ & $\begin{array}{l}1.2 \\
(0.8-1.8)\end{array}$ \\
\hline
\end{tabular}


Logistic regression analysis explored the relationship between patients' GDS score and their two-year survival in the study population. Analysis was run on available case basis after excluding 10 patients with missing GDS score. The analysis showed no statistically significant correlation between the two. Results of the analysis are summarized in table-13.

The value of regression coefficient ( 0.16$)$ and the Sig. ( $p$-value) of 0.46 support the null hypothesis that GDS is not a significant predictor of two-year survival in our patients. The odds ratio of 1.2 indicates that patients with a GDS score of one or higher are 1.2 times likely to die before two years compared to those who have a GDS score of zero. The $95 \%$ confidence intervals of the odds ratio vary from $0.8-1.8$ and contain 1 . This essentially confirms that the relationship is not significant as it could be in either direction, a positive or a negative relationship.

\subsubsection{Activities of Daily Living (ADL) score and two-year survival.}

Logistic regression analysis explored the relationship between patients' ADL score and their two-year survival in the study population. Analysis included all 123 patients and found a statistically significant correlation between the two. Results of the analysis are summarized in table-14. 
Table-14. Logistic regression analysis: $A D L$ and two-year survival in the study population

\begin{tabular}{|c|c|c|c|}
\hline Step & Summary of logistic & \multicolumn{2}{|l|}{ Results } \\
\hline \multirow[t]{3}{*}{1} & \multirow[t]{3}{*}{ Case processing summary } & $\begin{array}{l}\text { Included in the } \\
\text { analysis }\end{array}$ & 123 \\
\hline & & Missing cases & 0 \\
\hline & & Total & 123 \\
\hline 2 & $\begin{array}{l}\text { Omnibus tests of model } \\
\text { coefficients }\end{array}$ & Sig ( $p$-value) & 0.02 \\
\hline \multirow[t]{6}{*}{3} & \multirow[t]{6}{*}{ Variables in the equation } & B & 1.17 \\
\hline & & S.E & 0.62 \\
\hline & & Wald & 6.82 \\
\hline & & Df & 1 \\
\hline & & Sig (p-value) & 0.01 \\
\hline & & $\begin{array}{l}\operatorname{Exp}(B) \\
(95 \% C I)\end{array}$ & $\begin{array}{l}5.0 \\
(1.5-16.9)\end{array}$ \\
\hline \multirow[t]{3}{*}{4} & \multirow[t]{3}{*}{ Classification table } & $\begin{array}{l}\text { Percentage } \\
\text { correct (Alive) }\end{array}$ & 93.1 \\
\hline & & $\begin{array}{l}\text { Percentage } \\
\text { correct (Dead) }\end{array}$ & 27.3 \\
\hline & & Total & 81.3 \\
\hline
\end{tabular}

The value of regression coefficient (1.17) and the Sig. (p-value) of 0.01 confirms that $A D L$ is a significant predictor of two-year survival in our patients. The odds ratio of five indicates that patients with an ADL score of 11 or less are five times more likely to die before two years 
compared to those who have an ADL score of greater than 11 . The $95 \%$ confidence intervals of the odds ratio shows that this risk could vary from 1.5 to 16.9 times. The overall accuracy for ADL to predict two-year survival in the study population is $81 \%$.

\subsubsection{Instrumental Activities of Daily Living (IADL) score and}

\section{two-year survival.}

Table-15. Logistic regression analysis: IADL and two-year survival in the study population

\begin{tabular}{|c|c|c|c|}
\hline Step & Summary of logistic & \multicolumn{2}{|l|}{ Results } \\
\hline \multirow[t]{3}{*}{1} & \multirow[t]{3}{*}{ Case processing summary } & $\begin{array}{l}\text { Included in the } \\
\text { analysis }\end{array}$ & 123 \\
\hline & & Missing cases & 0 \\
\hline & & Total & 123 \\
\hline 2 & $\begin{array}{l}\text { Omnibus tests of model } \\
\text { coefficients }\end{array}$ & Sig (p-value) & 0.07 \\
\hline \multirow[t]{6}{*}{3} & \multirow[t]{6}{*}{ Variables in the equation } & B & -0.16 \\
\hline & & S.E & 0.09 \\
\hline & & Wald & 3.3 \\
\hline & & Df & 1 \\
\hline & & Sig (p-value) & 0.07 \\
\hline & & $\begin{array}{l}\operatorname{Exp}(\mathrm{B}) \\
(95 \% \mathrm{CI})\end{array}$ & $\begin{array}{l}0.8 \\
(0.6-6.1)\end{array}$ \\
\hline
\end{tabular}


Logistic regression analysis showed no statistically significant correlation between patients' IADL score and their two-year survival. Results of the analysis are summarized in table- 15 .

The value of regression coefficient $(-0.16)$ and the Sig. ( $p$-value) of 0.07 confirms that IADL score is not a significant predictor of two-year survival in our patients. The odds ratio of 0.8 indicates that patients with an IADL score of seven or less are 1.25 times less likely to die before two years compared to those who have an IADL score of eight. The $95 \%$ confidence intervals of the odds ratio vary from 0.6 to 6.1 , confirming the non-significant association that could be in either direction, positive or negative.

\subsubsection{American Society of Anaesthesiologists (ASA) score and two-year survival}

Logistic regression analysis showed a statistically significant correlation between patients' ASA score and their two-year survival. All 123 patients were included in the analysis. Results of the analysis are summarized in Table-16. 
Table 16. Logistic regression analysis: ASA and two-year survival in the study population

\begin{tabular}{|c|c|c|c|}
\hline Step & Summary of logistic & \multicolumn{2}{|l|}{ Results } \\
\hline \multirow[t]{3}{*}{1} & \multirow[t]{3}{*}{ Case processing summary } & $\begin{array}{l}\text { Included in the } \\
\text { analysis }\end{array}$ & 123 \\
\hline & & Missing cases & 0 \\
\hline & & Total & 123 \\
\hline 2 & $\begin{array}{l}\text { Omnibus tests of model } \\
\text { coefficients }\end{array}$ & Sig ( $p$-value) & 0.02 \\
\hline \multirow[t]{6}{*}{3} & \multirow[t]{6}{*}{ Variables in the equation } & B & 2.51 \\
\hline & & S.E & 0.76 \\
\hline & & Wald & 10.96 \\
\hline & & Df & 1 \\
\hline & & Sig (p-value) & 0.001 \\
\hline & & $\begin{array}{l}\operatorname{Exp}(B) \\
(95 \% C I)\end{array}$ & $\begin{array}{l}12.2 \\
(2.8-54.0)\end{array}$ \\
\hline \multirow[t]{3}{*}{4} & \multirow[t]{3}{*}{ Classification table } & $\begin{array}{l}\text { Percentage } \\
\text { correct (Alive) }\end{array}$ & 97 \\
\hline & & $\begin{array}{l}\text { Percentage } \\
\text { correct (Dead) }\end{array}$ & 27.3 \\
\hline & & Total & 84.6 \\
\hline
\end{tabular}

The value of regression coefficient (2.51) and the Sig. ( $p$-value) of 0.001 confirm that ASA is a significant predictor of two-year survival in our study patients. The odds ratio of 12.2 indicates a positive relationship, meaning that patients with an ASA score of four are 12 times more likely to die before two years compared to those who have an ASA score of three or less. The $95 \%$ confidence intervals of the odds ratio show that the risk could vary from 2.8 to 54 times. Overall 
accuracy for ASA to predict two-year survival in the study population is $85 \%$.

\subsection{Development of Breast Cancer in Elderly Treatment Algorithm}

The score of the three CGA variables that showed a significant correlation with two-year survival in our study population was combined to make a single variable called as Breast Cancer in Elderly Treatment Algorithm (BCETA) score. For each of the three components, i.e. MMSE, $A D L$, and ASA, patients received a BCETA score of either 0 , or 1 based on their dichotomised score. The score from these three components were added to give a final BCETA score based on which patients were divided into two groups. A low-risk group with a BCETA score of 0 , and a high-risk group with BCETA score of 1 or higher.

\begin{tabular}{|l|l|}
\hline Final BCETA score & Patient Group \\
\hline$M M S E+A D L+A S A=0$ & Low risk group \\
\hline$M M S E+A D L+A S A=1-3$ & High risk group \\
\hline
\end{tabular}

Logistic regression analysis was performed using the BCETA score as the independent variable and survival at two years as the dependent variable to find if the BCETA score is a significant predictor of two-year 
survival in our patients. The analysis showed a strong and statistically significant correlation between patients' BCETA score and their two-year survival. A total of 119 cases were included in the analysis after excluding 4 cases with missing data. Results of the analysis are summarized in table-17.

Table 17. Logistic regression analysis: BCETA and two-year survival in the study population

\begin{tabular}{|c|c|c|c|}
\hline Step & Summary of logistic & \multicolumn{2}{|l|}{ Results } \\
\hline \multirow[t]{3}{*}{1} & \multirow[t]{3}{*}{ Case processing summary } & $\begin{array}{l}\text { Included in the } \\
\text { analysis }\end{array}$ & 119 \\
\hline & & Missing cases & 4 \\
\hline & & Total & 123 \\
\hline 2 & $\begin{array}{l}\text { Omnibus tests of model } \\
\text { coefficients }\end{array}$ & Sig ( $p$-value) & 0.00 \\
\hline \multirow[t]{6}{*}{3} & \multirow[t]{6}{*}{ Variables in the equation } & $B$ & 1.97 \\
\hline & & S.E & 0.53 \\
\hline & & Wald & 13.9 \\
\hline & & Df & 1 \\
\hline & & Sig (p-value) & 0.00 \\
\hline & & $\begin{array}{l}\operatorname{Exp}(B) \\
(95 \% C I)\end{array}$ & $\begin{array}{l}7.2 \\
(2.6-20.3)\end{array}$ \\
\hline \multirow[t]{3}{*}{4} & \multirow[t]{3}{*}{ Classification table } & $\begin{array}{l}\text { Percentage } \\
\text { correct (Alive) }\end{array}$ & 86.7 \\
\hline & & $\begin{array}{l}\text { Percentage } \\
\text { correct (Dead) }\end{array}$ & 52.4 \\
\hline & & Total & 80.7 \\
\hline
\end{tabular}


The value of regression coefficient (1.97) and the Sig. ( $p$-value) of 0.00 confirms that BCETA is a significant predictor of two-year survival in our study patients. Patients with a BCETA score of one or higher are 7 times more likely to die before two years compared to those who have a BCETA score of zero. However, this risk could vary from 2.6 to 20 times based on the $95 \%$ confidence intervals of the odds ratio. Overall the accuracy for BCETA to predict two-year survival in the study population is $81 \%$. 


\section{BREAST CANCER IN ELDERLY TREATMENT ALGORITHM}

COMPREHENSIVE GERIATRIC ASSESSMENT

1. MINI-MENTAL STATE EXAMINATION

\begin{tabular}{|c|c|}
\hline MMSE SCORE & BCETA* SCORE \\
\hline $20-30$ & 0 \\
\hline $0-19$ & 1 \\
\hline
\end{tabular}

2. ACTIVITIES OF DAILY LIVING

\begin{tabular}{|l|l|}
\hline ADL SCORE & SCORE FOR ANALYSIS \\
\hline $12-20$ & 0 \\
\hline $0-11$ & 1 \\
\hline
\end{tabular}

3. AMERICAN SOCIETY OF ANAESTHESIOLOGIST SOCRE

\begin{tabular}{|l|l|}
\hline ASA SCORE & BCETA SOCRE \\
\hline $1-3$ & 0 \\
\hline 4 & 1 \\
\hline
\end{tabular}

TOTAL BCETA SCORE

\begin{tabular}{|l|l|l|}
\hline TOTAL BCETA SCORE & SURVIVAL & RECOMMENDED TXT \\
\hline 0 & $90 \%>2 \mathrm{yr}$ & SURGERY + ET or PET \\
\hline $1-3$ & $46 \%<2 \mathrm{yr}$ & PET \\
\hline
\end{tabular}

BCETA* - BREAST CANCER IN ELDERLY TREATMENT ALGORITHM 


\subsection{Summary of the statistical analysis}

Table-18 shows the overall summary of the univariate logistic regression analysis exploring association between the six components of CGA and two-year survival in the study population. The results show that individually MMSE, ADL, and ASA score are significant predictors $(p<0.05)$ of two-year survival.

Table-19 summarise the results of univariate logistic regression analysis using two-year survival as the dependent variable and MMSE, ADL, ASA and BCETA score individually as co-variates. Table-20 shows the sensitivity, specificity, positive predictive value, negative predictive value, C-statistic value and overall accuracy of MMSE, ADL, ASA and BCETA scores in predicting two-year survival in the study population. The C-statistic value (area under ROC curve) of the BCETA score, illustrating its discriminatory power to predict two-year survival in the study population, is much higher than the C-statistic value of MMSE, ADL and ASA scores individually (figures 3.1-3.4). This essentially confirms the BCETA as a better prognostic model with higher discriminatory power compared to the individual variables utilised for constructing the BCETA (i.e., MMSE, ADL, and ASA). 
Table-18. Summary statistics of Logistic regression analyzing the correlation between components of the CGA and two-year survival in the study population

\begin{tabular}{|l|l|l|l|l|l|l|l|l|}
\hline Variables & B & S.E & Wald & df & Sig. & \multicolumn{2}{|l|}{ Exp(B) } & \multicolumn{2}{|l|}{$\begin{array}{l}\text { U5 C.I. for } \\
\text { Exp(B) }\end{array}$} \\
\hline $\begin{array}{l}\text { SIC } \\
\text { score }\end{array}$ & -0.47 & 0.79 & 0.35 & 1 & 0.55 & 0.6 & 0.1 & 2.2 \\
\hline $\begin{array}{l}\text { MMS } \\
\text { score }\end{array}$ & 1.74 & 0.69 & 6.46 & 1 & 0.01 & 5.7 & 1.5 & 22.1 \\
\hline $\begin{array}{l}\text { GDS } \\
\text { score }\end{array}$ & 0.16 & 0.22 & 0.54 & 1 & 0.46 & 1.2 & 0.8 & 1.8 \\
\hline $\begin{array}{l}\text { ADL } \\
\text { score }\end{array}$ & 1.17 & 0.62 & 6.82 & 1 & 0.01 & 5.0 & 1.5 & 17.0 \\
\hline $\begin{array}{l}\text { IADL } \\
\text { score }\end{array}$ & -0.16 & 0.09 & 3.3 & 1 & 0.07 & 0.8 & 0.6 & 6.1 \\
\hline $\begin{array}{l}\text { ASA } \\
\text { Score }\end{array}$ & 2.50 & 0.76 & 10.96 & 1 & 0.00 & 12.2 & 2.8 & 54.0 \\
\hline
\end{tabular}


Table 19. Summary of MMSE, ADL, ASA and BCETA score and their association with two-year survival in the study population

\begin{tabular}{|l|l|l|l|l|l|l|l|l|}
\hline Variables & B & S.E & Wald & df & Sig. & Exp(B) & \multicolumn{2}{|l|}{$\begin{array}{l}\text { 95\% C.I. for } \\
\text { Exp(B) } \\
\text { Lower } \\
\text { Upper }\end{array}$} \\
\hline $\begin{array}{l}\text { MMSE } \\
\text { score }\end{array}$ & 1.74 & .69 & 6.46 & 1 & 0.01 & 5.7 & 1.5 & 22.1 \\
\hline $\begin{array}{l}\text { ADL } \\
\text { score }\end{array}$ & 1.17 & .62 & 6.82 & 1 & 0.01 & 5.0 & 1.5 & 17.0 \\
\hline $\begin{array}{l}\text { ASA } \\
\text { score }\end{array}$ & 2.50 & .76 & 10.96 & 1 & 0.00 & 12.2 & 2.8 & 54.0 \\
\hline $\begin{array}{l}\text { BCETA } \\
\text { score }\end{array}$ & 1.97 & .53 & 13.92 & 1 & 0.00 & 7.2 & 2.6 & 20.3 \\
\hline
\end{tabular}

Table 20. Summary statistics of MMSE, ADL, ASA and BCETA score predicting two-year survival in the study population

\begin{tabular}{|l|l|l|l|l|l|l|}
\hline Variables & $\begin{array}{l}\text { Sensitivi } \\
\text { ty \% }\end{array}$ & $\begin{array}{l}\text { Specifici } \\
\text { ty \% }\end{array}$ & $\begin{array}{l}\text { Positive } \\
\text { predictive } \\
\text { valve \% }\end{array}$ & $\begin{array}{l}\text { Negative } \\
\text { predictive } \\
\text { value \% }\end{array}$ & $\begin{array}{l}\text { C- } \\
\text { statistic } \\
\text { (area } \\
\text { under } \\
\text { ROC } \\
\text { curve) }\end{array}$ & $\begin{array}{l}\text { Overall } \\
\text { accuracy } \\
\%\end{array}$ \\
\hline $\begin{array}{l}\text { MMSE } \\
\text { Score }\end{array}$ & 85 & 50 & 95 & 23 & 0.59 & 82 \\
\hline $\begin{array}{l}\text { ADL } \\
\text { SCore }\end{array}$ & 85 & 46 & 93 & 27 & 0.60 & 81 \\
\hline $\begin{array}{l}\text { ASA } \\
\text { Score }\end{array}$ & 86 & 67 & 97 & 27 & 0.62 & 85 \\
\hline $\begin{array}{l}\text { BCETA } \\
\text { Score }\end{array}$ & 89 & 46 & 87 & 52 & 0.70 & 81 \\
\hline
\end{tabular}




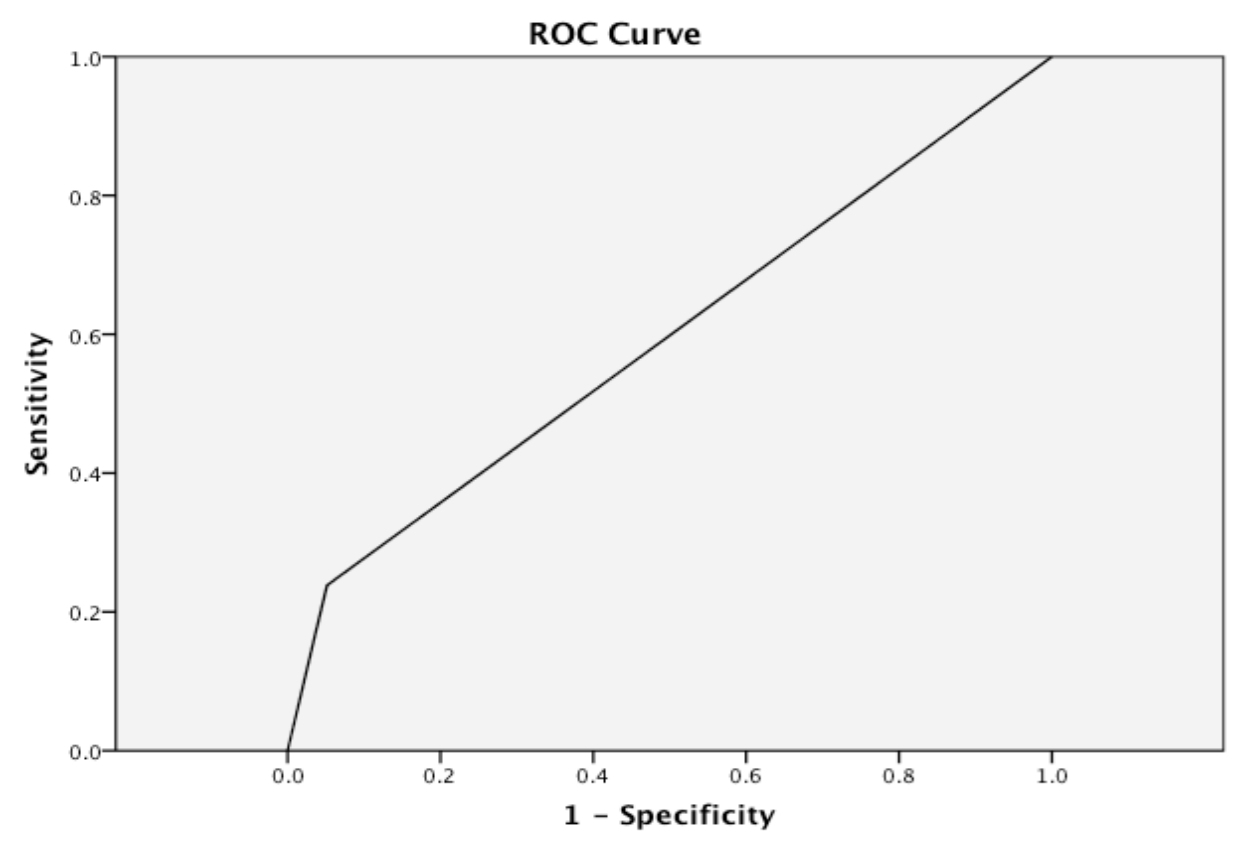

Diagonal segments are produced by ties.

Figure 3.1 ROC curve for MMSE

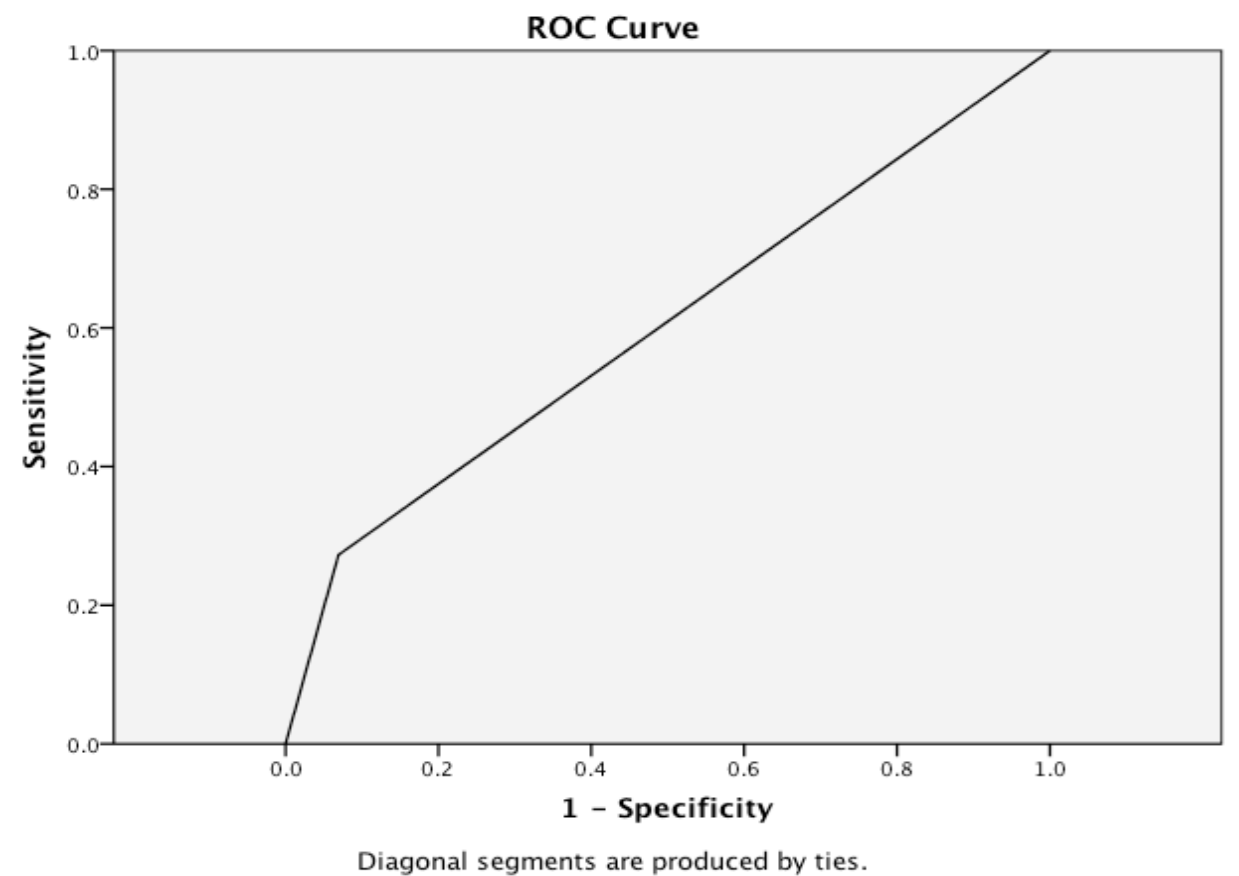

Figure 3.2 ROC curve for ADL 


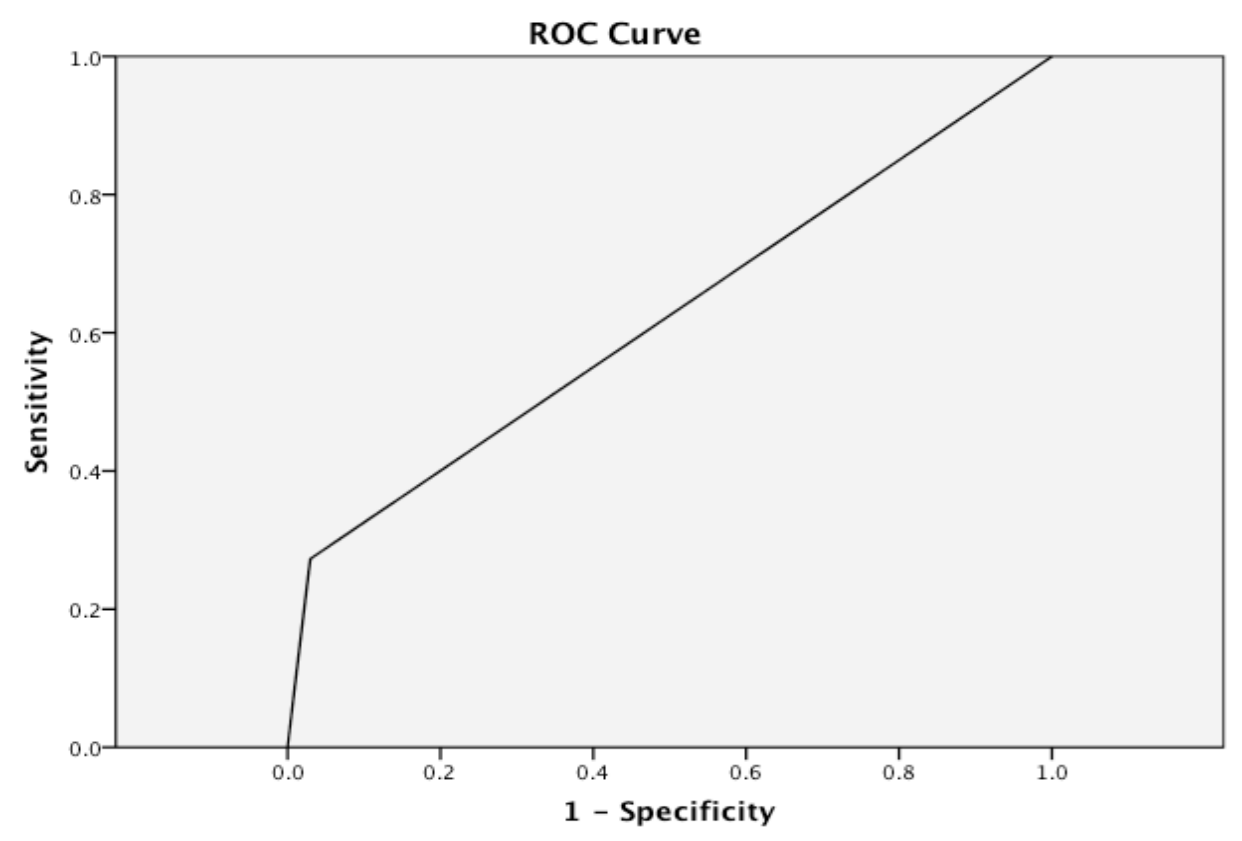

Diagonal segments are produced by ties.

Figure 3.3 ROC curve for ASA

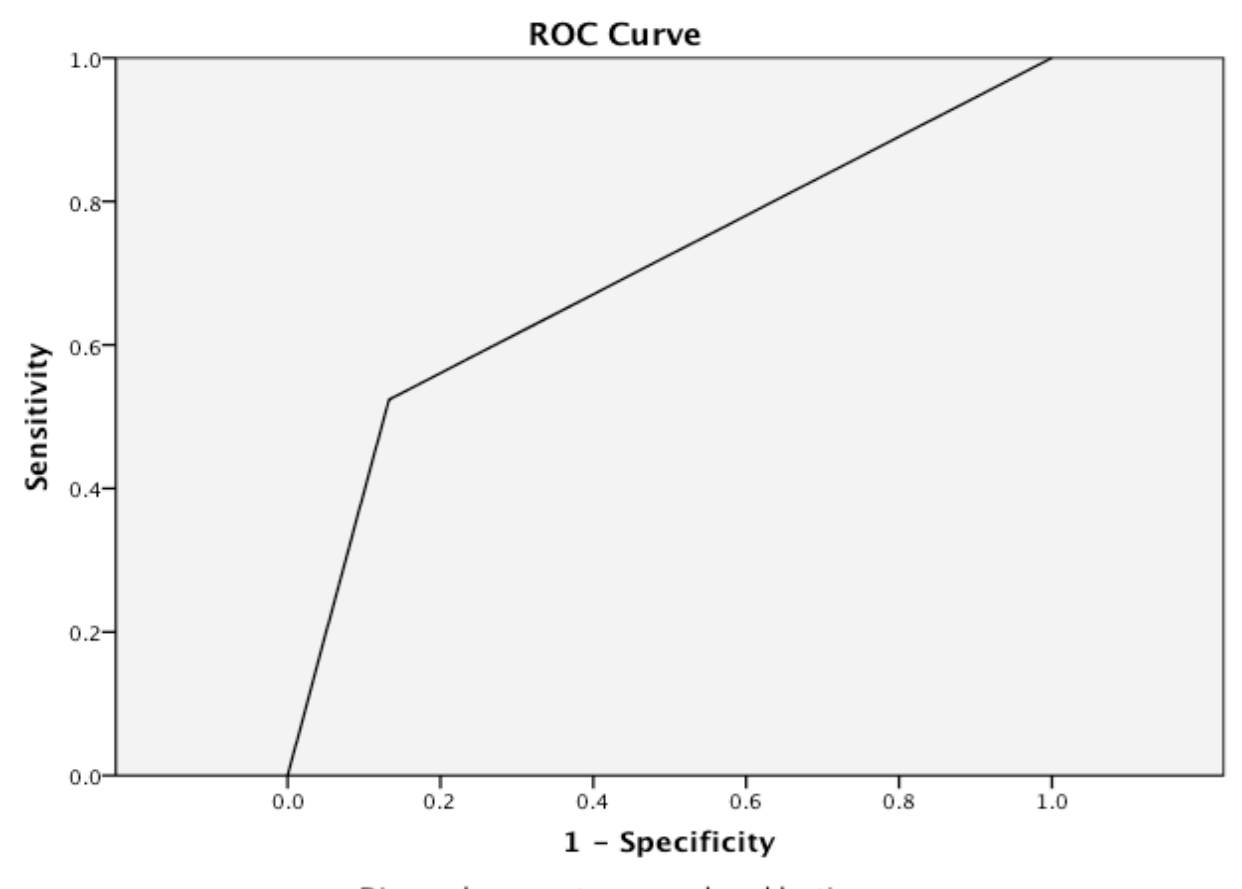

Diagonal segments are produced by ties.

Figure 3.4 ROC curve for BCETA 


\subsection{Validation of results}

A bootstrap technique was used for internal validation of the logistic regression analysis to confirm the association between the BCETA score and two-year survival in our patients. One hundred and nineteen patients were included in the bootstrap analysis after excluding four patients with missing data.

\section{Bootstrap Specifications}

Sampling Method

Number of Samples

Confidence Interval Level

Confidence Interval Type
Simple

1000

$95.0 \%$

Percentile

One thousand bootstrap samples were randomly selected from the original dataset.

\section{Bootstrap for Variables in the Equation}

\begin{tabular}{|c|c|c|c|c|c|c|c|}
\hline & \multirow[b]{3}{*}{$B$} & \multicolumn{5}{|c|}{ Bootstrap $^{a}$} \\
\hline & & & \multirow[b]{2}{*}{ Bias } & \multirow{2}{*}{$\begin{array}{l}\text { Std. } \\
\text { Error }\end{array}$} & \multirow{2}{*}{$\begin{array}{l}\text { Sig. (2- } \\
\text { tailed) }\end{array}$} & \multicolumn{2}{|c|}{$\begin{array}{l}95 \% \text { Confidence } \\
\text { Interval }\end{array}$} \\
\hline & & & & & & Lower & Upper \\
\hline \multirow[t]{2}{*}{$\begin{array}{l}\text { Step } \\
1\end{array}$} & $\begin{array}{l}\text { BCETA } \\
\text { score }\end{array}$ & 1.973 & .046 & .595 & .001 & 0.9 & 3.2 \\
\hline & Constant & -2.140 & -.053 & .375 & .001 & -3.1 & -1.5 \\
\hline
\end{tabular}

a: Bootstrap results based on 1000 bootstrap samples 
The relationship between the BCETA score and two-year survival was explored in each of the bootstrap samples using logistic regression analysis. Bootstrap analysis of the 1000 bootstrap samples confirmed the significant association between the BCETA score and two-year survival in our patients ( $p$-value $=0.00$ ) with $95 \%$ confidence interval of the B-coefficient between 0.9 and 3.2.

\subsection{Testing the BCETA}

1. Treatment recommendations based on clinical assessment and its correlation with two-year survival in eligible older breast cancer patients from the Leicester research clinic:

\begin{tabular}{|c|c|c|c|}
\hline & \multicolumn{2}{|c|}{ Clinical Decision } \\
\hline $\begin{array}{c}\text { Survival at } \\
\text { 2-year }\end{array}$ & ST & PET & Total \\
\hline Alive & 75 & 23 & 98 \\
Dead & 13 & 8 & 21 \\
Total & 88 & 31 & 119 \\
\hline
\end{tabular}

Logistic regression analysis showed no statistically significant association ( $p$-value $=0.166$ ) between clinical decisions $(C D)$ and twoyear survival in the study population (odds ratio $2.0,95 \%$ CI $0.7-6.0$ ). Clinical decisions correctly identified $85 \%(75 / 88)$ of patients who 
survived more than two years and $26 \%(8 / 31)$ of those who survived less than two years. The overall accuracy for CD was 70\% $(83 / 119)$.

2. Treatment recommendations based on guidance from the BCETA and its correlation with two-year survival in eligible older breast cancer patients:

\begin{tabular}{|c|c|c|c|}
\hline & \multicolumn{2}{|c|}{$\begin{array}{c}\text { Recommendation from } \\
\text { BCETA }\end{array}$} \\
\hline $\begin{array}{c}\text { Survival at } \\
\text { 2-year }\end{array}$ & ST & PET & Total \\
\hline Alive & 85 & 13 & 98 \\
Dead & 10 & 11 & 21 \\
Total & 95 & 24 & 119 \\
\hline
\end{tabular}

Logistic regression analysis revealed a statistically significant association $(p$-value $=0.00)$ between the BCETA score and two-year survival in the study population (odds ratio $7.2,95 \%$ CI $2.5-20.3$ ). BCETA correctly identified $87 \%(85 / 98)$ of patients who survived more than two years and $52 \%(11 / 21)$ of those who survived less than two years. The overall accuracy for BCETA was $81 \%(96 / 119)$. 
Table-21. Summary statistics of Clinical Decisions and BCETA score and their relationship with two-year survival

\begin{tabular}{|l|l|l|l|l|l|l|}
\hline Variables & $\begin{array}{l}\text { Sensitivi } \\
\text { ty \% }\end{array}$ & $\begin{array}{l}\text { Specifici } \\
\text { ty \% }\end{array}$ & $\begin{array}{l}\text { Positive } \\
\text { predictive } \\
\text { valve \% }\end{array}$ & $\begin{array}{l}\text { Negative } \\
\text { predictive } \\
\text { value \% }\end{array}$ & $\begin{array}{l}\text { C- } \\
\text { statistic } \\
\text { (Area } \\
\text { under } \\
\text { ROC } \\
\text { curve) }\end{array}$ & $\begin{array}{l}\text { Overall } \\
\text { accuracy } \\
\%\end{array}$ \\
\hline $\begin{array}{l}\text { Clinical } \\
\text { Decisions }\end{array}$ & 76 & 38 & 85 & 26 & 0.58 & 70 \\
\hline $\begin{array}{l}\text { BCETA } \\
\text { score }\end{array}$ & 89 & 46 & 87 & 52 & 0.70 & 81 \\
\hline
\end{tabular}

Table-21 summarises the result of clinical decisions and BCETA score in predicting two-year survival in the study population. It shows that the C-statistic value (area under the ROC curve) or discriminatory power of the BCETA model to differentiate between those who would or would not survive for two years is much better $(0.70)$, compared to 0.58 for the clinical decisions. The overall accuracy for the BCETA prognostic model was $81 \%$ compared to $70 \%$ for the clinical decisions. Chi square test statistics confirmed the BCETA score to be significantly better $(p=0.03)$ than clinical decision alone in predicting two-year survival in the study population. 
Chapter 4. Discussion \& Conclusion 


\section{Discussion}

In the UK, there has been a trend over recent decades towards treating older breast cancer patients with hormonal treatment alone; the figures reported, range from $20-40 \%$ [51]. This reliance on endocrine therapy, in patients who live long enough, results in persistent or recurrent local disease, sometimes becoming locally advanced and then difficult to treat, months and years after diagnosis. To establish whether primary endocrine therapy is justifiable for women who are fit for surgery, several randomized control trials $[19,54-57]$ compared the efficacy of primary endocrine therapy vs. surgery plus endocrine therapy in older breast cancer patients. They concluded that PET is inferior to surgery plus endocrine therapy in terms of local control in all patients, and overall survival in the 70 to 75 years group.

The National Institute for Clinical Excellence guidelines [22] and a Cochrane review of the randomised control trials comparing PET and surgery plus ET in elderly patients [53] recommended that elderly breast cancer patients should be considered for surgery in addition to appropriate systemic therapy unless they refuse it, or they have a short life expectancy and are therefore unlikely to benefit from it. In clinical practice, however, there was no validated assessment in place that 
could predict life expectancy in these patients and guide treatment decisions. In this study, we used a form of Comprehensive Geriatric Assessment to predict two-year survival in elderly breast cancer patients. Based on the Comprehensive Geriatric Assessment scoring and its predicted survival, a treatment algorithm was devised that could be used for guidance to recommend whether primary endocrine therapy or surgery plus endocrine treatment would be best indicated in individual older breast cancer patients.

The two-year survival cut-off was used for two main reasons. First, the median response duration of PET is about two years [53], meaning that patients who survive for longer than two years may develop resistance to PET and will need change of treatment at a stage when they would be older and perhaps less fit. Second, during the first two years there is no survival difference between patients receiving PET or surgery plus endocrine therapy, for hormone receptor positive, early breast cancer [53]. Therefore, it would be safe to treat these patients with PET alone, if they are not expected to survive for longer than two years.

Previously, prognostic indices have been developed and validated, to predict short and long-term mortality, in different cohorts of patients [75-77]. These indices, however, could not be applied to our group of 
patients because of their complexity, time consumption and/or nonapplicability of some of their variables to our patients. Many of the variables used in these indices, that were applicable to our patients and easy to use in a breast clinic, were included in the comprehensive geriatric assessment of our patients.

The comprehensive geriatric assessment model we used in our clinic, included assessment of all the key domains that could help in the management of elderly breast cancer patients and is also practical in a busy clinic setting. It included six components: Satariano Index of Comorbidities, Mini Mental State Examination, Geriatric Depression Score, Activities of Daily Living (Barthel Index), Instrumental Activities of Daily Living, and American Society of Anaesthesiologists score. The score of each of these components was dichotomized into low-risk and high-risk categories, at cut-off levels, which were clinically relevant and had been previously used. Univariate logistic regression analysis using individual components of the CGA against the dependent variable (two-year survival) showed only three components having a significant association with two-year survival in the study population. Those components are: Mini Mental State Examination score (MMSE), Barthel Index (ADL) and American Society of Anaesthesiologists (ASA) score. Essentially, this means that significant cognitive impairment, functional dependence or 
an ASA grade above three, are each associated with reduced life expectancy in this elderly patient population.

\section{Cognitive Impairment}

The effect of cognitive impairment on survival has been well documented. Lower levels of cognitive function are associated with increased mortality in older patients $[76,82,83,111]$. The underlying mechanism for this association is still unclear; however, cognitive impairment may contribute to mortality in different ways. Deficiencies in language comprehension, in recall, or in other cognitive areas may contribute to failure to seek timely health care, to use recommended treatments or medications, or to recognize signs and symptoms of disease, resulting in poor health outcomes [111].

Our study also confirmed the effect of cognitive impairment on survival. It was found to be a significant predictor of two-year mortality in our patients ( $p$-value 0.01). Patients with significant cognitive impairment (MMSE score of less than 20) were shown to have a low chance of twoyear survival compared to those having better cognitive function (MMSE score of 20 or more). Our results were consistent with other similar studies. Inouye et al. [76] from their study on "the importance of 
functional measures in predicting mortality among 525 older hospitalized patients," found cognitive function to be one of the three main prognostic factors for two-year mortality in their patients. They reported that elderly hospitalized patients with significant cognitive impairment (MMSE score of less than 20) were more likely to die in the next two years compared to those having better cognitive function.

Another study by McGuire et al. [82], confirmed the significant association between cognitive function and two-year mortality in older diabetic patients. Their study included 559 US adults with diabetes, aged $\geq 70$ years. Stump TE et al. [83] reported, from a prospective cohort study of 3957 patients, that moderate-to-severe cognitive impairment is associated with an increased risk of mortality in older primary care patients, after controlling for confounding factors. H.R. Kelman et al. [111] studied the association of cognitive impairment on survival of 1855 older community residents in Bronx, New York. They found that after adjustment for the effects of potentially confounding variables, persons with significant cognitive impairment were more than twice as likely as unimpaired persons to die within four years. 
All these studies, though they were conducted in different cohorts of patients with different circumstances, indicated the importance of cognitive function and its relation with mortality in elderly patients.

\section{Functional Dependence}

Functional capacity refers to the ability to carry out daily activities in a normal or accepted way. Maintenance of functional capacity is an important indicator of health in the elderly; the loss of this capacity is associated with a rise in morbidity and mortality [112]. Functional dependence exists when the adaptation of the environment or the use of technical aids cannot compensate for disability, and the help of a third person is needed to carry out activities of daily living [113]. Generally, disability in old people is assessed based on their difficulty carrying out the activities of daily living, or those activities everybody does everyday, in order to live independently and integrated within the environment.

Functional dependence has been reported a strong predictor of mortality in older people $[77,84,114]$. Our data analysis also confirmed a statistically significant association between the dependence in Activities of Daily Living (Barthel Index) and two-year survival in our 
patients ( $p$-value 0.009 ), meaning that it is a valuable predictor of twoyear survival in elderly breast cancer patients. Patients having significant dependence in daily living activities (BI score of less than 12) were more likely to die within the next two years compared to those having less or no dependence (BI of 12 or more). We, however, did not observe any statistically significant association between patients' IADL score and their two-year survival ( $p$-value 0.068).

Walter LC et al. [77] reported findings similar to our study. They developed and validated a prognostic index for one-year mortality of older adults after hospital discharge using information readily available at discharge. Their study included 2922 patients above the age of 70 . They reported that a number of dependent ADLs have significant association with one-year mortality; however, there was no correlation between IADL score and one-year mortality.

Carey EC et al. [84] developed and validated a functional morbidity index to predict two-year mortality in 7393 community dwelling elders. They reported a significant association between functional dependence and two-year mortality in these people. Covinsky et al. [114] provided convincing evidence for the prognostic importance of functional status in seniors admitted to acute care hospitals. Data about six activities of 
daily living (ADLs) were collected from 823 medical patients, and the patients were followed for mortality and resource use. They found dependence in ADL as the most important predictor of mortality in these patients.

Our study, in highlighting the prognostic impact of functional status, provides further evidence for the importance of assessing functional status in elderly patients. Functional status reflects the end-impact of illnesses, loss of organ function with disease and age, and psychosocial factors in a given patient, and it is likely that this explains its prognostic value.

\section{American Society of Anaesthesiologist score}

American society of anaesthesiologist (ASA) classification is the most widely used anaesthetic risk assessment scheme in anaesthesia. Although the ASA grade provides a general measure of patients' fitness before surgery, it has been reported as an important predictor of perioperative and early post-operative mortality in patients undergoing surgery $[97,98]$. Recently, the ASA score has been assessed and reported as a significant predictor of longer-term survival in surgical patients $[115,116]$. Our data analysis also confirmed a strong 
correlation between ASA score and two-year survival of our patients $(p=0.002)$. Patients having an ASA score of 3 or less, were more likely to survive beyond two years, compared to those with an ASA score of 4 .

Aharonoff GB et al. [115] looked into predictors of one-year mortality following hip surgery in 612 ambulatory, community dwelling, and cognitively intact elderly patients in New York. They found the ASA score one of the significant predictors of one-year mortality in these patients. In another prospective study of patients, aged 95 and above, Holt G. et al. [116] looked into the factors affecting outcome after surgery for hip fracture. They found ASA grade a significant predictor of one-year mortality in these patients, independent of other factors. Rogers S et al. [117] explored the relation between American Society of Anesthesiologists' (ASA) score and 18 months survival in 278 patients treated for oral and oropharyngeal squamous cell carcinoma from 1995 to 1999 . They reported the ASA score a significant predictor of survival $(p=0.003)$ in these patients.

Some studies, however, disputed the predictive value of ASA score. Kanatas et al. [118] used the American Society of Anesthesiologists' (ASA) grading to investigate a possible link between coexisting conditions and disease-free survival in 114 patients with head and neck 
cancer patients. Their analysis did not show a significant association between the ASA grade and survival in these patients.

Overall, the importance of anaesthetic assessment using ASA scale, to assess patients' fitness for surgical procedures could not be denied. However, this study highlights its importance, in elderly patients with early breast cancer, for two reasons. First, it assesses their suitability for any possible surgical procedure; second, the anaesthetic assessment score can be used in their BCETA score, to recommend an optimal treatment for their breast cancer, since it helps predict survival in these patients.

\section{Comprehensive Geriatric Assessment variables having no relevance to two-year survival in our patients}

Other components of our CGA, which did not show any significant relevance to two-year survival in our patients, included the Satariano Index of Co-morbidities, Geriatric Depression Score, and IADL. We also used patient age as a variable to explore its relationship with two-year survival in our patients; importantly, the association was not significant $(p=0.4)$. Patients included in our study ranged from age $70-94$, with a median age of 82 . Other studies have also reported similar findings. 
Satariano et al. [25] studied the effect of co-morbidity on three-year survival of women with primary breast cancer. Their study included 936 women with invasive breast cancer, aged 40 to 84 years. They did not find a statistically significant association between patient age and their three-year survival [25]. Walter LC et al. [77] developed and validated a prognostic index for one-year mortality in elderly patients after hospital discharge. The study included 1495 patients, of age 70 and above. They reported no independent association between patient age and survival. Since there is no clear evidence that age is predictive of outcome in elderly breast cancer patients, therefore, old age should not be considered a good reason for effective treatment to be withheld.

\section{Co-morbidities:}

The influence of co-morbid illnesses on survival outcomes in oncology has long been recognized and recently documented for a variety of malignancies, including bladder, lung, head and neck, colorectal, and breast cancers. Several co-morbidity indices have been developed and validated in different groups of patients. Some of the main indexes are: Charlson Co-morbidity Index [72], Satariano Index of Co-morbidity [25], the Index of Co-existent Disease [86], and the Kaplan-Feinstein Index [119]. 
Of particular relevance is the Satariano Index of Co-morbidity, which has been developed and subsequently validated in a cohort of breast cancer patients and reported to have significant association with survival in breast cancer patients [25]. We therefore selected this comorbidity index for our study, to record patient's co-morbid illnesses. We analysed the data to find a correlation between Satariano index of co-morbidity and two-year survival in our patients; however, no statistically significant correlation was found between the two $(p>0.05)$. Janssen-Heijnen et al. [120] conducted a study on the prognostic effects of rising age and co-morbidity in unselected elderly Dutch, small cell lung cancer patients. They also reported a negligible prognostic effect of co-morbidity on the overall outcome of elderly patients with small cell lung cancer.

However, many other studies $[25,72,73]$ reported a significant impact of co-morbidity on survival, independent of other factors. Satariano et al. [25] reported that breast cancer patients with three or more comorbidities have an increased risk of death over a three-year follow-up period, independent of age, breast cancer staging and treatment type. Their study included 936 women, aged 40 to 84 years. 
Charlson et al. [72] developed a weighted co-morbidity index that predicted the risk of death from co-morbid disease in breast cancer patients over a period of 10 -year follow-up. It has also been validated in different cohorts of patients.

G. Nagel et al [73] studied the impact of co-morbidity on survival of postmenopausal women with breast cancer. They found that the level of co-morbidity had a significant influence on the three-year survival in these patients.

These studies showed a significant association between the comorbidity indices and long-term survival (>three years) in breast cancer patients. However, our interest was limited to a short survival (two years), which might be the reason for lack of a significant correlation. Another possible reason could be the age of patients; we only included older patients above the age of 70 in our study; whereas, the studies that showed significant association between co-morbidity and survival, included both, young and old patients. Also, our patients were selected as frail at the outset.

We would recommend perhaps using other co-morbidity indices in future studies, which also include severity and time of co-morbidities, to 
find if they would be helpful in predicting short-term survival in elderly breast cancer patients.

\section{Geriatric Depression Score}

Assessment for psychiatric morbidity from depression is part of our Comprehensive Geriatric Assessment. It has been reported to be associated with reduced survival from conditions such as ischaemic heart disease and diabetes [90]. However, in cancer patients, the effect of psychiatric morbidity on survival outcome has yielded inconsistent results in different studies. However, our analysis did not confirm the presence of any correlation between the GDS and two-year survival in our patients $(p>0.5)$. This could be because depression was uncommon in our patients and our patient numbers are relatively small.

Our results were consistent with the negative finding of other studies $[121,122]$, which investigated the potential relationship between psychiatric morbidity and survival in cancer and non-cancer patients.

Tross S et al. [121] prospectively examined the contribution of potential psychological predictors to length of disease-free and overall survival in 280 women with stage II breast cancer. However, the study failed to provide evidence that psychological factors (including depression) 
contributed to the length of disease-free or overall survival of these women. In another study, Vogt T et al. [122], followed 2573 members of a health maintenance organization for 15 years. They also reported no significant association between the psychiatric morbidity and survival in these patients.

\section{Development of Breast Cancer in Elderly Treatment Algorithm (BCETA)}

The ultimate aim of this study was to devise a treatment algorithm that could predict two-year survival in older breast cancer patients, based on which they could be recommended optimal treatment for their breast cancer. Ideally, we should run a multivariate regression analysis that includes the three significant predictor variables from univariate logistic regression analysis and build a final prognostic model based on those predictors, which retain a statistically significant association with the two-year survival. However, because of the low number of events (22 deaths) in the study, a valid multivariate regression model could not be built to run an analysis that includes three independent variables. These three variables (MMSE, ADL \& ASA) have been confirmed in other studies as significant predictors of mortality independent of other variables $[76,77,82,83,84,111,115,116,117]$. Also, these variables 
assess different domains of human body i.e. MMSE assess cognitive function; ADL assess physical function and ASA assess general well being of patients including their medical conditions. We therefore combined the score of these three variables and developed a single variable known as Breast Cancer in Elderly Treatment Algorithm (BCETA) score.

In the BCETA, we aggregated the dichotomised score of MMSE, ADL, and ASA, giving us a final BCETA score with a range between 0 and 3 . The final BCETA score was divided into low-risk (0) and high-risk $(\geq 1)$ based on clinical relevance. Patients having significant cognitive impairment and/or functional dependence, and/or an ASA score of 4, were ranked in the high-risk group and those without any of these three conditions were ranked in the low-risk group. We performed logistic regression analysis to explore relationship between the dichotomised score of BCETA and two-year survival in the study population. Analysis confirmed the BCETA score as a strong predictor of two-year survival in our patients $(p$-value $=0.00)$. Patients with BCETA score of 0 had $89 \%$ chance of surviving two years or more; those with a score of 1-3 had $46 \%$ chance of less than two-year survival. 
To confirm the prognostic value of BCETA score, we calculated Cstatistic value (area under the ROC curve) for the BCETA model. We also compared it to the C-statistic value of the three individual variables utilised for constructing it (i.e., MMSE, ADL, and ASA). The C-statistic value for BCETA was 0.70 compared to the C-statistic value for MMSE (0.59), ADL (0.60) and ASA (0.62) [Table-20]. This clearly confirms that the BCETA score has higher discriminatory power in differentiating between those who would or wouldn't survive for two years, compared to the three individual variables MMSE, ADL, and ASA. The C-statistic value also confirms the BCETA model as a prognostic index with good discriminatory power. We repeated the BCETA logistic regression analysis after entering the age and then co-morbidity status as variables into the model; however, the results were stable showing no impact of these two variables on the BCETA prognostic model.

The method we used is not a standard method to develop survival prognostic index and would need to be confirmed in further studies with larger population. However, it has previously been used in literature [123] to build survival prognostic model. Perry et al. [123] using a similar method, devised a biologic survival prognostic model for patients with diffuse B-cell lymphoma. They studied 199 patients (125 in the training and 74 in the validation cohort). They developed a biologic 
prognostic model (BPM) based on three variables that were confirmed by univariate regression analysis as having significant association with overall and disease free survival in their study population. The variables were: Microvessel density (MVD), SPARC (secreted protein, acidic, and rich in cysteine), Choi algorithm. These three variables were previously confirmed in other studies as independent predictors of survival in B-cell lymphoma patients. In developing the prognostic model, the authors assigned one score for worse prognosis in each of these three factors. They dichotomised the score of this prognostic model into low-risk and high-risk groups. Analysis revealed significant association between this prognostic model and survival in their patients. The authors confirmed the validity of their prognostic model in a validation cohort of 74 patients.

The prognostic model we developed is clinically relevant and can be translated as: patients having significant cognitive impairment, functional dependence, or an ASA grade above 3, either alone or in combination, are less likely to survive for more than two years. Therefore, these patients may benefit from PET if their breast cancer is hormone receptor positive. Whereas, patients not fulfilling any of these three criteria are very likely to survive for longer than two years and would benefit from standard treatment for their breast cancer. 


\section{Validation of the BCETA}

Ideally, the BCETA validation would involve applying it prospectively to a new group of patients; however, due to restriction of time and resources, we used a bootstrapping technique for validation of the BCETA score and its prediction of two-year survival in our patients. Bootstrapping is a valid method for internal replication \& validation of statistical analysis and has been widely used in medical studies $[104,105]$. We used SPSS 19 to perform the bootstrap analysis of 1000 randomly selected bootstrap samples. The analysis confirmed a significant association between the BCETA score and two-year survival in our patients $(P=0.001)$ with $95 \%$ confidence interval of the $B$ coefficient between 0.9 and 3.2. This confirmed the validity and stability of our results across numerous combinations of the study participants.

\section{Testing the BCETA}

We retrospectively applied the BCETA to eligible breast cancer patients who were seen in the Leicester research clinic and compared the clinical decisions made in the clinic with the treatment decisions that would have been made if we had applied BCETA to those patients. We wanted 
to explore if clinical assessment supplemented by the BCETA score is a better approach than clinical assessment alone in identifying patients who would or would not survive for two years, based on which an optimal treatment could be recommended for their breast cancer. Logistic regression analysis using clinical decisions as a variable to predict two-year survival yielded the following results: sensitivity $76 \%$, specificity $38 \%$, positive predictive value $85 \%$, negative predictive value $26 \%$, odds ratio 2.0 (95\% CI 0.6-6.0), p-value 0.17 and overall accuracy of $70 \%$.

In comparison, the results for BCETA were: sensitivity $89 \%$, specificity $46 \%$, positive predictive value $87 \%$, negative predictive value $52 \%$, odds ratio 7.2 (95\% CI 2.6-20.3), p-value 0.00 and overall accuracy of $81 \%$.

The C-statistic value (area under the ROC curve) or the discriminatory power of the BCETA model to differentiate between those who would or would not survive for two years was 0.70 compared to 0.58 for the clinical decisions, confirming the BCETA model a better prognostic index than clinical decision. Also, Chi square test statistics showed a statistically significant difference ( $p$-value 0.036 ) between the two models, favouring the BCETA. This essentially means that BCETA could 
be helpful in improving the management of elderly breast cancer patients if it is added to clinical assessment and decision making process.

\section{Strengths of the study}

1. The study included clinically rich prospective data, collected by a team of clinicians including a geriatrician, an anaesthetist, and a breast surgeon.

2. Complete two-year follow-up for mortality, disease progression, and metastatic disease.

3. Selection of few, clinically relevant, and previously validated variables for the CGA, to make the generalisability of the results easy.

4. Selection of cut-off points that were clinically meaningful and used in previous studies.

\section{Limitations of the study}


1. The study was conducted at a single site, in a university hospital setting, within a limited geographic area. As with other prognostic indices, the validity and generalisability of this model needs to be tested in other locations with different groups of patients.

2. Because of the unexpected low number of events in the study group, a multivariate regression analysis could not be performed to confirm that the three variables (MMSE, ADL, ASA) retain their predictive ability in a multivariate model. Further studies with larger population would be needed to confirm the BCETA survival prognostic model.

3. The BCETA was validated by internal replication (bootstrap technique). Ideally, it should be validated in a prospective study, preferably including a similar patient population from a different Unit.

4. The assessment of co-morbidities in our patients included only the presence or absence of a co-morbid condition rather than the degree of ill-health it produces. More sophisticated measures of co-morbidities, which also assess severity and time of co-morbidities, may be incorporated in future studies to see its relevance with survival. 
5. The study group was selected, including patients who had more comorbidities and functional dependence than a typical onco-geriatric series. This provided us with rich clinical data for analysis; however, future studies would be recommended in a non-selected elderly breast cancer population.

6. No quality of life assessment was performed for comparison between the groups.

7. Other variables like socio-demographic status including domestic support and social isolation were not controlled for, though they could potentially affect survival.

\section{Conclusion}

This study devised a treatment algorithm that could help in predicting two-year survival in older breast cancer patients, based on which they could be recommended an optimal treatment for their breast cancer.

We used comprehensive geriatric assessment to find if any of its six components would be helpful in predicting two-year survival in our patients. The use of comprehensive geriatric assessment to develop a 
mortality prognostic index is not new. There are a few such indices available in literature; however, none of them was particularly applicable to elderly breast cancer patients. Therefore, a simple and workable comprehensive geriatric assessment was used in our specially established, Leicester research clinic for early breast cancer in elderly patients.

Analysis of our data confirmed only three components of the CGA i.e., MMSE, ADL, and ASA, having a significant association with two-year survival in our patients. These three components were formulated together into Breast Cancer in Elderly Treatment Algorithm (BCETA). Patients were scored either in the low-risk or high-risk group, according to their BCETA score. Logistic regression analysis confirmed the BCETA score to be a significant predictor of two-year mortality in our patients, and found its prognostic value to be higher than that provided by the individual variables utilized for constructing the BCETA (i.e., MMSE, $A D L$, and $A S A)$.

In summary, patients with BCETA score in the low-risk group had a high chance of surviving two years or more; those in the high-risk group had a lower chance of two-year survival. Clinically, this means that patients having significant cognitive impairment, functional dependence, or an 
ASA grade above 3, either alone or in combination, are less likely to survive for more than two years. Therefore, these patients may be treated with PET if their breast cancer is hormone receptor positive. Whereas, patients not fulfilling any of these three criteria are more likely to survive for longer than two years and may be recommended standard treatment for their breast cancer.

This study has some limitations, which have been discussed. Most importantly, the BCETA would need to be validated in a larger prospective study, which is currently ongoing at the Leicester breast cancer research clinic.

The study is the first step towards optimisation of breast cancer treatment in elderly patients. It has laid down important groundwork for future research. Further studies incorporating different assessment tools, in larger patient groups, may help in devising better prognostic indices, which could guide treatment decisions in older patients, to ensure that they receive optimal treatment for their breast cancer. 
Appendices 


\section{Appendix 1}

\section{Review of literature for the study}

The literature review for this study focuses on standard treatment of early breast cancer, differences in treatment between young and older patients and the reasons why older patients receive substandard treatment for their breast cancer. It also discusses the role of Comprehensive Geriatric Assessment in survival prognostic indices and how it could be used to optimise the care of older cancer patients.

Three major electronic medical databases (Pubmed, Medline and Embase) were searched for published papers using key words "EARLY BREAST CANCER", "PRIMARY ENDOCRINE THERAPY", "BREAST CANCER IN ELDERLY", "COMPREHENSIVE GERIATRIC ASSESSMENT" and "SURVIVAL PROGNOSTIC INDEX". The key words were used independently and in combination for more targeted search. Papers published in English language and without any time restriction were selected. More than 500 titles were reviewed and 85 relevant papers were selected for the review. Also, additional relevant papers were hand-searched along the course of the review, where needed for a specific issue. The National Institute for Health and Clinical Excellence 
(NICE) guidance and Cochrane meta-analysis were also consulted for the literature review. 


\section{References}




\section{References:}

1. Office for National Statistics, Cancer Statistics registrations:

Registrations of cancer diagnosed in 2007, England. Series MB1 no.38. 2010, National Statistics: London.

2. Cancer Research UK (2011). Cancer Stats report - Breast Cancer UK, Cancer Research UK. Available from:

http://info.cancerresearchuk.org/cancerstats/types/breast/

3. August DA, Rea T, Sondak VK. (1994). Age-related differences in breast cancer treatment. Ann Surg Oncol. 1994 Jan;1(1):45-52.

4. Shackney SE, Silverman JF. (2003). Molecular evolutionary patterns in breast cancer. Adv Anat Pathol 2003; 10: 278-290.

5. Simpson, P.T., Reis-Filho, J.S., Gale, T. \& Lakhani, S.R. (2005). Molecular evolution of breast cancer. J Pathol, 205, 248-54.

6. Buerger $H$, Otterbach $F$, Simon $R$, Schäfer $K L$, Poremba $C$, Diallo $R, \ldots$ Boecker W. (1999). Different genetic pathways in the evolution of invasive breast cancer are associated with distinct morphological subtypes. J Pathol. 1999 Dec;189(4):521-6.

7. Ellsworth RE, Hooke JA, Shriver CD, Ellsworth DL. (2009). Genomic heterogeneity of breast tumor pathogenesis. Clin Med Oncol. $2009 \mathrm{Jul}$ $29 ; 3: 77-85$.

8. Skinner KA, Silverstein MJ. (2001). The management of ductal carcinoma in situ of the breast. Endocr Relat Cancer. 2001 Mar;8(1):3345. Review.

9. Page DL, Dupont WD, Rogers LW, Landenberger M. (1982). Intraductal carcinoma of the breast: follow-up after biopsy only. Cancer. 1982;49:751-758.

10. Page DL, Dupont WD, Rogers LW, Jensen RA, Schuyler PA. (1995). Continued local recurrence of carcinoma 15-25 years after a diagnosis of ductal carcinoma in situ of the breast treated only by biopsy. Cancer. 1995;76:1197-1200.

11. A Evans. Breast Institute, City Hospital, Nottingham, UK. Ductal carcinoma in situ (DCIS): are we overdetecting it? From Symposium 
Mammographicum 2004 Edinburgh, UK. 19th - 20th July 2004. Breast Cancer Res 2004, 6(Suppl 1):P23doi:10.1186/bcr842.

12. Leonard RC, Rodger A, Dixon JM. (1994). ABC of breast diseases. Metastatic breast cancer. BMJ. 1994 Dec 3;309(6967):1501-4.

13. Soldo BJ, Agree EM. (1998). America's elderly. Washington, DC: Population Reference Bureau, Inc., 1998.

14. Quinn M, Babb P, Brock A, Kirby L, Jones J. 2001 Cancer Trends in England and Wales, 1950-1999. Studies on Medical and Population Subjects, No. 66 National Statistics, UK. London, The Stationary Office (pp.) 42-43.

15. Tabar L, Yen M-F, Vitak B, Chen H-HT, Smith RA, Duffy SW. (2003) Mammography service screening and mortality in breast cancer patients: 20 year follow-up before and after introduction of screening. Lancet 361: 1405-1410.

16. Golledge J, Wiggins JE, Callam MJ. (2000). Age-related variation in the treatment and outcomes of patients with breast carcinoma. Cancer 88: $369-374$.

17. Yancik R, Wesley MN, Ries LAG, Havlik RJ, Edwards BK, Yates JW. (2001) Effect of age and comorbidity in post-menopausal breast cancer patients aged 55 years and older. J Am Med Assoc 285: 885-892.

18. El-Tamer MB, Ward BM, Schifftner T, Neumayer L, Khuri S, Henderson W. (2007). Morbidity and mortality following breast cancer surgery in women: national benchmarks for standards of care. Ann Surg. 2007 May;245(5):665-71.

19. Fennessy M, Bates T, MacRae K, Riley D, Houghton J, Baum M (2004). Late follow-up of a randomized trial of surgery plus tamoxifen versus tamoxifen alone in women aged over 70 years with operable breast cancer. Br J Surg, 91: 699-704.

20. Clarke M, Collins R, Darby S, Davies C, Elphinstone P, Evans E,...Wang Y (2005); Early Breast Cancer Trialists' Collaborative Group (EBCTCG). Effects of radiotherapy and of differences in the extent of surgery for early breast cancer on local recurrence and 15-year survival: an overview of the randomised trials. Lancet. 2005 Dec 17;366(9503):2087-106. 
21. Fisher B, Anderson S, Bryant J, Margolese RG, Deutsch M, Fisher ER, Jeong JH, Wolmark N (2002). Twenty-year follow-up of a randomized trial comparing total mastectomy, lumpectomy, and lumpectomy plus irradiation for the treatment of invasive breast cancer. N Engl J Med. 2002 Oct 17;347(16):1233-41.

22. National Institute for Clinical Excellence. (2002) Guidance on Cancer Services: Improving Outcomes in Breast Cancer. Manual Update London: NICE. Available from:

http://guidance.nice.org.uk/Topic/Cancer/Breast

23. Tahir M, Osman KA, Shabbir J, Rogers C, Suarez R, Reynolds T, Bucknall T. (2008) Preoperative axillary staging in breast cancer-saving time and resources. Breast J. 2008 Jul-Aug;14(4):369-71.

24. Golshirsh A, Wood WC, Senn H-J, Glick JH, Gelber RD (1995). Meeting highlights international consensus panel on the treatment of primary breast cancer. J Natl Caner Inst 1995;87:1441-5.

25. Satariano WA, Ragland DR: (1994). The effect of comorbidity on 3year survival of women with primary breast cancer. Ann Intern Med 1994, 120:104-10.

26. Audisio Riccardo (2004) The surgical risk of elderly patients with cancer. Surgical oncology 2004;13(4):169.

27. Gennari R, Curigliano G, Rotmensz N, Robertson C, Colleoni M, Zurrida S (2004) Breast carcinoma in elderly women: features of disease presentation, choice of local and systemic treatments compared with younger postmenopausal patients. Cancer 101: 1302-1310.

28. De Haes JC, Curran D, Aaronson NK, Fentiman IS (2003). Quality of life in breast cancer patients aged over 70 years, participating in the EORTC 10850 randomised clinical trial. Eur J Cancer. 2003 May;39(7):945-51.

29. Sandison AJ, Gold DM, Wright P, Jones PA (1996). Breast conservation or mastectomy: treatment choice of women aged 70 years and older. Br J Surg. 1996 Jul;83(7):994-6.

30. Giordano SH, Hortobagyi GN, Kau SW, Theriault RL, Bondy ML (2005). Breast cancer treatment guidelines in older women. J Clin Oncol. 2005 Feb 1;23(4):783-91. 
31. Hurria A, Leung D, Trainor K, Borgen P, Norton L, Hudis C (2003). Factors influencing treatment patterns of breast cancer patients age 75 and older.Crit Rev Oncol Hematol. 2003 May;46(2):121-6.

32. Wildiers H, Kunkler I, Biganzoli L, Fracheboud J, Vlastos G, BernardMarty C,...Aapro M; International Society of Geriatric Oncology (2007) Management of breast cancer in elderly individuals: recommendations of the International Society of Geriatric Oncology. Lancet Oncol. 2007 Dec;8(12):1101-15.

33. Ballard-Barbash R, Potosky AL, Harlan LC, Nayfield SG, Kessler LG (1996). Factors associated with surgical and radiation therapy for early stage breast cancer in older women. J Natl Cancer Inst. 1996 Jun $5 ; 88(11): 716-26$.

34. Litvak DA, Arora R (2006). Treatment of elderly breast cancer patients in a community hospital setting. Arch Surg. 2006 Oct; 141(10):985-90; discussion 990. Erratum in: Arch Surg. 2006 Dec;141(12):1245.

35. Wyckoff J, Greenberg H, Sanderson R, Wallach P, Balducci L (1994). Breast irradiation in the older woman: a toxicity study. J Am Geriatr Soc. 1994 Feb;42(2):150-2.

36. Wyld L, Reed MW (2003). The need for targeted research into breast cancer in the elderly. Br J Surg. 2003 Apr;90(4):388-99.

37. Smith BD, Haffty BG, Hurria A, Galusha DH, Gross CP (2006). Postmastectomy radiation and survival in older women with breast cancer. J Clin Oncol. 2006 Oct 20;24(30):4901-7.

38. Diab SG, Elledge RM, Clark GM (2000). Tumor characteristics and clinical outcome of elderly women with breast cancer. J Natl Cancer Inst. 2000 Apr 5;92(7):550-6.

39. Fisher B, Costantino J, Redmond C, Poisson R, Bowman D, Couture J, Dimitrov NV, Wolmark N, Wickerham DL, Fisher ER, et al. A randomized clinical trial evaluating tamoxifen in the treatment of patients with node-negative breast cancer who have estrogen-receptorpositive tumors. N Engl J Med. 1989 Feb 23;320(8):479-84.

40. Early Breast Cancer Trialists' Collaborative Group (EBCTCG). Effects of chemotherapy and hormonal therapy for early breast cancer on 
recurrence and 15-year survival: an overview of the randomised trials. Lancet. 2005 May 14-20;365(9472):1687-717.

41. BIG 1-98 Collaborative Group, Mouridsen $\mathrm{H}$, Giobbie-Hurder A, Goldhirsch A, Thürlimann B, Paridaens R, Smith I,...Coates AS. Letrozole therapy alone or in sequence with tamoxifen in women with breast cancer. N Engl J Med. 2009 Aug 20;361(8):766-76.

42. Crivellari D, Sun Z, Coates AS, Price KN, Thürlimann B, Mouridsen $\mathrm{H}, .$. Goldhirsch $A$. Letrozole compared with tamoxifen for elderly patients with endocrine-responsive early breast cancer: the BIG 1-98 trial. J Clin Oncol. 2008 Apr 20;26(12):1972-9. Epub 2008 Mar 10.

43. Monnier A. Long-term efficacy and safety of letrozole for the adjuvant treatment of early breast cancer in postmenopausal women: a review. Ther Clin Risk Manag. 2009 Oct;5(5):725-38. Epub 2009 Sep 15.

44. Cummings SR and Melton LJ. Epidemiology and outcomes of osteoporotic fractures. Lancet. 2002; 359:1761-7.

45. Brufsky AM, Bosserman LD, Caradonna RR, Haley BB, Jones CM, Moore HC,...Perez EA. Zoledronic acid effectively prevents aromatase inhibitor-associated bone loss in postmenopausal women with early breast cancer receiving adjuvant letrozole: Z-FAST study 36-month follow-up results. Clin Breast Cancer. 2009 May;9(2):77-85.

46. Briesacher BA, Gurwitz JH, Soumerai SB. Patients at-risk for costrelated medication nonadherence: a review of the literature. J Gen Intern Med. 2007 Jun;22(6):864-71. Epub 2007 Apr 5.

47. Preece PE, Wood RA, Mackie CR, Cuschieri A. Tamoxifen as initial sole treatment of localised breast cancer in elderly women: a pilot study. Br Med J (Clin Res Ed). 1982 Mar 20;284(6319):869-70.

48. Gaskell DJ, Hawkins RA, de Carteret S, Chetty U, Sangster K, Forrest AP. Indications for primary tamoxifen therapy in elderly women with breast cancer. Br J Surg. 1992 Dec;79(12):1317-20.

49. Stotter A, Walker R. Tumour markers predictive of successful treatment of breast cancer with primary endocrine therapy in patients over 70 years old: a prospective study. Crit Rev Oncol Hematol. 2010 Sep;75(3):249-56. Epub 2009 Dec 6. 
50. Hind D, Wyld L, Beverley CB, Reed MW. Surgery versus primary endocrine therapy for operable primary breast cancer in elderly women (70 years plus). Cochrane Database Syst Rev. 2006 Jan 25;(1):CD004272.

51. Wyld L, Garg DK, Kumar ID, Brown H, Reed MWR (2004) Stage and treatment variation with age in postmenopausal women with breast cancer: compliance with guidelines. $\mathrm{Br}$ J Cancer 90: 1486-1491.

52. Tahir M, Robinson T, Stotter A. How not to neglect the care of elderly breast cancer patients? Breast. 2011 Apr 27. [Epub ahead of print]

53. Hind D, Wyld L, Reed MW. Surgery, with or without tamoxifen, vs tamoxifen alone for older women with operable breast cancer: cochrane review. Br J Cancer. 2007 Apr 10;96(7):1025-29. Epub 2007 Feb 6.

54. Mustacchi G, Ceccherini R, Milani S, Pluchinotta A, De Matteis A, Maiorino L, Farris A, Scanni A, Sasso F (2003) Tamoxifen alone versus adjuvant tamoxifen for operable breast cancer of the elderly: long-term results of the phase III randomised controlled multicenter GRETA trial. Ann Oncol 14: 414420.

55. Fentiman IS, Christiaens M-R, Paridaens R, Van Geel A, Rutgers E, Berner J,...Therasse $P$ (2003). Treatment of operable breast cancer in the elderly: a randomised clinical trial EORTC 10851 comparing tamoxifen alone with modified radical mastectomy. Eur J Cancer 39: 309-316.

56. Robertson JFR, Ellis IO, Elston CW, Blamey RW (1992). Mastectomy or tamoxifen as initial therapy for operable breast cancer in elderly patients: 5-year follow up. Eur J Cancer 28A: 908-910.

57. Gazet J-C, Ford HT, Coombes RC, Bland JM, Sutcliffe R, Quilliam J, Lowndes S (1994). Prospective randomised trial of tamoxifen vs surgery in elderly patients with breast cancer. Eur J Surg Oncol 20: 207-214.

58. Van Tulder MW, Assendelft WJ, Koes BW, Bouter LM. Method guidelines for systematic reviews in the Cochrane Collaboration Back Review Group for Spinal Disorders. Spine (Phila Pa 1976). 1997 Oct $15 ; 22(20): 2323-30$.

59. Conroy SP, Stevens T, Parker SG, Gladman JR (2011). A systematic review of comprehensive geriatric assessment to improve outcomes for 
frail older people being rapidly discharged from acute hospital:

'interface geriatrics'. Age Ageing. 2011 Jul;40(4):436-43.

doi:10.1093/ageing/afr060.

60. Elkin EB, Hurria A, Mitra N, Schrag D, Panageas KS (2006).

Adjuvant chemotherapy and survival in older women with hormone receptor-negative breast cancer: assessing outcome in a populationbased, observational cohort. J Clin Oncol. 2006 Jun 20;24(18):2757-64.

61. Giordano SH, Duan Z, Kuo YF, Hortobagyi GN, Goodwin JS. Use and outcomes of adjuvant chemotherapy in older women with breast cancer. J Clin Oncol. 2006 Jun 20;24(18):2750-6.

62. Muss HB, Woolf S, Berry D, et al. Adjuvant chemotherapy in older and younger women with lymph node-positive breast cancer. JAMA 2005;293:1073-81.

63. Muss HB, Berry DA, Cirrincione CT, et al. Adjuvant chemotherapy in older women with early-stage breast cancer. N Engl J Med. 2009 May 14;360:2055-2055-65.

64. Sliwkowski MX, Lofgren JA, Lewis GD, Hotaling TE, Fendly BM, Fox JA. Nonclinical studies addressing the mechanism of action of trastuzumab (Herceptin). Semin Oncol. 1999 Aug;26(4 Suppl 12):6070.

65. Piccart-Gebhart MJ, Procter M, Leyland-Jones B, et al: Trastuzumab after adjuvant chemotherapy in HER2-positive breast cancer. N Engl J Med 353:1659-1672, 2005.

66. Romond EH, Perez EA, Bryant J, Suman VJ, Geyer CE Jr, Davidson $\mathrm{NE}$, ...Kaufman PA. Trastuzumab plus adjuvant chemotherapy for operable HER2-positive breast cancer. N Engl J Med. 2005;353:16731684. doi: 10.1056/NEJMoa052122.

67. Wanebo HJ, Cole B, Chung M, Vezeridis M, Schepps B, Fulton J, Bland $\mathrm{K}$. Is surgical management compromised in elderly patients with breast cancer? Ann Surg. 1997;225:579-586. doi: 10.1097/00000658199705000-00014.

68. Mandelblatt JS, Hadley J, Kerner JF, Schulman KA, Gold K, Dunmore-Griffith J, Edge S, Guadagnoli E, Lynch JJ, Meropol NJ, Weeks JC, Winn R. Patterns of breast carcinoma treatment in older women: 
patient preference and clinical and physical influences. Cancer. 2000;89:561-573. doi: 10.1002/1097.

69. Turner NJ, Haward RA, Mulley GP, Selby PJ. Cancer in old age - is it inadequately investigated and treated? BMJ. 1999;319:309-12.

70. Lickley HL. Primary breast cancer in the elderly. Can J Surg. 1997 Oct; $40(5): 341-51$.

71. Lavelle K, Todd C, Moran A, Howell A, Bundred N, Campbell M. Nonstandard management of breast cancer increases with age in the UK: a population based cohort of women $>$ or $=65$ years. Br J Cancer. 2007 Apr 23;96(8):1197-203.

72. Charlson ME, Pompei $\mathrm{P}$, Ales $\mathrm{K}$, et al: A new method of classifying comorbidity in longitudinal studies: Development and validation. J Chronic Dis 40: 373-383, 1987.

73. Nagel G, Wedding U, Röhrig B, Katenkamp D. The impact of comorbidity on the survival of postmenopausal women with breast cancer.. J Cancer Res Clin Oncol. 2004 Nov;130(11):664-70.

74. Stotter A, Tahir M, Pretorius R, Robinson T. Experiences of a multidisciplinary elderly breast cancer clinic: using the right specialists, in the same place, with time. In: Management of breast cancer in older women. Eds Reed MW, Audisio RA. Springer 2010.

75. Pilotto A, Ferrucci L, Franceschi M, D'Ambrosio LP, Scarcelli C, Cascavilla $L, . .$. Leandro $G$. Development and validation of a multidimensional prognostic index for one-year mortality from comprehensive geriatric assessment in hospitalized older patients. Rejuvenation Res. 2008 Feb;11(1):151-61.

76. Inouye SK, Peduzzi PN, Robison JT, Hughes JS, Horwitz RI, Concato J. Importance of functional measures in predicting mortality among older hospitalized patients. JAMA. 1998 Apr 15;279(15):1187-93.

77. Walter LC, Brand RJ, Counsell SR, Palmer RM, Landefeld CS, Fortinsky RH, Covinsky KE. Development and validation of a prognostic index for 1-year mortality in older adults after hospitalization. JAMA. 2001 Jun 20;285(23):2987-94.

78. Rubenstein LZ. An overview of comprehensive geriatric assessment: rationale, history, program models, basic components. In: Rubenstein 
LZ, Wieland D, Bernabei R, eds. Geriatric Assessment Technology: The State of the Art. New York, NY: Springer; 1995.

79. Gallo JJ, Fulmer T, Paveza GJ, eds. Handbook of Geriatric Assessment. 3rd ed. Gaithersburg, Md: Aspen; 2000.

80. Buchner DM, Wagner EH: Preventing frail health. Clin Geriatr Med 1992, 8:1-17.

81. Freedman VA, Martin LG, Schoeni RF. Recent trends in disability and functioning among older adults in the United States: a systematic review. JAMA. 2002;288(24):3137-3146.

82. McGuire LC, Ford ES, Ajani UA. The impact of cognitive functioning on mortality and the development of functional disability in older adults with diabetes: the second longitudinal study on aging. BMC Geriatr. 2006 May $1 ; 6: 8$.

83. Stump TE, Callahan CM, Hendrie HC. Cognitive impairment and mortality in older primary care patients. J Am Geriatr Soc. 2001 Jul;49(7):934-40.

84. Carey EC, Walter LC, Lindquist K, Covinsky KE. Development and validation of a functional morbidity index to predict mortality in community-dwelling elders. J Gen Intern Med. 2004 Oct;19(10):102733.

85. Scott WK, Macera CA, Cornman CB, et al: Functional health status as a predictor of mortality in men and women over 65. J Clin Epidemiol 50: 291-296, 1997.

86. Greenfield S, Blanco D, Elashoff R. Development and test of a new index of comorbidity index. Clinical Research 1987; A35: 346.

87. Spiers N, Matthews R, Jagger C, Matthews F, Boult C, Robinson T. Diseases and impairments as risk factors for onset of disability in the older population in England and Wales: Findings form the Medical Research Council Cognitive Function and Ageing Study. Journal of Gerontology Biological and Medical Sciences 2005; 60: 248-254.

88. Linn BS, Linn MW, Gurel L. Cumulative illness rating scale. J Am Geriatr Soc. $1968 ; 16(5): 622-626$. 
89. Folstein M, Folstein S, McHugh P. Mini mental health for grading the cognitive status of patients for the clinicians. Journal of Psychiatric research 1975; 12: 189-198.

90. Barefoot JC, Helms MJ, Mark DB, Blumenthal JA, Califf RM, Haney TL, O'Connor CM, Siegler IC, Williams RB. Depression and long-term mortality risk in patients with coronary artery disease. Am J Cardiol. 1996 Sep 15;78(6):613-7.

91. Van Marwijk H, Wallace P, de Bock G, Hermans J, Kaptein A, Mulder J. Evaluation of the feasibility, reliability and diagnostic value of shortened versions of the geriatric depression scale. British Journal of General Practice 1995; 45: 195-199.

92. Karnofsky D, Burchenal J. The clinical evaluation of chemotherapeutic agents in cancer. In Macleod C, ed. Evaluation of chemotherapeutic agents. New York: Columbia University Press 1949: 199-205.

93. Mahoney F, Barthel D. Functional evaluation: the Barthel index. MD State Med J 1965; 14: 61-66.

94. Royal College of Physicians and the British Geriatrics Society. Standardised assessment scales for elderly people. London: Royal College of Physicians and the British Geriatrics Society, 1992.

95. Lawton M, Brody E. Assessment of older people: self-maintaining and instrumental activities of daily living. Gerontologist 1969; 9: 179186.

96. Oken MM, Creech RH, Tormey DC, Horton J, Davis TE, McFadden ET, Carbone PP. Toxicity and response criteria of the Eastern Cooperative Oncology Group. Am J Clin Oncol 1982;5:649-655.

97. Wolters U, Wolf T, Stützer H, Schröder T. ASA classification and perioperative variables as predictors of postoperative outcome. $\mathrm{Br}$ J Anaesth. 1996 Aug;77(2):217-22.

98. Menke $H$, Klein A, John KD, Junginger T. Predictive value of ASA classification for the assessment of the perioperative risk. Int Surg. 1993 Jul-Sep;78(3):266-70.

99. Inouye SK, Wagner DR, Acampora D, Horwitz RI, Cooney LM Jr, Hurst LD, Tinetti ME. A predictive index for functional decline in 
hospitalized elderly medical patients. J Gen Intern Med. 1993;8:645652.

100. Inouye SK, Rushing JT, Foreman MD, Palmer RM, Pompei P. Does delirium contribute to poor hospital outcomes? A three-site epidemiologic study. J Gen Intern Med. 1998 Apr;13(4):234-42.

101. D'Ath P, Katona P, Mullan E, Evans S, Katona C. Screening, detection and management of depression in elderly primary care attenders. I: The acceptability and performance of the 15 item Geriatric Depression Scale (GDS15) and the development of short versions. Fam Pract. 1994 Sep;11(3):260-6.

102. Roberts L, Counsell C. Assessment of clinical outcomes in acute stroke trials. Stroke. 1998 May;29(5):986-91.

103. Granger CV, Devis LS, Peters MC, Sherwood CC, Barrett JE. Stroke rehabilitation: analysis of repeated Barthel Index measures. Arch Phys Med Rehabil. 1979;60:14-17.

104. Donnan GA, Davis SM, Chambers BR, for the Australian Streptokinase (ASK) Trial Study Group. Streptokinase for acute ischemic stroke with relationship to time of administration. JAMA. 1996;276:961-966.

105. PACE participants, Audisio RA, Pope D, Ramesh HS, Gennari R, van Leeuwen BL, West C, Corsini G.,...Marshall E. Shall we operate? Preoperative assessment in elderly cancer patients (PACE) can help. A SIOG surgical task force prospective study. Crit Rev Oncol Hematol. 2008 Feb;65(2):156-63. Epub 2007 Dec 21.

106. Karkouti K, Djaiani G, Borger MA, Beattie WS, Fedorko L, Wijeysundera $D$, Ivanov J, Karski J. Low hematocrit during cardiopulmonary bypass is associated with increased risk of perioperative stroke in cardiac surgery. Ann Thorac Surg. 2005 Oct; $80(4): 1381-7$.

107. Austin PC, Tu JV. Automated variable selection methods for logistic regression produced unstable models for predicting acute myocardial infarction mortality. J Clin Epidemiol. 2004 Nov;57(11):1138-46.

108. Thompson, B. (1996). AERA editorial policies regarding statistical significance testing: Three suggested reforms. Educational Researcher, 25(2), 26-30. 
109. Guthrie, A. C. (2001, February). Using bootstrap methods with popular statistical programs. Paper presented at the annual meeting of the Southwest Educational Research Association, New Orleans.

110. Kline, R. B. (2005). Principles and practice of structural equation modeling (2nd ed.). New York: Guilford.

111. Kelman HR, Thomas C, Kennedy GJ, Cheng J. (1994). Cognitive impairment and mortality in older community residents. Am J Public Health. 1994 Aug;84(8):1255-60.

112. Stuck AE, Walthert JM, Nikolaus T, Büla CJ, Hohmann C, Beck JC. (1999). Risk factors for functional status decline in community-living elderly people: a systematic literature review. Soc Sci Med. 1999 Feb;48(4):445-69.

113. Millán-Calenti JC, Tubío J, Pita-Fernández S, González-Abraldes I, Lorenzo T, Fernández-Arruty T, Maseda A. (2010). Prevalence of functional disability in activities of daily living ( $A D L)$, instrumental activities of daily living (IADL) and associated factors, as predictors of morbidity and mortality. Arch Gerontol Geriatr. 2010 MayJun;50(3):306-10. Epub 2009 Jun 10.

114. Covinsky KE, Justice AC, Rosenthal GE, Palmer RM, Landefeld CS. (1997). Measuring prognosis and case mix in hospitalized elders. The importance of functional status. J Gen Intern Med. 1997 Apr;12(4):2038.

115. Aharonoff GB, Koval KJ, Skovron ML, Zuckerman JD. (1997). Hip fractures in the elderly: predictors of one year mortality. J Orthop Trauma. 1997 Apr;11(3):162-5.

116. Holt G, Macdonald D, Fraser M, Reece AT. (2006). Outcome after surgery for fracture of the hip in patients aged over 95 years. J Bone Joint Surg Br. 2006 Aug;88(8):1060-4. PubMed PMID: 16877606.

117. Rogers S, Kenyon P, Lowe D, Grant C, Dempsey G. (2005). The relation between health-related quality of life, past medical history, and American Society of Anesthesiologists' ASA grade in patients having primary operations for oral and oropharyngeal cancer. $\mathrm{Br} \mathrm{J}$ Oral Maxillofac Surg. 2005 Apr;43(2):134-43. 
118. Kanatas A, Gorton $H$, Smith AB, Mannion C, Ong TK, Mitchell D. (2010). ASA grade and disease-free mortality in head and neck cancer patients: a prospective study. Br J Oral Maxillofac Surg. 2010 Dec;48(8):591-3. Epub 2009 Dec 8.

119. Kaplan MH, Feinstein AR. (1974). The importance of classifying initial co-morbidity in evaluating the outcome of diabetes mellitus. J Chronic Dis 1974;27:387-404.

120. Janssen-Heijnen $M L$, Lemmens $V E$, van den Borne $B E$, Biesma $B$, Oei SB, Coebergh JW. (2007). Negligible influence of comorbidity on prognosis of patients with small cell lung cancer: a population-based study in the Netherlands. Crit Rev Oncol Hematol. 2007 May;62(2):1728. Epub 2007 Jan 2.

121. Tross S, Herndon J 2nd, Korzun A, Kornblith AB, Cella DF, Holland JF, Raich P.,... Holland JC. (1996). Psychological symptoms and diseasefree and overall survival in women with stage II breast cancer. Cancer and Leukemia Group B. J Natl Cancer Inst. 1996 May 15;88(10):661-7.

122. Vogt T, Pope C, Mullooly J, Hollis J. (1994). Mental health status as a predictor of morbidity and mortality: a 15-year follow-up of members of a health maintenance organization. Am J Public Health. 1994 Feb;84(2):227-31.

123. Perry AM, Cardesa-Salzmann TM, Meyer PN, Colomo L, Smith LM, Fu K.,...Weisenburger DD. (2012). A new biologic prognostic model based on immunohistochemistry predicts survival in patients with diffuse large B-cell lymphoma. Blood. 2012 Sep 13;120(11):2290-6. doi: 10.1182/blood-2012-05-430389. 